University of San Diego

Digital USD

2010-05-01

\title{
The Relationship between Reading Fluency, Writing Fluency, and Reading Comprehension in Suburban Third-Grade Students
}

Mary Leonard Palmer EdD

University of San Diego

Follow this and additional works at: https://digital.sandiego.edu/dissertations

Part of the Leadership Studies Commons

\section{Digital USD Citation}

Leonard Palmer, Mary EdD, "The Relationship between Reading Fluency, Writing Fluency, and Reading Comprehension in Suburban Third-Grade Students" (2010). Dissertations. 901.

https://digital.sandiego.edu/dissertations/901

This Dissertation: Open Access is brought to you for free and open access by the Theses and Dissertations at Digital USD. It has been accepted for inclusion in Dissertations by an authorized administrator of Digital USD. For more information, please contact digital@sandiego.edu. 
THE RELATIONSHIP BETWEEN READING FLUENCY, WRITING FLUENCY, AND READING COMPREHENSION IN SUBURBAN

\section{THIRD-GRADE STUDENTS}

by

Mary Leonard Palmer

A Dissertation Submitted to the Faculty of

San Diego State University and the University of San Diego

in Partial Fulfillment

of the Requirements for the Degree

Doctor of Education

Dissertation Committee:

Douglas Fisher, Ph.D., San Diego State University

Nancy Frey, Ph.D., San Diego State University

Lea Hubbard, Ph.D., University of San Diego

May 2010 
Copyright (C) 2010

by

Mary Leonard Palmer

All Rights Reserved 


\section{DEDICATION}

This dissertation is dedicated to my husband, Dave, and my daughters, Katie and Lizzy. 


\begin{abstract}
OF THE DISSERTATION
The Relationship Between Reading Fluency, Writing Fluency, and

Reading Comprehension in Suburban Third-Grade Students

by

Mary Leonard Palmer

Doctor of Education
\end{abstract}

San Diego State University and the University of San Diego, 2010

The topic of reading fluency is of great importance in education today. Research has shown a significant positive relationship between reading fluency and reading comprehension. However, little is known about writing fluency and its connection with reading comprehension.

The purpose of this study was to examine the relationships between reading fluency, writing fluency, and reading comprehension. First, using the principles of assessing reading fluency, I designed a writing assessment and measured the writing fluency of 54 3rd graders. I examined the writing assessments as they related to the students' reading fluency and reading comprehension scores. Secondly, I performed a quasi-experimental scientific study with 3 rd grade students. The control group $(n=36)$ were taught the board-adopted language arts curriculum, while the experimental group $(n=18)$ had systematic direct instruction in reading and writing fluency in addition to the regular language arts curriculum.

The research questions were: What is the relationship between students' reading comprehension and reading fluency among a group of third graders? What is the relationship between their reading comprehension and writing fluency? What is the relationship between their reading fluency and writing fluency? Will the experimental group of students with direct instruction in reading and writing fluency outperform the control group in reading comprehension? What other factors are involved in increasing reading comprehension?

Pearson's correlation statistic, paired t-tests, independent samples t-tests, and multiple linear regression analysis were used to analyze the data. All statistical analyses were performed using PASW (formerly SPSS) for Windows.

Consistent with reading research, the results showed there was a strongly positive correlation between reading comprehension and reading fluency. This study also found a correlation between reading comprehension and writing as well as a correlation between reading comprehension and writing fluency. However, the link between reading comprehension and writing fluency was not found in pretest measurement, or the posttestpretest measurement. The ANOVA results showed that reading and writing fluency explained a statistically significant $50 \%$ of the total variance in reading comprehension scores. This study also showed a strong positive correlation between reading fluency and writing fluency in the posttest measurement. In the quasi-experimental study, the experimental group did not outperform the experimental group: both groups made significant progress.

The major implication of this study is that writing could help increase reading comprehension, which results in another tool for teachers to use in teaching reading 
comprehension. This could result in an additional emphasis in teaching writing skills in the classroom. 


\section{TABLE OF CONTENTS}

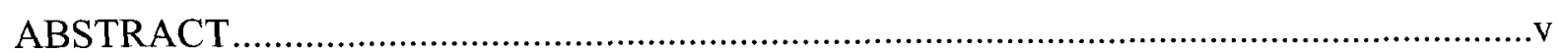

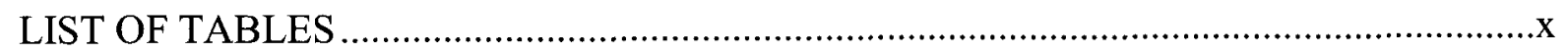

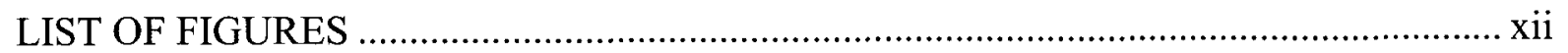

\section{CHAPTER}

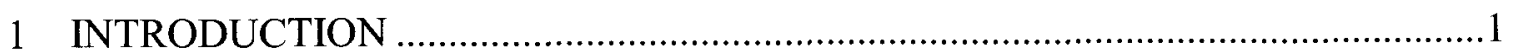

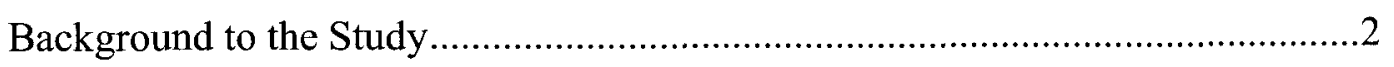

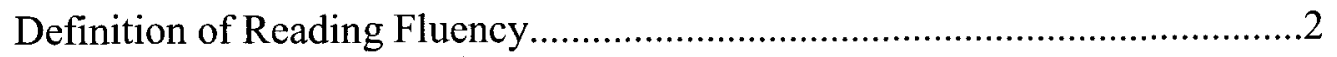

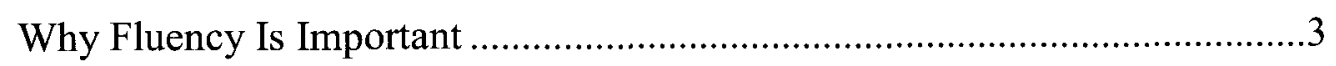

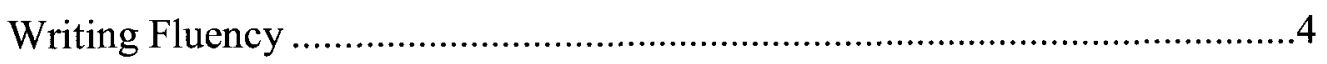

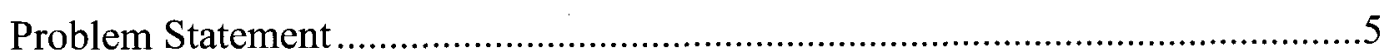

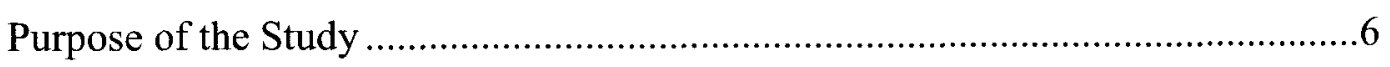

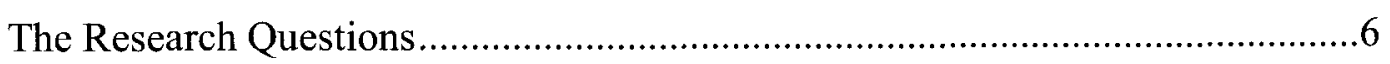

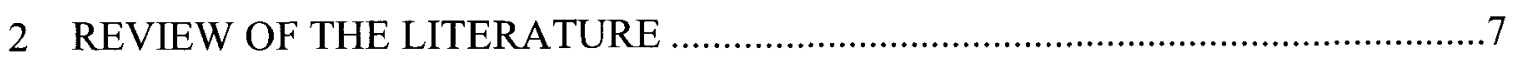

Theoretical Bases for Oral Reading Fluency ......................................................

Automaticity Theory ….......................................................................

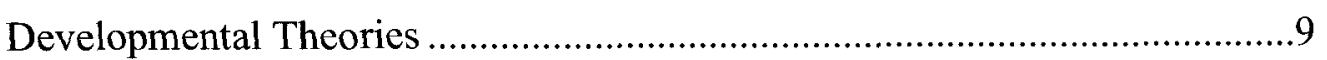

Chall's Six Stages of Reading Development .............................................9

Ehri's Stages of Reading Development ................................................... 10

Wolf 's Developmental Theory ..............................................................10

Compensatory-Encoding Theory (C-ET) ………….............................11

Prosody in Fluent Reading.......................................................................11

Other Theoretical Perspectives .............................................................12

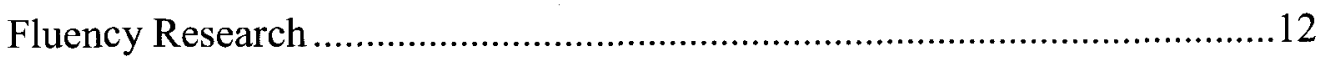

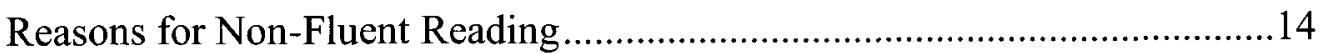

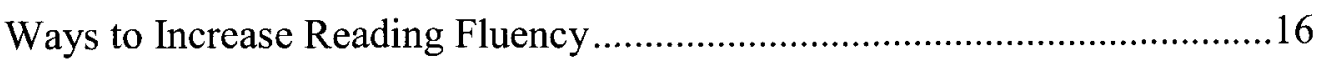

Backlash on Reading Fluency...............................................................17

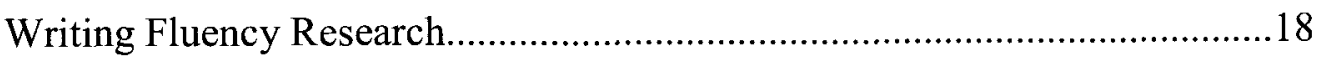




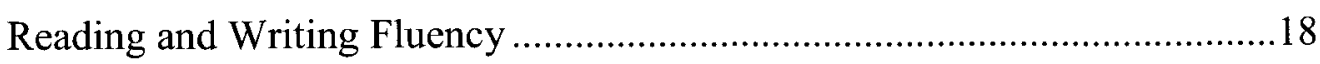

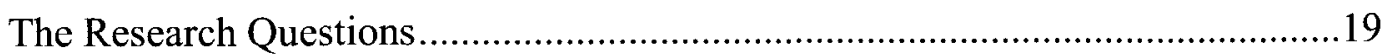

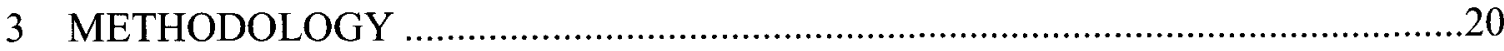

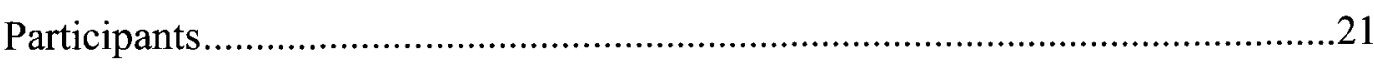

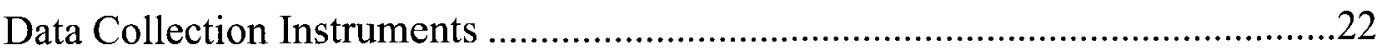

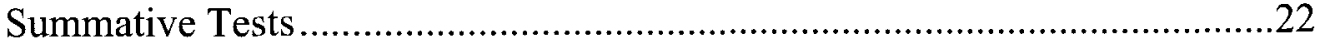

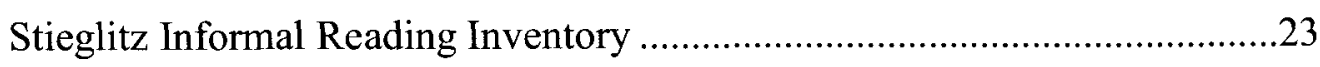

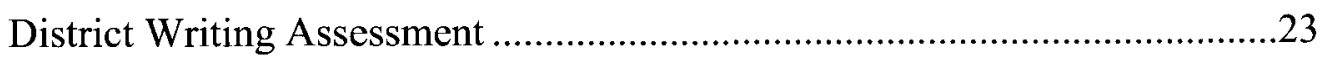

Two Reading Fluency Assessments.............................................................23

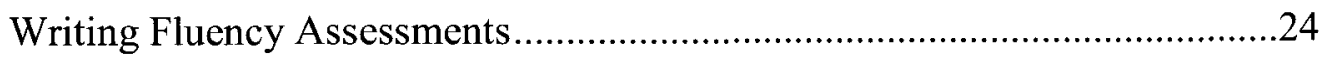

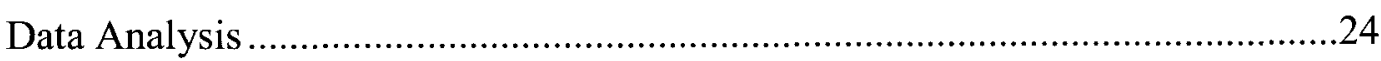

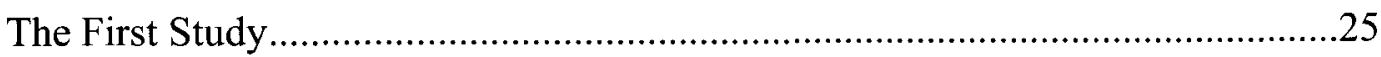

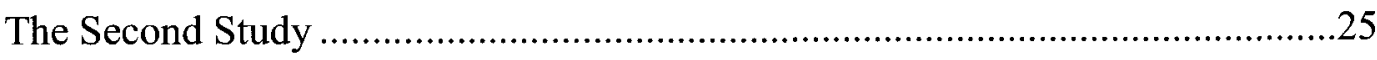

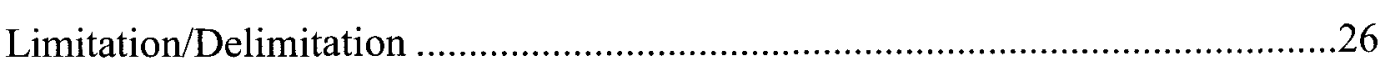

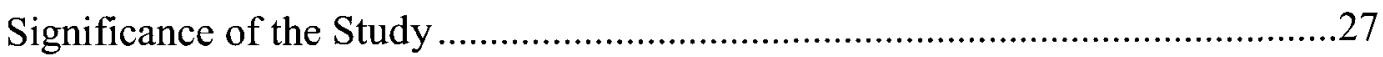

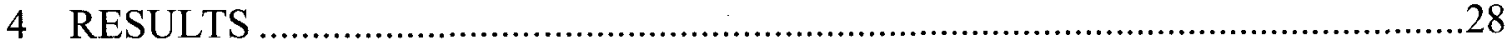

Descriptive Statistics for Demographic Variables...........................................28

Research Questions From the Study ..................................................................

Research Question \#1 .................................................................................

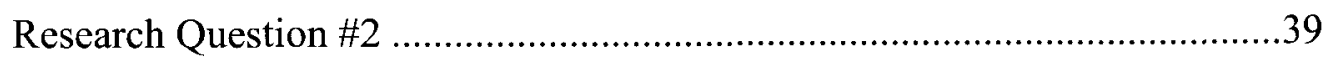

Research Question \#3 ...........................................................................43

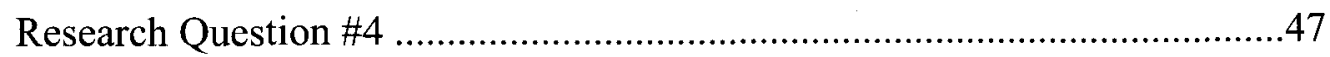

Research Question \#5 ...............................................................................4

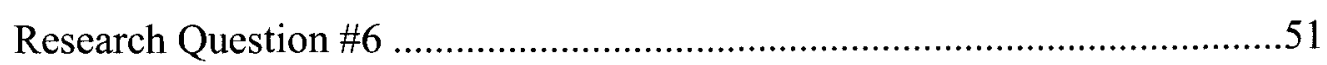

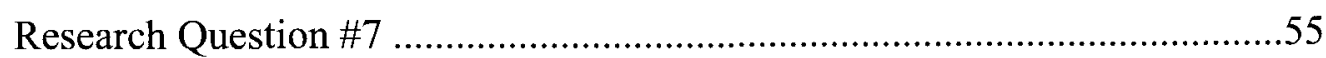

Research Question \#8 ...........................................................................59

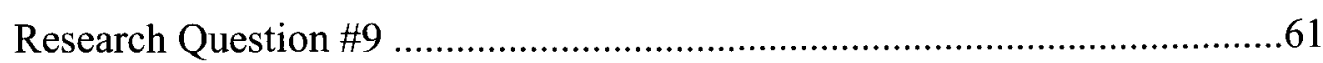

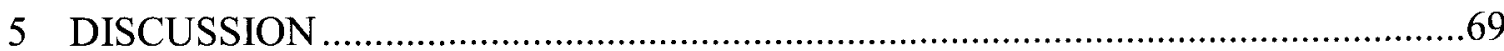

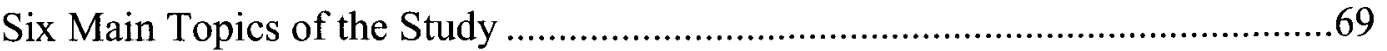

Reading Comprehension and Reading Fluency .............................................69

Reading Comprehension and Writing........................................................ 70 
Correlations Between Reading Fluency and Writing Fluency to Reading Comprehension ............................................................................

The Link Between Reading Fluency and Writing Fluency ............................71

Quasi-Experimental Scientific Study............................................................72

Correlations of Demographic Variables .........................................................73

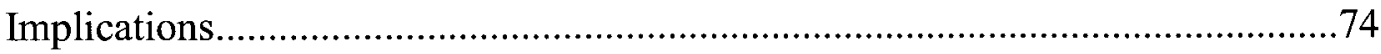

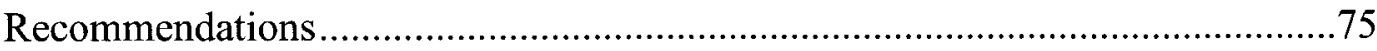

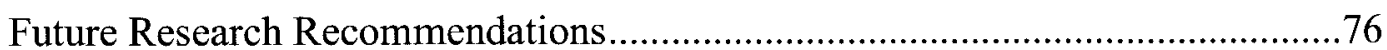

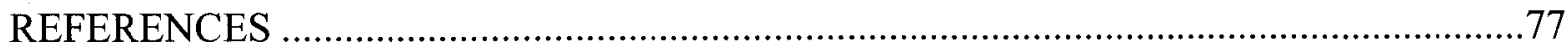

APPENDICES

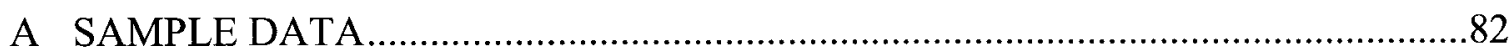

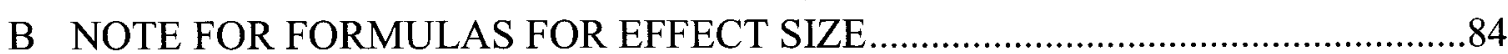




\section{LIST OF TABLES}

PAGE

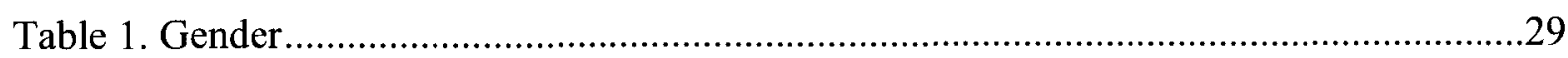

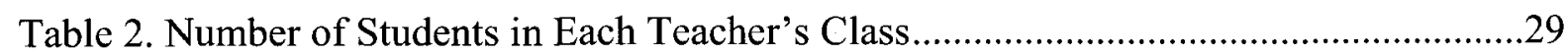

Table 3. Total Number of Students in Control and Experimental Groups .............................29

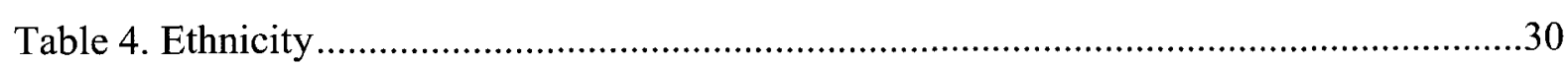

Table 5. Participation in Free and Reduced Lunch Program ..............................................30

Table 6. English as a Second Language Learner ......................................................................30

Table 7. English Language Arts Star Test Performance Level.................................................31

Table 8. English Language Arts Star Test Scores................................................................. 31

Table 9. Correlation Between Reading Comprehension, Reading Fluency, and Writing Fluency (Pretest).

Table 10. Correlations Between Reading Comprehension, Reading Fluency, and Writing Fluency (Posttest) .........................................................................................36

Table 11. Correlations Between Change in Reading Comprehension, Change in Reading Fluency, and Change in Writing Fluency (Posttest-Pretest)... .38

Table 12. Reading Comprehension Control Group and Experimental Group ..........................40

Table 13. Reading Comprehension Independent Samples Test...........................................40

Table 14. Reading Fluency Control Group and Experimental Group ....................................41

Table 15. Reading Fluency Independent Samples Test ............................................................41

Table 16. Writing Fluency Control Group and Experimental Group ...................................42

Table 17. Writing Fluency Independent Samples Test .......................................................42

Table 18. Reading Comprehension Control Group .................................................................44

Table 19. Reading Comprehension Control Group Independent Samples Test .....................44

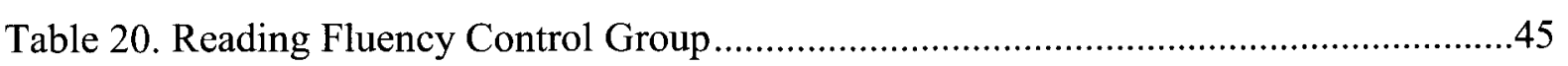

Table 21. Reading Fluency Control Group Independent Samples Test...................................45

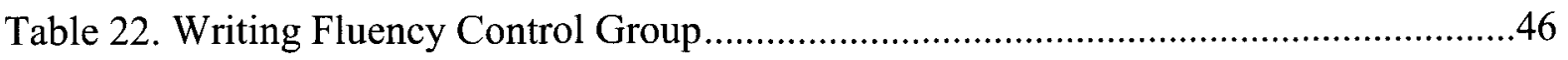

Table 23. Writing Fluency Control Group Independent Samples Test ................................46

Table 24. Reading Comprehension Experimental Group ....................................................48

Table 25. Reading Comprehension Experimental Group Paired Samples Test ......................48 
Table 26. Reading Fluency Experimental Group 49

Table 27. Reading Fluency Experimental Group Paired Samples Test. .49

Table 28. Writing Fluency Experimental Group ...................................................50

Table 29. Writing Fluency Experimental Group Paired Samples Test...............................50

Table 30. Reading Comprehension Control/Experimental Group.....................................52

Table 31. Reading Comprehension Control/Experimental Independent Samples Test.........52

Table 32. Reading Fluency Control/Experimental Groups Reading Fluency .......................53

Table 33. Reading Fluency Control/Experimental Groups Reading Fluency Independent Samples Test ..........................................................................53

Table 34. Writing Fluency Control/Experimental Groups ...........................................55

Table 35. Writing Fluency Control/Experimental Groups ............................................54

Table 36. Reading Comprehension Control/Experimental (Posttest/Pretest)......................56

Table 37. Reading Comprehension Control/Experimental (Posttest/Pretest)......................56

Table 38. Reading Fluency Control/Experimental Posttest/Pretest ..................................57

Table 39. Reading Fluency Control/Experimental Posttest/Pretest....................................57

Table 40. Writing Fluency Control/Experimental Posttest/Pretest....................................58

Table 41. Writing Fluency Control/Experimental Posttest/Pretest Independent

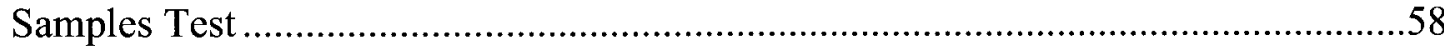

Table 42. Dependent Variable Reading Comprehension Scores (Posttest) in Relation to Reading and Writing Fluency

Table 43. Coefficients of Dependent Variable Reading Comprehension Scores (Posttest) in Relation to Reading and Writing Fluency

Table 44. Dependent Variable Reading Comprehension in Relation to Demographic Variables

Table 45. Coefficients of Dependent Variable Reading Comprehension in Relation to Demographic Variables

Table 46. Correlations Between Reading Comprehension and Writing Strategies and Sentence Structure (Pretest)

Table 47. Correlations Between Reading Comprehension and Writing Strategies and Sentence Structure (Posttest)

Table 48. Correlations Between Change in Reading Comprehension and Change in Writing Strategy and Change in Sentence Structure (Posttest-Pretest)

Table 49. Sample Data From My Third Grade Class of 19 Students 


\section{LIST OF FIGURES}

Figure 1. Pretest measurement of reading comprehension and reading fluency. .....................33

Figure 2. Pretest measurement of reading comprehension and writing fluency.......................33

Figure 3. Pretest measurement of writing fluency and reading fluency. .................................34

Figure 4. Posttest measurement of reading comprehension and reading fluency.....................35

Figure 5. Posttest measurement of reading comprehension and writing fluency.....................35

Figure 6. Posttest measurement of writing fluency and reading fluency.................................36

Figure 7. Posttest-pretest change in reading comprehension and change in reading fluency.

Figure 8. Posttest-pretest change in reading comprehension and change in writing fluency.

Figure 9. Posttest-pretest change in writing fluency and change in reading fluency. .............38

Figure 10. Control/experimental groups: Pretest reading comprehension score. ....................40

Figure 11. Control/experimental groups: Pretest reading fluency score..................................41

Figure 12. Control/experimental groups: Pretest writing fluency score ................................42

Figure 13. Control group: Pretest reading comprehension score.........................................44

Figure 14. Control group: Pretest reading fluency score. .....................................................45

Figure 15. Control group: Pretest writing fluency score.......................................................46

Figure 16. Experimental group: Pretest/Posttest reading comprehension score.......................48

Figure 17. Experimental group: Pretest/Posttest reading fluency score. ................................49

Figure 18. Experimental group: Pretest/Posttest writing fluency score..................................50

Figure 19. Posttest control/experimental reading comprehension scores...............................52

Figure 20. Posttest control/experimental reading fluency scores. .........................................53

Figure 21. Posttest control/experimental writing fluency.....................................................5

Figure 22. Control/Experimental posttest-pretest reading comprehension..............................56

Figure 23. Control/experimental posttest/pretest reading fluency.......................................57

Figure 24. Control/experimental posttest/pretest writing fluency. ........................................58

Figure 25. Pretest measurement of reading comprehension and writing strategies.................63

Figure 26. Pretest measurement of reading comprehension and sentence structure.................63 
Figure 27. Pretest measurement of writing strategies and sentence structure. .....................64

Figure 28. Posttest measurement of reading comprehension and writing strategy...............65

Figure 29. Posttest measurement of reading comprehension and sentence structure.............65

Figure 30. Posttest measurement of and writing strategies and sentence structure...............66

Figure 31. Change in reading comprehension and change in writing strategy....................67

Figure 32. Change in reading comprehension and change in sentence structure. ................67

Figure 33. Change in reading comprehension and change in sentence structure. .................68 


\section{CHAPTER 1}

\section{INTRODUCTION}

As an elementary school teacher I have found, almost without fail, if a student read aloud a selected passage fluently without errors, the student would have a perfect score on the comprehension questions. This happened time and time again, regardless of the grade level I taught. I wondered: "What was this link between reading fluency and comprehension?"

I know now there have been numerous studies showing high reading fluency correlates to high comprehension scores. The results of the study Fourth-Grade Students Reading Aloud: NAEP 2002 Special Study of Oral Reading (Daane, Campbell, Grigg, Goodman, \& Oranje, 2005) found students who read with the fewest errors demonstrated greater comprehension. It also showed the speed of oral reading was positively related to comprehension. While research has established high fluency results in high reading comprehension scores, studies have also shown the reverse: students who were low in fluency also showed difficulty comprehending what they read (Pinnell et al., 1995).

As a teacher, if I helped my students increase their reading fluency, would this result in my students having greater reading comprehension? Timothy Rasinski is one of many researchers who believe if a student practices to read orally and increases their reading fluency it will lead to higher comprehension. Dozens of workbooks are on the market for teachers to use to help their students increase their fluency, thus leading to the goal of greater reading comprehension. Two such books are The Fluent Reader: Oral Reading Strategies for Building Word Recognition, Fluency, and Comprehension (Rasinski, 2003) and Building Fluency: Lessons and Strategies for Reading Success (Blevins, 2001).

Research has shown a significant positive relationship between reading fluency and reading comprehension (Dowhower, 1987; Kuhn \& Stahl, 2003; Rasinski, 2003). However, little is known about writing fluency and its connection with reading comprehension. Using the techniques used for assessing reading fluency, I will take a fresh look at writing fluency and reading comprehension. What is the role of reading fluency in regards to writing fluency 
and reading comprehension? Would an increase in reading fluency correspond to an increase in writing fluency? Would an increase in writing fluency correspond to an increase in reading comprehension? What other factors come into play in regards to an increase in comprehension?

\section{BACKGROUND TO THE STUDY}

The topic of reading fluency is of great importance in education today: it is currently at the forefront of the international reading magazine Reading Today, the National Reading Panel report (NRP) Teaching Children to Read (National Institute of Child Health and Human Development [NICHD], 2000), the national federal law No Child Left Behind, and a widely used fluency measure in Reading First-funding programs, DIBELS. The front page of the current issue of Reading Today, the International Reading Association (IRA) magazine, lists reading fluency as one of fourteen "very hot" topics in the field of education for the second year in a row (Cassidy \& Cassidy, 2005-2006). The National Reading Panel report (NRP) Teaching Children to Read (NICHD, 2000) determined reading fluency was one of five essential components of effective reading comprehension and recommended fluency be assessed formally on a regular basis. An assessment to test reading fluency, Dynamic Indicators of Basic Early Literacy Skills (DIBELS; Good \& Kaminski, 2002) was based upon the essential early literacy domains from the National Reading Panel (NICHD, 2000). DIBELS is widely used by school districts across the country: it has been used to assess over $1,800,000$ students (Samuels, 2007). "Fluency is indeed a vital aspect of literacy. It deserves our serious attention" (Samuels \& Farstrup, 2006, p. 2). Fluency's current popularity is a far cry from Allington's 1983 charge that reading fluency was the most neglected skill in reading (Allington, 1983).

\section{Definition of Reading Fluency}

Teachers recognize fluent readers immediately. They enjoy listening to their students read every word accurately and effortlessly with good pacing, paying attention to punctuation, reading in phrases so the content makes sense, and reading with good expression. Teachers can also spot the non-fluent reader easily as the student laboriously reads word-by-word, very choppy, with frequent repetitions as well as long pauses in a near monotone voice. I have noticed that my students who are avid readers read aloud with great 
fluency. This is an example of Stanovich's (1986) Matthew effect that states students who read a lot improve and those who do not read a lot show little improvement. "Many teachers have always had an intuitive sense that the fluency or fluidity of oral reading is an indicator of successful reading" (Altwerger, Jordan, \& Shelton, 2007, p. 6).

Various teachers, experts, and researchers have defined oral reading fluency in different ways. The word fluency comes from the Latin word fluens, which means to flow. Teachers may describe fluent reading as "reading as if talking" with words flowing effortlessly. The NRP (2000) states fluent readers are characterized by the ability to read orally with speed, accuracy, and proper expression. La Berge and Samuels (1974) define fluency as the ability to translate letters-to-sound-to-words fluently and effortlessly. They describe a fluent reader as one whose decoding processes are automatic, requiring no conscious attention, thus enabling readers to allocate their attention to the comprehension and meaning of the text. As Samuels concluded, "to summarize the differences between beginning and fluent readers, one may say that beginning readers cannot simultaneously decode and comprehend a text, whereas fluent readers can do both tasks at the same time" (Samuels, 2002, p. 171).

While accuracy in word recognition (decoding) and automaticity in word recognition are important, Rasinski (2000) warns that fluency is not just about the speed of reading, as he says reading is not a NASCAR race. He feels the definition of fluency must include prosody: interpretive and meaningful reading.

\section{Why Fluency Is Important}

The ultimate goal is not to just help students become fluent readers or fast readersthe goal is to help students improve in reading comprehension. The National Reading Panel states that reading fluency is important because it provides a bridge between word recognition and comprehension (NICHD, 2000). On one side of the bridge is the ability to identify words quickly and decode automatically, while on the other side of the bridge is the ability to understand text. Fluency, with its automatic decoding, accuracy, and prosody, is the link between the two. When students read fluently, they do not have to focus exclusively on an author's individual words; they can focus on the author's message. To have good 
comprehension you must also have fluent reading, because non-fluent reading takes up valuable mental capacity that is needed for comprehension to happen (Pressley, 2002).

It is becoming increasingly apparent that fluency plays an important role in terms of a reader's ability to construct meaning from text, the ultimate goal of reading instruction. The two primary ways in which fluency plays a part in learners' reading development involves the development of automatic word recognition and prosody, elements of fluency that allow oral reading to sound like spoken language. (Kuhn, 2004, p. 338)

Another reason that fluency is important is that fluent readers are more likely to read than non-fluent readers. "Non-fluent readers find reading difficult, even punishing, so they don't choose to read and, therefore, do not enjoy the benefits of reading, such as increased vocabulary, more sophisticated understanding of the world, and fluency" (Cooper, Chard, \& Kiger, 2006, p. 102)

The NRP (2000) recommended teachers assess reading fluency regularly. There are two reasons why assessing reading fluency is important. The first reason is because reading fluency has been proven to be one of the best indicators of reading comprehension (Fuchs, Fuchs, Hosp, \& Jenkins, 2001). Secondly, by assessing fluency regularly, teachers can discover if students have decoding, syllabication, or other word recognition problems, and can reteach those skills.

Besides high reading fluency corresponding to high reading comprehension, there are other benefits to reading fluency. Fluency helps learners perform a skill for an extended period of time with better attention to the task and with less distraction and fatigue (Binder, Haughton, \& Van Eyk, 1990). Fluency also helps readers stay on task and engage in extended reading activities, such as SSR (Binder, 1996). Increased fluency helps students have a more positive attitude toward reading and a more positive concept of themselves as readers (Rasinki, 2003). Finally, fluency helps readers to retain or recall information (Binder, 1996).

\section{Writing Fluency}

Many researchers believe there is a connection between reading and writing. Both reader and writer use symbolic structures of meaning, follow similar patterns of thinking, and both involve past experiences with language (Rosenblatt, 2004). "The parallels in the reading and writing processes and the nature of the transaction between author and reader make it 
reasonable to expect that the teaching of one can affect the student's operation in the other" (Rosenblatt, 2004, p. 1388).

Clay (2001) writes about the reciprocity of learning to read and write; she believes writing strengthens early literacy learning in classrooms. Both reading and writing deal with phonological information and how to search, monitor, self-correct, and make decisions about words. She concludes that reading and writing can help each other.

Many researchers have noted the similarity of comprehending and composing and how doing one increases the ability to do the other. Some believe writing is the foundation of reading, when students write they are putting together reading. Chomsky (1978) suggested that for some children, writing might be a way into reading. Over 35 years of research has shown the importance of the writing-reading interaction and writing beneficial effect on reading development (Farnan \& Dahl, 2003). Fearn and Farnan (2001) note the similarities of reading and writing:

Reading and writing both demand enormous information about language and how language works, how to manage or control language, and how to use language to make meaning. Reading and writing are natural and critical interactions within the language arts. (Fearn \& Farnan, 2001, p. 17)

In their book Practical Fluency, teachers Max and Gayle Brand (2006) explain how their fluency instruction includes both reading and writing. They are inspired by Frank Smith's words, "They must read like a writer in order to write like a writer" (Smith, 1988, p. 23). Not only do the Brands believe reading and writing are intertwined, but they have a reciprocal relationship. "While we are teaching kids to read, we are also teaching them to write, and while writing, our students are learning about reading” (Brand \& Brand, 2006, p. 3).

\section{Problem Statement}

Studies have shown that the speed of oral reading is positively related to comprehension (Daane et al., 2005). Many researchers and teachers believe improving a child's reading fluency can improve their reading comprehension (Fuchs et al., 2001). Some research has shown reading and writing to be reciprocal skills (Clay, 2001). If reading and writing are related, could there be a connection between a student's writing skills and their reading comprehension? If increasing students' writing skill does increases their reading comprehension, this gives us another avenue to improve reading comprehension. 
It is very common for teachers to measure their students' reading fluency; there are many assessments readily available. However, most teachers have not considered measuring their students' writing fluency. Yet, many researchers believe reading and writing are parallel processes. There is very limited, if any, research on writing fluency. Using principles of Fearn and Farnan (2001), I will develop a writing fluency assessment.

While there are a great number of studies examining reading fluency and reading comprehension, there are limited, if any, studies regarding the relationship writing fluency and reading comprehension. Thus, there is a need for studies that examine the impact of writing fluency on reading comprehension and reading fluency.

\section{Purpose Of The Study}

This study will respond to the need described above. Specifically, the purpose of this study is to examine the relationships between reading fluency, writing fluency, and reading comprehension. It will examine if writing fluency is associated with reading comprehension. I will give students reading fluency assessments and writing fluency assessments. I will examine the assessments as it relates to the students' reading comprehension scores.

\section{The ReSEARCH QUESTIONS}

The study will address the following questions: What is the relationship between students' reading comprehension and reading fluency among a group of third graders? What is the relationship between their reading comprehension and writing fluency? What is the relationship between their reading fluency and writing fluency? Will the students who demonstrate increased writing fluency also demonstrate increased reading comprehension? What other factors influence reading comprehension? 


\section{CHAPTER 2}

\section{REVIEW OF THE LITERATURE}

A theoretical framework for understanding the reading process provides a basis for conceptualizing oral reading fluency. Primary theories regarding fluency contribution to a reader's understanding of the text are automaticity theory, developmental theories, compensatory-encoding theory, and prosody. Then fluency research will be explored.

\section{THEORETICAL BASES FOR ORAL READING FLUENCY}

There are two primary theories regarding fluency. The first and better known theory, the automaticity theory, accounts for the accurate and effortless decoding that characterizes fluent readers. The second and more recent theory focuses on the role of prosody, reading with expression.

\section{Automaticity Theory}

The theoretical article on automatic information processing in reading by LaBerge and Samuels (1974) was "one of the more important milestones in contemporary conceptions of reading fluency" (Rasinski, 2006, p. 11). According to the automaticity theory, "reading fluency is defined as the ability to decode and comprehend at the same time" (Samuels, 2002, p. 39). The theory states the human brain only has a limited capacity to process information simultaneously. The three most basic processes that all readers use are decoding (ability to say the word), comprehension (constructing a meaningful understanding of the text), and attention (cognitive energy to process information). The more processing space used for decoding, the less processing space is available for comprehension. Beginning readers who need attention to decode words will have less attention for comprehension. Fluent readers decode words so fast and easy it is nearly automatic; thus, they are able to focus more on comprehension.

The LaBerge and Samuels (1974) theory on automatic information processing in reading suggest that only when the surface-level processing of words in reading (e.g., lettersound rules, letter combinations, meaning of words) becomes automatic can a reader become 
fluent. LaBerge and Samuel's theory was a bottom-up serial-stage model of reading that required the lower level processes (word identification) be completed before the higher level processes (comprehension). Their model does not rely on contextual facilitation. This theory is important because it was one of the first modern theoretical conceptions of reading fluency (Rasinski, 2006) and it shed important light on automaticity. However, it focused mainly on word recognition and it did not explain all situations such as prosody, readability of the text, and text topic.

Based upon this theory, Samuels designed the repeated reading technique (Samuels, 1979). In repeated reading students read a passage over and over until a particular rate of words per minutes is achieved. As students practiced rereading of texts, Samuels believed they were developing automaticity in word decoding and word processing and this improvement could be generalized to new passages the students had not previously read. Repeated reading is one of the most researched and successful reading techniques for increasing fluency (Dowhower, 1987). However, Schreiber (1991) disagreed with Samuels on the reason why students increased reading fluency. Instead of increased fluency due to word automaticity, Schreiber believed students were developing a greater awareness of the prosodic features of oral reading and speech such as the syntactic organization of the written text. At the same time Samuels was testing repeated readings for improving reading fluency, Chomsky (1978) developed a method of repeated reading that included the Neurological Impress Method (NIM) first developed by Heckelman in 1969.

Stanovich (1986) redefined the automaticity theory in his model of interactive compensatory explanation. Stanovich suggested that an important difference between good and poor readers was in the way they processed text while reading. While good readers used automatic, attention-free processes for word decoding reserving extra energy for comprehending what they read, poor readers were not able to do so. Poor readers compensated for their difficulty in recognizing word automatically by using more contextbound strategies. Struggling readers may become too dependent on context or pictures to recognize new words quickly and accurately; thus their reading is slow and halting. In this theory, lower level processes do not have to be completed before the higher level processes can be initiated. With this interactive model, prior contextual knowledge helps in word identification so the reader can compensate for poor word-level skills. The automaticity 
theories view fluency as an outcome of reading connected text that can be improved upon once the child already knows to read.

\section{Developmental Theories}

The three models of reading development by Chall, Ehri, and Wolf, are phase theories that outline an ordered, step-by-step, natural sequence of operations that all beginning readers use. They emphasize that reading develops before formal reading education begins. The developmental process goes from letter fluency to word-level to connected text level, therefore, it must be taught early and explicitly.

\section{Chall's Six Stages of Reading DEVELOPMENT}

According to Chall's (1996) theoretical model, learners progress through six stages of reading development. The first stage of early reading or emergent literacy stage (birth through age six) is developed before formal instruction. It includes concepts about print, phoneme awareness, and book-handling knowledge. Next is the initial stage of conventional literacy or the beginning of formal reading instruction (grades 1 through 2). The learners recognize basic sound-symbol correspondence in order to aid their decoding ability. The third stage is most important to this study because it is confirmation and fluency or "ungluing from print" (grades 2 through 3). Learners develop automaticity with print and read with prosody with appropriate phrasing, stress, and intonation in their reading. At this stage it is easier to construct meaning from text because the learner is not struggling with word identification. The next stage called "reading for learning the new" (grades 4 though 8) involves reading a great deal of expository text. In the multiple viewpoints stage (grades 9 through 12), "the learner" is expected to critically evaluate various viewpoints on a given topic. The last stage is "construction and reconstruction" (throughout college and beyond) in which the reader develops her or his own perspective on a topic. Although Chall's theory is one of the most well-known and most widely quoted, it has been criticized for being too global and wide of a range to be used effectively for fluency work (Pikulski, 2006). 


\section{EHRI'S STAGES OF READING DEVELOPMENT}

Ehri believes sight-word reading development consists of four distinct phases: prealphabetic, partial alphabetic, full alphabetic, and consolidated alphabetic (Ehri, 1991). The prealphabetic phase (3-6 years, pre K-K) corresponds with Chall's early reading stage. It is considered prealphatic because letter-sound relationship is not involved in the recognition of sight words. Beginning readers often remember sight words based on visual aspects of a word. In partial alphabetic (5-8 years/K-1), although the learner can read some sight words because he or she has some letter-sound correspondence, it is incomplete because the learner does not know the complete spelling system. The full alphabetic phase (6-8 years/late K-2) parallels Chall's initial stage of conventional literacy. In Ehri's fully alphabetic stage students become increasingly familiar with the sounds that letter represent. In the final phase of consolidated alphabetic ( 7 years-adulthood/grade $2 \&$ beyond), the learner has automatic and accurate word recognition. This final phase corresponds with the confirmation and fluency stage of Chall's model.

Ehri's stages are very important because they show there is a cohesive sequence to word-recognition development and a reader may struggle because they have not received instruction that reflects that sequence. Ehri's theory of stages of reading development focuses much more on the decoding aspects, recognizes and acknowledges the important role of language and construction of meaning, and seems more directly related to fluency and its development (Pikulski, 2006).

\section{WOLF'S DEVELOPMENTAL THEORY}

Wolf believes fluency is a developmental process that involves all components of reading acquisition (Wolf, 2001). She believes explicit fluency instruction needs to be part of reading instruction from the beginning. It should be taught in preschool before the students becomes a reader, not waiting until it become a problem when a student cannot read text.

Wolf (2001) states she can predict as early as kindergarten which students will have trouble becoming a fluent reader. These struggling students do not integrate visual and verbal processes as rapidly as other children. Wolf believes the first and most important skill is to develop phoneme awareness (the child's ability to hear and manipulate phonemes).

Secondly, these students need to decode as automatically as possible. To do this they need to 
practice reading and to get as much exposure to letter or letter pattern as possible. Finally students can grow in reading fluency through word knowledge and vocabulary development.

Wolf's definition of fluency is much more complex and detailed than any other definition of fluency. Although it includes decoding, reading rate, and prosody of many other definitions (NRP, 2000; Rasinski, 2003), it stresses the stages in the developmental process:

In its beginnings, reading fluency is the product of the initial development of accuracy and the subsequent development of automaticity in underlying sublexical processes, lexical processes, and their integration in single word reading and connected text. These include perceptual, phonological, orthographic, and morphological processes at the letter-, letter-pattern, and word-level, as well as semantic and syntactic processes at the word-level and connected text-level. After is if fully developed, reading fluency refers to a level of accuracy and rate where decoding is relatively effortless; where oral reading is smooth and accurate with correct prosody; and where attentions can be allocated to comprehension. (Wolf \& Katzir-Cohen, 2001, p. 219)

\section{COMPENSATORY-ENCODING THEORY (C-ET)}

There may be a case in which a student has nonfluent reading skills but does not have lower comprehension. This may an example of compensatory-encoding theory (C-ET). C-ET identifies actions that can overcome weak reading skills. To overcome confusion in reading, students can use "compensations" such as slowing their reading rate, pausing, reading aloud, or rereading the text. "According to C-ET, readers with poor word reading, small verbal working memory capacities, or poor listening comprehension can comprehend well, as long as they are motivated to understand and free to compensate" (Walczyk \& Griffith-Ross, 2007, p. 563).

\section{Prosody in Fluent Reading}

While automaticity and accuracy of decoding words are very important, many researchers now believe prosody is the key to fluency. Prosody is a general linguistic term to describe rhythmic and tonal features of speech (Dowhower, 1991). It includes intonation (pitch), stress (emphasis), tempo (rate) and duration (timing). Schreiber (1991) states oral reading fluency can be characterized as smooth, expressive production with appropriate phrasing or chunking groups of words into meaningful phrases in accordance to the syntactic structure of the text. 
Besides being able to decode automatically, fluent readers chunk or parse text into syntactically appropriate units—mainly phrases (Rasinski, 2003). Allington's 1983 seminal article "Fluency: The Neglected Goal" twenty-five years ago, states: "I think fluency is reading phrases, with appropriate intonation and prosody - fluency is reading with expression" (Allington, 2006, p. 94).

A recent longitudinal study examined the development of reading prosody and its impact on reading skills (Miller \& Schwanenflugel, 2008). Ninety-two students were tested at the end of grades 1 and 2, then reassessed on oral reading fluency and reading comprehension at the end of third grade. The researchers found that the "development of reading prosody is an important element of reading fluency and should be considered a key aspect of any definition of it" (p. 352).

\section{Other Theoretical Perspectives}

Other theoretical perspectives that influence this study are Jean Piaget's Theory of Cognitive Development (Wadsworth, 1978), Lev Vygotsky's theory of the Zone of Proximal Development (Lee \& Smagorinksy, 2000), and John Dewey's Progressive Education theory (Dewey, 1938). Their writings contributed to the constructivism theory which states learning takes place when students actively build knowledge and skills.

Children learn to read through social interactions with those around them. One of the jobs of the teacher is to identify the stage a child has reached and help the child move to the next stage supporting the student until the student can do it on his own. (Au, 2002, p. 394)

I believe students need social, hands-on, child centered experiences in order for them to learn by actively construct their own understanding, for this reason, computer or online strategies will not used in this study. However, assessment by computer will be used in the study.

\section{Fluency Research}

Studies have shown oral reading fluency to be an indicator of overall reading competence. In the Fuchs et al. (2001) study students read two 400-word passages for 5 minutes. They were given three direct reading comprehension measures: orally answering 10 questions about the passage, retelling the passage, and completing a cloze activity. The fourth measure was orally reading the passage. The students' oral reading fluency was most strongly associated with reading comprehension, more so than answering the direct 
comprehension measures. "Oral reading fluency from text serves to predict reading comprehension, and comprehension in turns serves to predict oral reading text fluency" (Fuchs et al., 2001, p. 247). This study actually showed that oral fluency was a better predictor of comprehension than direct comprehension questions.

In Stecker, Roser, and Martinex (1998) review of fluency research, they found "fluency as been shown to have a 'reciprocal relationship' with comprehension, with each fostering the other" (p. 300). While studies have shown fluency is both a contributor to and a product of comprehension, there is debate whether fluency enhances comprehension growth (which is in line with automaticity theory), or comprehension facilitates fluency growth through top-down processes. Klauda and Guthrie (2008) assessed 278 fifth-grade students' comprehension and fluency at the whole-passage level. "The results involving the directionality of the relationship between fluency and comprehension support the ideas that these two reading skills have a reciprocally predictive relationship" (p. 319). Thus, according to this study, increasing students' fluency will increase their comprehension, and increasing their comprehension will increase their fluency.

This paper will examine three studies that has shown that direct instruction in fluency can result in greater student outcomes in fluency and comprehension. In the first study, Fluency and Comprehension Interventions for Third-Grade Students, Vaughn and colleagues (2000) conducted a 12-week study with 111 students. The students were divided into two groups: those with significant reading problems and those who were low to average achieving. The groups were assigned to interventions designed to target either fluency or comprehension. Partner Reading (PR) was used to increase fluency and strategic reading to enhance comprehension. In PR, students heard fluent reading modeled, they re-read passages several times, and they graphed their fluency scores. In Collaborative Strategic Reading (CSR) students were taught strategies to apply before, during, and after the reading process. Although in this study third graders made gains in rate of reading and correct words read per minute, they did not make gains in comprehension. However, the authors state that in previous studies CSR and PR have been associated with improved outcomes in reading for all students, including those with reading disabilities. According to Chard, Vaughn, and Tyler (2002), "This study provides for the close link between fluency and comprehension instruction" (p. 332). 
In the second study, the quasi-experimental scientific study second-grade study in New York (Sivin-Kachala \& Bialo, 2004), the experimental treatment group of six classes used Fluency Formula, a program which incorporates a developmental approach to teaching fluency, using repeated oral reading, phrase-cued text passages, and oral fluency assessments. The control group of six classes did not use Fluency Formula but the school's standard language arts program. Results showed students who used Fluency Formula significantly increased oral reading fluency, while students in the control group had no such increase. Students' improvement in fluency corresponded with improvements in reading comprehension. "Reading fluency has repeatedly been proven to be one of the best overall indicators of reading comprehension" (p. 4).

The third study was Stahl and Heubach's (2005) Fluency-Oriented Reading Instruction (FORI), a two year project to reorganize second-grade classes around the goal of fluency. Based on a development stage model of reading, the program included redesigned basal reading lesson repeated reading and partner reading, a free-choice reading period each day, and a home reading program. Of the 84 students involved in the study all but two were reading a grade level or higher by the end of the year. Results showed students made significant progress in both rate and accuracy growth in fluency and accuracy.

Although Stahl and Heubach's above study included free-choice reading period each day, according to the National Reading Panel (NICHD, 2000) there is no research evidence currently available to confirm instructional time spent on silent, unassisted, independent reading (such as Drop Everything and Read and Sustained Silent Reading) improve reading fluency or reading achievement.

\section{Reasons for Non-Fluent Reading}

There are many reasons why struggling readers have difficulty becoming fluent readers. The first and most common reason is that the child does not know how to decode words: decoding is the first prerequisite to fluency. In decoding the child learns the lettersound rules that result in reading accurately. If a child cannot decode words, he or she may have weaknesses in phonics and/or phoneme awareness. Explicit phonic instruction can help the child learn the basic rules about letters and sounds. Phoneme awareness is being aware of 
the tiny sounds or phonemes that make up words in speech. Small group instruction or oneon-one tutoring may be necessary for students with phoneme awareness weaknesses.

Children whose decoding skills are accurate but halting may be in need of practice. This is especially true for children who are second language learners. These children should be immersed in literature; they should be read to on a regular basis and they should read books at or slightly below grade level. Children should not read difficult books by themselves because this could lead to frustration and discouragement. Students should practice reading text that is at the instructional level (text the student can read with 90-94\% accuracy) or independent level (text the student can read with 95\% accuracy or above) (Fountas \& Pinnell, 2006).

If a student reads fluently but his or her comprehension is low, this could be an example of word calling. Stanovich (1986) defined word calling "when the words in the text are efficiently decoded into their spoken forms without comprehension of the passage taking place" (p. 372). In this case, fluent word reading is not enough; the student needs to be able to comprehend the passage.

Finally, some children have fine phoneme awareness and decoding skills, but their reading is laborious and slow with poor comprehension skills. Sometimes these children just need more practice reading. However, some of these children may have a different rate in which they process written language: the areas in the brain that put together visual and verbal processes do not work together automatically.

Phoneme awareness, automatic decoding skills, and practice contribute to making a reader fluent. Phoneme awareness skills should be developed in preschool, kindergarten, and first grade — even before a child begins to read. Children need to become as automatic as possible in learning to decode. Practice is always necessary, but it is important to realize the fact that not all children learn to read in the same way. Some children may need 40 exposures to learn letter patterns while others may need 100 exposures before the patterns become automatic. Studies now show that vocabulary and word knowledge (multiple meanings and functions in a word) contribute to children's growth of fluency. Teachers are encouraged to explicitly teach spelling, vocabulary, suffixes, and grammar at the word level, and then progress to increased fluency at the sentence and paragraph level (Wolf, 2001). 


\section{Ways to Increase Reading Fluency}

There are many strategies teachers can use to help a child increase their reading fluency. One of the most researched and most used techniques to increase reading fluency is repeated reading (Samuels, 1979). In repeated reading students reads a passage over and over until a particular rate of words per minutes is achieved. It is believed repeated reading speeds up fluency, and then fluency contributes to comprehension. The National Reading Panel (NICHD, 2000) came out strongly in favor of repeated reading concluding it had a clear and positive effect on reading fluency.

Reading research indicate that several techniques can lead to gains in reading fluency: the oral-assisted reading technique; student reads while listening to a fluent reader read the same text (Kuhn \& Stah1, 2001); Neurological Impress Method: teacher and student read book at the same time while teaching reading into the student's dominant ear (Heckelman, 1969; Topping, 1987); Taped-Assisted (auditory modeling): student reads while listening to a fluent reader read the same text on a tape recorder (Carbo, 1978; Chomsky, 1978); FORI (Fluency Oriented Reading Instruction) a story is read by teacher, read independently, read at home, and reread with a partner (Stahl \& Heubach, 2005); Paired Repeated Reading: students read short passages of text and evaluate their own as well as their partner's improvement (Koskinen \& Blum, 1984).

Teachers can provide students with models of fluent reading by reading aloud to their students. Teachers can combine reading instructions with opportunities for students to read books at their independent level or reading ability. There are many strategies to practice fluency: partner reading, student-to-adult reading, choral reading, text segmenting (cueing phrase boundaries in text, e.g., "In winter/I like/to ski/at the mountains."), and readers' theatre. Fluency practice passages can also be assigned as homework.

Not only are decoding skills necessary for fluency, language development and vocabulary development are also important to fluency (NICHD, 2000; Pikulski, 2006). Language skills are important so that student can be familiar with the syntax and grammar of words and phrases they are reading. These language skills can be built through conversations and discussions. Fluency is dependent on the readers' vocabulary as well as their decoding skills. It is important to explicitly teach vocabulary words, including high-frequency vocabulary. Writing can also be used as a tool for increasing vocabulary. "Developing the 
oral-language and vocabulary skills of children, particularly those who are learning English as a second language or those who spent their preschool years in language-restricted environments, is one of the greatest challenges facing us as educators" (Pikulski, 2006, p. 81).

Although there is great interest in oral reading, the vast majority of reading done in school today is silent reading comprehension. Oral reading is still very important, especially to struggling readers, because oral reading is "an observable reflection of decoding and fluency, which are nothing less than essential for reading comprehension" (Pikulski, 2006, p. 71).

Should text fluency be assessed by oral or silent reading? Fuchs et al. (2001) asked 365 fourth-grade students to read a passage for 2 minutes and answer six literal recall questions and two inferential questions. Two passages were read: one orally and the other silently. To assess the silent reading, students reported the last word read during silent reading. Curriculum-based measurement (CBM) was used to assess oral fluency. In CBM, teachers count the number of words read correctly in one minute, subtracting for decoding errors and miscues (Deno, 1985). Results showed the oral reading fluency score was significantly higher than the silent reading fluency scores. This study suggests oral reading is a better way to assess fluency than silent reading.

\section{Backlash on Reading Fluency}

Some educators today are questioning the emphasis currently being placed on reading fluency in the classroom. In their book, Rereading Fluency, the authors "question whether there is sufficient scientific evidence to support the prominence of fluency in today's classrooms" (Altwerger et al., 2007, p. 7). In her article "Fluency Fallacy," Manning (2004) expresses her concern that there is an over-emphasis on fluency that comes at the expense of comprehension. In "Fluent to a Fault," the author, using the analogy of race cars, suggests putting fluency in the passenger seat and letting comprehension take the wheel. She feels students are focusing on reading fast, being timed on a stopwatch, and beating their last score as they graph their results on their progress report. She is afraid if we focus on fluency in an isolated manner, we might create a classroom of word-callers (Marcell, 2007). Jerry Johns (2007), a past president of IRA, is concerned educators are creating unintended consequences 
in monitoring fluency. He is worried students may find the fluency test's reading selection to be very difficult and teachers may be unintentionally frustrating students and teaching them that fast and accurate decoding is the essence of reading.

Some researchers are concerned that students are being assessed by how fast and quickly they read a word. This takes away from prosody and comprehension. As Samuels states in his article, "the danger of using reading speed as the measure of progress is that some students and teachers focus on speed at the expense of understanding" (Samuels, 2007, p. 565).

\section{Writing Fluency Research}

Although there is a great deal of research about reading fluency, there is very little research or information on writing fluency. In their book, Practical Fluency, Brand and Brand made the connection between reading and writing fluency, however, they did not do a research study. They share their classroom experiences and their book is a guide for teachers to show what the practice of teaching reading and writing fluency looks like in a classroom.

In 2005, Dorothy Leal created an assessment to help teachers objectively evaluate their students' word-writing ability for fluency, accuracy, and complexity. She called her assessment the Word Writing CAFÉ (Complexity, Accuracy, and Fluency Evaluation). Although this assessment is for all grade levels and can be given whole class, it only assesses the students' fluency in writing words. It is not designed to assess students' sentence writing ability (Leal, 2005).

In Interactions: Teaching Writing and the Language Arts, Fearn and Farnan develop a writing system called Power Writing. "Power Writing is designed to promote fluency" (Fearn \& Farnan, 2001, p. 195). The writing assessment used in this study is based on Power Writing. Students are instructed to write as much as they can in one minute and then the number of words is counted. Unlike the Word Writing CAFÉ system, in Power Writing students write in sentences.

\section{Reading and Writing Fluency}

Research has shown students' oral reading fluency is most strongly associated with reading comprehension (Daane et al., 2005; Fuchs et al., 2001). Research also shows that reading fluency has a reciprocal relationship with comprehension with each fostering the 
other (Stecker et al., 1998). Several studies have shown that direct instruction in reading fluency can result in greater student outcomes in reading fluency and comprehension (SivinKachala \& Bialo, 2003; Stahl \& Heubach, 2005; Vaughn et al., 2000). Many researchers believe in the reciprocity of learning to read and write: helping a student to read can help a student write (Brand \& Brand, 2006; Clay, 2001). Using these findings, this study will explore the relationship between reading comprehension, reading fluency, and writing fluency. It will also see if direct instruction in reading fluency will increase students' reading fluency and writing fluency.

\section{The ReSEARCH Questions}

The study will address the following questions: What is the relationship between students' reading comprehension and reading fluency among a group of third graders? What is the relationship between their reading comprehension and writing fluency? What is the relationship between their reading fluency and writing fluency? Will the students who demonstrate increased writing fluency also demonstrate increased reading comprehension? In a classroom where there is direct instruction in reading fluency, will the students improve their comprehension, reading fluency, and/or writing fluency? 


\section{CHAPTER 3}

\section{METHODOLOGY}

Research shows high reading fluency leads to high reading comprehension scores. The results of the study Fourth-Grade Students Reading Aloud: NAEP 2002 Special Study of Oral Reading (Daane et al., 2005) found students who read aloud with the fewest errors demonstrated greater comprehension. It also showed the speed of oral reading was positively related to comprehension. The panel recommends that teachers assess reading fluency regularly. While research has shown high fluency results in high reading comprehension scores (Fuchs et al., 2001), studies have also shown the reverse: students who were low in fluency also showed difficulty comprehending what they read (Pinnell et al., 1995).

Many researchers believe reading and writing are similar processes, and if that is true, writing fluency may have an impact on reading comprehension. While much research has been done on reading fluency, little is known about writing fluency. Given the link between reading fluency and reading comprehension, is there a similar connection between writing fluency and reading comprehension? This study will assess writing fluency and see if it has a relationship with reading comprehension.

This quantitative study will have two parts. The first part will be analyzing data to investigate a correlation between reading and writing fluency and comprehension. I want to see if there are mutual influences of reading and writing fluency and then explore the links between writing fluency and reading fluency, writing fluency and reading comprehension, and reading fluency and reading comprehension.

This research will also include a quasi-experimental scientific study. While all three 3 rd grade classes will teach the board-adopted language arts curriculum, my class will have systematic direct instruction in reading and writing fluency. The study will investigate to determine whether instructions that incorporated metacognitive strategies led to an increase in reading comprehension. 
In this chapter, I will first describe the characteristics of the participants involved in this study. Next, data collection methods and timelines will be described and the instruments used to gather data will be identified and described.

\section{PARTICIPANTS}

The sample for this study will be comprised of all the third graders, a total of approximately 60 students, attending the upper middle-class suburban elementary school where I teach. There are approximately 500 students in grades Kindergarten through 6 th grade at the school: $81 \%$ of the students are White, $11 \%$ Asian, $7 \%$ Hispanic, $1 \%$ other and $7 \%$ of the students are economically disadvantaged; $96 \%$ of the students are fluent English speakers. Kindergarten through 3rd grade are part of the class reduction program and have 20 or less students, while grades 4th-6th average 31 students. Most families own their homes and over $90 \%$ of the parents have attended college. The school was recognized as a California Distinguished School by the state of California and has an API score of 939. In the 2006/2007 STAR scores, $67 \%$ of the students scored Advanced or Proficient in English/Language Arts and 82\% scored Advanced or Proficient in Mathematics.

This school is one of nine schools in a K-6 elementary union school district of approximately 5,600 students. All nine schools in the district have been recognized as National Blue Ribbon Schools. The district's student population is $80 \%$ White, $3 \%$ Asian, $15 \%$ Hispanic, and $3 \%$ other. The schools are situated in a coastal city with a population of approximately 58,000 .

Third grade students were chosen to participate in this study for several reasons. First, some developmental researchers believe it is absolutely critical for students to be reading fluently by the end of the 3 rd grade or they run the risk of failure as word demand increases in the higher grades:

One of the most important milestones during elementary years is the rite of passage at the end of grade 3. Children who are not fluent comprehending readers at the end of grade 3 are at risk for a cycle of learning failure from grade 4 on when the requirements for reading increase exponentially. One of the most critical insights in fluency research is the urgency to help all our children become fluent, comprehending readers by grade 3 . (Wolf, n.d., para. 20) 
Secondly, the goal of the federal law, No Child Left Behind, is to have students reading at grade level by third grade. Finally, I am a third grade teacher with easy access to the participants.

\section{Data Collection Instruments}

There will be several instruments used for data collection in this study, including Summative Tests, Stiegletz Informal Reading Inventory, District Writing Assessments, Reading Fluency Score, Reading Fluency Rubric, and Writing Fluency Score.

\section{Summative Tests}

These multiple choice summative assessments are district-required tests produced by the reading series publishers Houghton Mifflin. The First-Quarter Test (given in November) and Midyear Summative Test (given in February at the end of the first trimester) will be used. The tests assess the following areas:

1. Decoding and Word Recognition (Score from 0 to 10): An example of the cloze questions is: "The top of your leg is called your . a.) tie b.) thin c.) thigh d.) though."

2. Vocabulary and Concept Development (Score from 0 to 15): The vocabulary word is underlined and used in a sentence. An example: "I felt foolish when I sang the wrong song. What does foolish mean? a.) wise b.) silly c.) careful d.) happy." Dictionary skills are also tested; a dictionary entry is shown with 4-5 questions referring to the entry.

3. Reading Comprehension; Literary Response and Analysis (Score from 0 to15): After each of the three reading passages (4 to 8 paragraphs, approximately 170 to 260 words long), there are 5 comprehension questions. The reading passages range from narrative with inference questions, nonfiction explanatory text, a retelling of Aesop's fable, to informational text.

4. Writing Strategies (Score from 0 to 10): After a paragraph questions asking about topic sentences and which sentence does not belong in the paragraph are asked. Also a graph and index is shown with questions relating to it.

5. Language Conventions: 10 questions on sentence structure testing knowledge of complete sentences and combining sentences. 5 questions on grammar, capitalization, and punctuation, and 5 questions on spelling. In spelling students are to identify the misspelled word in a sentence.

6. Listening (Score 0 to 5): The students must listen as a teacher reads a three paragraph passage aloud to the class. The teacher can only read the passage once and cannot answer questions about it. The students answer five multiple choice questions about the passage. 


\section{Stieglitz Informal Reading Inventory}

The district requires each teacher to assess their students three times a year using the Stieglitz Informal Reading Inventory (Stieglitz, 1997). The Stieglitz is an individually administered test consisting of a reading passage the students reads aloud to the teacher. While the student reads, the teacher does a running record, marking any reading errors the student makes. The student then orally answers six comprehension questions about the story. The Stieglitz is a diagnostic tool the teacher uses to determine the students reading grade level. The score will range from 1 to 4 .

\section{District Writing Assessment}

The district's August Benchmark is a descriptive writing assessment about a special item and the November Benchmark is a personal narrative with the prompt "A Family Gathering" which is a narrative story. The writing is scored on a 4 point rubric.

\section{Two Reading Fluency Assessments}

There will be two reading fluency assessments. The reading fluency score will be the student's oral reading rate which results in a number score from 25 to 150 . The reading fluency rubric will have scores from 0 to 6 .

The student's oral reading rate is determined by taking a one-minute sampling of his or her oral reading of a passage at his reading level (Blevins, 2001). The passage must be unfamiliar to the student, can be taken from any grade-level textbook or book series, and must contain a minimum of 200 words. Two copies of the passage is required, one copy for the student to read and one for the teacher to record any errors the student makes while reading. As the student reads, the teacher follows along and marks on their copy any words incorrectly read. If a student stops or struggles with a word for 3 seconds, the teacher says the word and marks it incorrect. The teacher places a mark after the last word read and then tallies the words read, subtracting for each word read incorrectly. To be at grade level, a student in third grade should have a reading fluency score between 90 and 105. For this study I will use just the total number of words read correctly: I will not convert it to a rubric. I did this so the results of the reading fluency test would be in the same form as the writing fluency test. My school district requires students be tested for their fluency rate at least three times a 
year. I will do two reading fluency assessments on each student: one in November and another one in February.

The reading fluency rubric notes the student's inflection, phrasing, following punctuation marks. A score of 1 would show word by word oral reading while a score of 6 would show exceptional reading fluency.

\section{Writing Fluency Assessments}

The district does not have a writing fluency assessment. I will create the students' writing fluency assessment by using the Power Writing system of writing created by two San Diego State professors, Leif Fearn and Nancy Farnan (Fearn \& Farnan, 2001). In Power Writing students "write in the midst of pressure to produce quantity in limited time ... Power Writing develops fluency applied to writing" (p. 69).

The students are instructed to write sentences for 1 minute. Spelling should be conventionally as possible, but inventive spelling is accepted. The students may write on any topic or a prompt may be given. Examples of prompts may include: "Write a sentence that contains the name of something that is red." Other prompts might include "Think of a sentence that contains the name of something you see when you walk home from school" or "Think of a sentence that contains something you have in your kitchen." The teacher tallies the number of words in the sentences. The sentence needs to make sense; it cannot be just a list of words. The focus is on sentence thinking and writing. If a word cannot be identified, it will be excluded from the total. The writing fluency in my class ranged from 67 to 153 . I will do two writing fluency assessments on each student: one in November and another one in February.

\section{DATA ANALYSis}

This experiment will include the following steps:

1. Students will be pretested before they receive instruction. Pretesting should show that the treatment and control groups do not differ before instruction. Comparing pretest to posttest performance should show whether gains have resulted from the instruction.

2. Students were randomly assigned to experimental and control groups. The experimental group receives instruction in fluency. The control group received no special instruction beyond that provided in the classroom at school.

3. Post-testing students after instruction. The posttest would show whether fluency trained groups made greater gains than control groups, indicating whether that 
instruction was effective. Reading posttest show whether fluency instruction improved students' reading ability (Ehri, 1991).

\section{THE FIRST STUdY}

The quantitative method of multiple regression will be used to analyze the data. Multiple regression analysis examines the degree of relationship among the variables. I will be examining the effects of the variables of reading fluency and writing fluency to reading comprehension. I will also use the demographic variables of gender, ethnicity, and socioeconomic status as determined by eligibility of free and reduced lunch. Since this study is non-experimental, causality cannot be inferred. Since it is a relatively small sample size, generalizability is limited.

\section{ThE SECOND STUdY}

One way to judge the impact of teaching of fluency is to look at the effect size- the extent to which performance of the treatment group is greater than the performance of the control group. Effect sizes can be small (.20), moderate (.50), or large (.80).

The three 3 rd grade classes are demographically and academically equal. "All classes are balanced in regards to the number of boys and girls, student achievement levels, ethnicity, behavioral issue, health concerns, special needs, and parental involvement" (T. Reeve, personal communication, August 16, 2007). The teachers all have similar experience. They are all white, suburban women over the age of 51 . They have all taught for 11 or more years at this school and they are fully credentialed. They are all married: two teachers have no children, one teacher has two children. They all live within 15 miles of the school. Two teachers have life-long credentials that they received over twenty five years ago. These teachers have never had any instruction or inservices on fluency. This mirrors what Rasinski (2006) states: "textbooks for training teachers in reading instruction provided little, if any, in-depth focus on defining, teaching, or assessing reading fluency" (p. 10).

In order to show efficacy of the intervention, students' November and February scores will be analyzed to see if there was a statistically significant difference between the two groups. Means and standard deviations will be used. All statistical analyses will use PASW (formerly SPSS) for Windows (PASW 18.0, SPSS Inc., Chicago, IL). All of the analyses will be two-sided with a 5\% alpha level. Pearson's correlation statistic, paired t- 
tests, independent samples t-tests, multiple linear regression analysis will also be used to analyze the data.

The treatment class will have the following direct instruction in fluency:

Whole Class Activities:

1. Choral Reading Phrasing, Rate, and Intonation: "Twist and Turn!" in Overhead Lesson for Fluency

2. Choral Reading Poetry and Rhymes: "I Had a Little Puppy" and "My Bonnie Lies Over the Ocean" in Texts for Fluency Practice

3. Teacher modeled Fluency Reading: excerpts from "Aesop's Fables" (focus on dialogue, pacing, and sentence length) and "Pippi Longstocking" (focus on nonEnglish words, phrasing, and sentence length) in Read-Aloud Passages \& Strategies to Model Fluency

4. Passages for Kids to Read Aloud at Home: "The Three Billy Goats Gruff" in Weekby-Week Homework for Building Reading Comprehension \& Fluency

5. Choral Reading Intonation and Phrasing: "More Disgusting Broccoli Pie, Please!" in Perfect Poems With Strategies for Building Fluency

6. Choral Reading Phrase-Cued "Passage Pass It On!" in Building Fluency: Lessons and Strategies for Reading Success

Small Group:

1. Book Adventure: Students read books and are tested on comprehension online.

2. Readers" Theatre: Fairy tale (4 parts) "Red Riding Hood Rap" in Building Fluency

3. Reader's Theatre: (6 parts) "A Garage Sale, Trustworthiness" in Character Counts!

4. Reader's Theatre: (11 parts) Focus on prosody. "The Wolf and the Young Kids" in Fluency Practice Read-Aloud Plays

5. Paired Reading Record Sheet: Students will time each other reading using special one minute timers in The Fluent Reader and Partnering for Fluency

6. Tape-recording reading

7. Minibooks: "Meeting George Washington" in Fluency Practice Mini-Book

8. Neurological Impress Method Plus (NIM): A method in which the teacher sits next to the student speaking into the student's dominant ear. Both teacher and student hold the book and read it aloud with the teacher's finger tracking the words and the student's finger resting on top of the teacher's finger (Flood, Lapp, \& Fisher, 2003).

\section{LIMITATION/DELIMITATION}

This study includes only $3 \mathrm{rd}$ graders because many researchers believe $3 \mathrm{rd}$ grade is the most important year in developing fluency and reading comprehension. 
Since my school has a low level of students with a second language, this study will address a limited number of English Learning Students. Also, there are a predominately white, middle class number of students eligible for a free or reduced lunch. The study includes a limited number of students so it is not generalizable.

The study is short term, taking place over the span of four months. See Appendix A for sample data from my third grade class of 19 students.

\section{SIGNIFICANCE OF THE STUDY}

This study may have far reaching implications for teaching of literature. The study may help teachers be better informed regarding their instructional practices. For example, if the study does show a relation between writing fluency and reading comprehension, this may significantly increase the amount of time students spend writing. 


\section{CHAPTER 4}

\section{RESULTS}

The Results chapter will be divided into two sections. The first section will be a description of the sample and the second section will examine the research questions from the study, the data analysis techniques used, and the results. All statistical analyses were performed using PASW (formerly SPSS) for Windows (PASW 18.0, SPSS Inc., Chicago, IL). All of the analyses were two-sided with a 5\% alpha level. Pearson's correlation statistic, paired t-tests, independent samples t-tests, multiple linear regression analysis were used to analyze the data.

\section{DESCRIPTIVE STATISTICS FOR DEMOGRAPHIC VARIABLES}

Demographic characteristics of the study sample were described using the mean, standard deviation and range for continuous scaled variables and frequency and percent for categorical scaled variables. Table 1 shows the study sample consisted of 54 students, 32 (59\%) males and 22 (41\%) females. Table 2 shows Teacher AA, Teacher BB, and Teacher $\mathrm{CC}$ each had 18 students in their class. Table 3 shows the study group is composed of 36 students in the control group and 18 students in the experimental group for a total of 54 students. Table 4 shows $41(76 \%)$ students were white, 7 (13\%) were Hispanic/Latino, 3(6\%) were Japanese, and 1(19\%) each were Chinese, Middle East, and Russian. Only 2 students of the 54 total participated in the free or reduced lunch program as shown in Table 5. Table 6 shows that only 4 students of the 54 were English as a Second Language Learner. In the ELA Star Test 17 (35\%) students scored Advanced, 16 (33\%) scored Proficient, 12 (25\%) scored Basic, 3 (6\%) scored Below Basic, and 1 (2\%) scored Far Below Basic as shown in Table 7. Table 8 shows the average (SD) ELA Star Score was 378.1(60.2) and the range was from 251 to 528 . 
Table 1. Gender

\begin{tabular}{llcccc}
\hline \hline \multicolumn{5}{c}{ Gender } \\
\hline \hline \multirow{2}{*}{ Valid } & & & & Cumulative \\
& & Frequency & Percent & Valid Percent & Percent \\
& Female & 32 & 59.3 & 59.3 & 59.3 \\
& Male & 22 & 40.7 & 40.7 & 100.0 \\
& Total & 54 & 100.0 & 100.0 & \\
\hline \hline
\end{tabular}

Table 2. Number of Students in Each Teacher's Class

\begin{tabular}{|c|c|c|c|c|c|}
\hline \multicolumn{6}{|c|}{ Teacher ID } \\
\hline & & Frequency & Percent & Valid Percent & $\begin{array}{c}\text { Cumulative } \\
\text { Percent } \\
\end{array}$ \\
\hline \multirow[t]{4}{*}{ Valid } & $A A$ & 18 & 33.3 & 33.3 & 33.3 \\
\hline & BB & 18 & 33.3 & 33.3 & 66.7 \\
\hline & $\mathrm{CC}$ & 18 & 33.3 & 33.3 & 100.0 \\
\hline & Total & 54 & 100.0 & 100.0 & \\
\hline
\end{tabular}

Table 3. Total Number of Students in Control and Experimental Groups

\begin{tabular}{llcccc}
\hline \hline \multicolumn{5}{c}{ Study Group } \\
\hline \multirow{2}{*}{ Valid } & & & & Cumulative \\
& Control & 36 & 66.7 & 66.7 & 66.7 \\
& Experimental & 18 & 33.3 & 33.3 & 100.0 \\
& Total & 54 & 100.0 & 100.0 & \\
\hline \hline
\end{tabular}


Table 4. Ethnicity

\begin{tabular}{|c|c|c|c|c|c|}
\hline \multicolumn{6}{|c|}{ Ethnicity } \\
\hline & & Frequency & Percent & Valid Percent & $\begin{array}{c}\text { Cumulative } \\
\text { Percent }\end{array}$ \\
\hline \multirow[t]{7}{*}{ Valid } & White & 41 & 75.9 & 75.9 & 75.9 \\
\hline & Hispanic/Latino & 7 & 13.0 & 13.0 & 88.9 \\
\hline & Japanese & 3 & 5.6 & 5.6 & 94.4 \\
\hline & Chinese & 1 & 1.9 & 1.9 & 96.3 \\
\hline & Middle East & 1 & 1.9 & 1.9 & 98.1 \\
\hline & Russian & 1 & 1.9 & 1.9 & 100.0 \\
\hline & Total & 54 & 100.0 & 100.0 & \\
\hline
\end{tabular}

Table 5. Participation in Free and Reduced Lunch Program

\begin{tabular}{lccccc}
\hline \hline \multicolumn{5}{c}{ Free/Reduced Lunch Program } \\
\hline \hline \multirow{6}{*}{ Valid } & & & & \\
& & Frequency & Percent & Valid Percent & $\begin{array}{c}\text { Cumulative } \\
\text { Percent }\end{array}$ \\
& No & 52 & 96.3 & 96.3 & 96.3 \\
& Yes & 2 & 3.7 & 3.7 & 100.0 \\
& Total & 54 & 100.0 & 100.0 & \\
\hline \hline
\end{tabular}

Table 6. English as a Second Language Learner

\begin{tabular}{lccccc}
\hline \hline \multicolumn{5}{c}{ English as a Second Language Learner } \\
\hline \hline \multirow{6}{*}{ Valid } & & & & Cumulative \\
& Fo & 50 & 92.6 & 92.6 & 92.6 \\
& Yes & 4 & 7.4 & 7.4 & 100.0 \\
& Total & 54 & 100.0 & 100.0 & \\
\hline \hline
\end{tabular}


Table 7. English Language Arts Star Test Performance Level

\begin{tabular}{|c|c|c|c|c|c|}
\hline \multicolumn{6}{|c|}{ ELA Star Performance Level } \\
\hline & & Frequency & Percent & Valid Percent & $\begin{array}{c}\text { Cumulative } \\
\text { Percent } \\
\end{array}$ \\
\hline \multirow[t]{6}{*}{ Valid } & Far Below Basic & 1 & 1.9 & 2.0 & 2.0 \\
\hline & Below Basic & 3 & 5.6 & 6.1 & 8.2 \\
\hline & Basic & 12 & 22.2 & 24.5 & 32.7 \\
\hline & Proficient & 16 & 29.6 & 32.7 & 65.3 \\
\hline & Advanced & 17 & 31.5 & 34.7 & 100.0 \\
\hline & Total & 49 & 90.7 & 100.0 & \\
\hline Missing & System & 5 & 9.3 & & \\
\hline Total & & 54 & 100.0 & & \\
\hline
\end{tabular}

Table 8. English Language Arts Star Test Scores

\begin{tabular}{|c|c|c|c|c|c|c|}
\hline \multicolumn{7}{|c|}{ Statistics } \\
\hline \multirow[t]{2}{*}{ Variables } & \multicolumn{2}{|c|}{$\mathrm{N}$} & \multirow[b]{2}{*}{ Mean } & \multirow[b]{2}{*}{ Std. Deviation } & \multirow[b]{2}{*}{ Minimum } & \multirow[b]{2}{*}{ Maximum } \\
\hline & Valid & Missing & & & & \\
\hline ELA Star Score & 49 & 5 & 378.12 & 60.230 & 251 & 528 \\
\hline
\end{tabular}

\section{RESEARCH QUESTIONS FROM THE STUDY}

Listed below are the research questions taken from the study. They will be analyzed using Pearson's correlation statistic.

\section{Research Question \#1}

What is the relationship between students' reading comprehension and reading fluency among a group of third graders? What is the relationship between their reading comprehension and writing fluency? What is the relationship between their reading fluency and writing fluency? Will the students who demonstrate increased writing fluency also demonstrate increased reading comprehension?

Pearson's correlation statistic was used to evaluate the relationships between reading fluency, writing fluency and reading comprehension, separately for the pretest and posttest measurements. In addition, Pearson's correlation statistic was used to evaluate the 
relationships between the change from pretest to post test in reading fluency, writing fluency and reading comprehension. Figures 1 through 3 are scatter plots which graphically depict the relationships between reading fluency, writing fluency and reading comprehension based on the pretest measurements. Table 9 shows there was a statistically significant, strong positive correlation between reading comprehension and reading fluency, $r(54)=0.62 ; \mathrm{p}<$ 0.001 . There was not a statistically significant correlation between reading comprehension and writing fluency, $r(54)=0.21 ; p=0.12$. There was not a statistically significant correlation between reading fluency and writing fluency, $r(54)=0.26 ; p=0.058$. The strong correlation between reading comprehension and reading fluency replicates most of the research on this topic. For the pretest, it was not surprising there was no correlation between reading fluency and writing fluency. Figures 4 through 6 are scatter plots which graphically depict the relationships between reading fluency, writing fluency and reading comprehension based on the posttest measurements. Table 10 shows there was a statistically significant, strong positive correlation between reading comprehension and reading fluency, $\mathrm{r}(54)=0.71$; $\mathrm{p}<0.001$. There was a statistically significant, moderately strong positive correlation between reading comprehension and writing fluency, $r(54)=0.38 ; p=0.005$. There was a statistically significant, strong positive correlation between reading fluency and writing fluency, $r(54)=0.46 ; p<0.001$. Throughout the study we will most likely see a strong correlation between reading comprehension and reading fluency in all testing situations, reflecting current research. In the posttest situation, the positive correlation between reading comprehension and writing fluency, and between reading fluency and writing fluency, is consistent with my thesis. Figures 7 through 9 are scatter plots which graphically depict the relationships between the change (posttest-pretest) in reading fluency, writing fluency and reading comprehension. Table 11 shows there was a statistically significant, strong positive correlation between the change in reading comprehension and the change in reading fluency, $r(54)=0.44 ; p=0.001$. There was not a statistically significant correlation between the change in reading comprehension and the change in writing fluency, $r(54)=0.08 ; p=0.57$. There was not a statistically significant correlation between the change in reading fluency and the change in writing fluency, $r(54)=-0.06 ; p=0.67$. Again, the positive correlation between the change in reading comprehension and the change in reading fluency is 


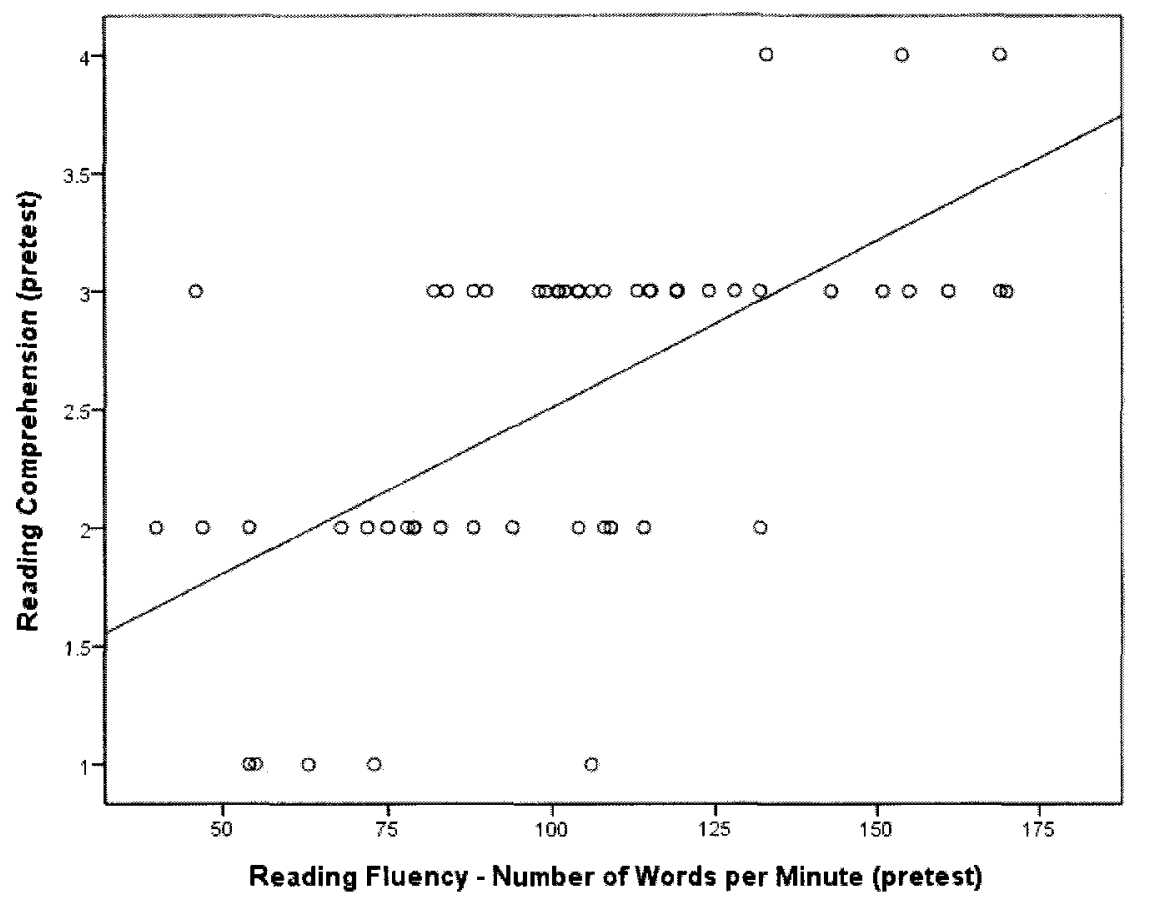

Figure 1. Pretest measurement of reading comprehension and reading fluency.

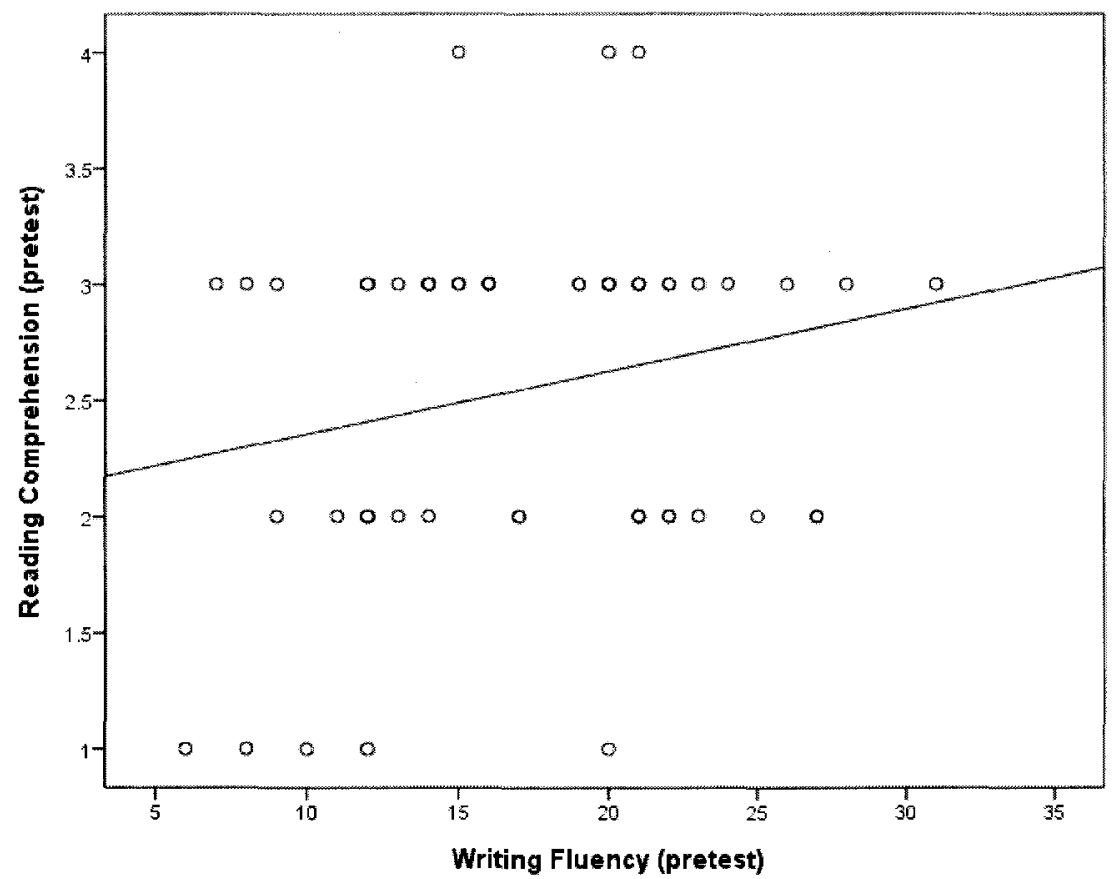

Figure 2. Pretest measurement of reading comprehension and writing fluency. 


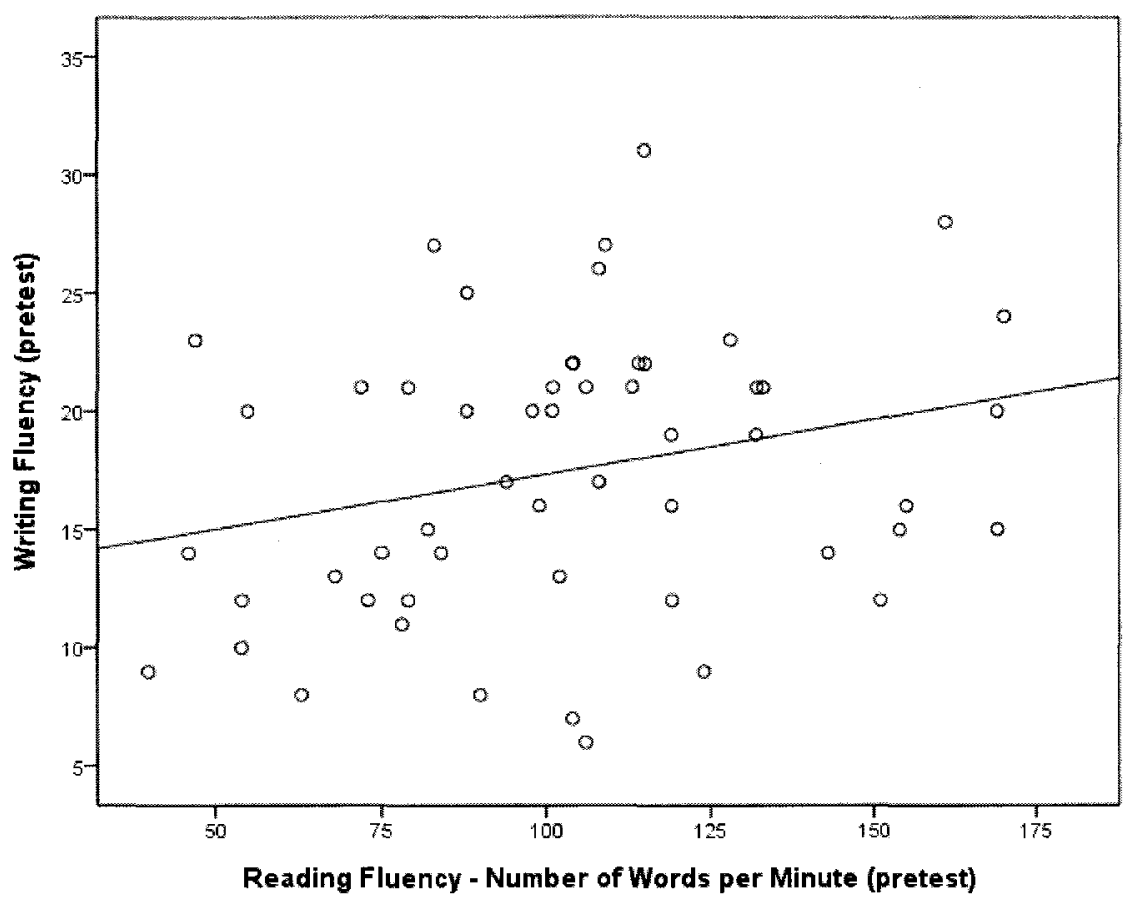

Figure 3. Pretest measurement of writing fluency and reading fluency.

Table 9. Correlation Between Reading Comprehension, Reading Fluency, and Writing Fluency (Pretest)

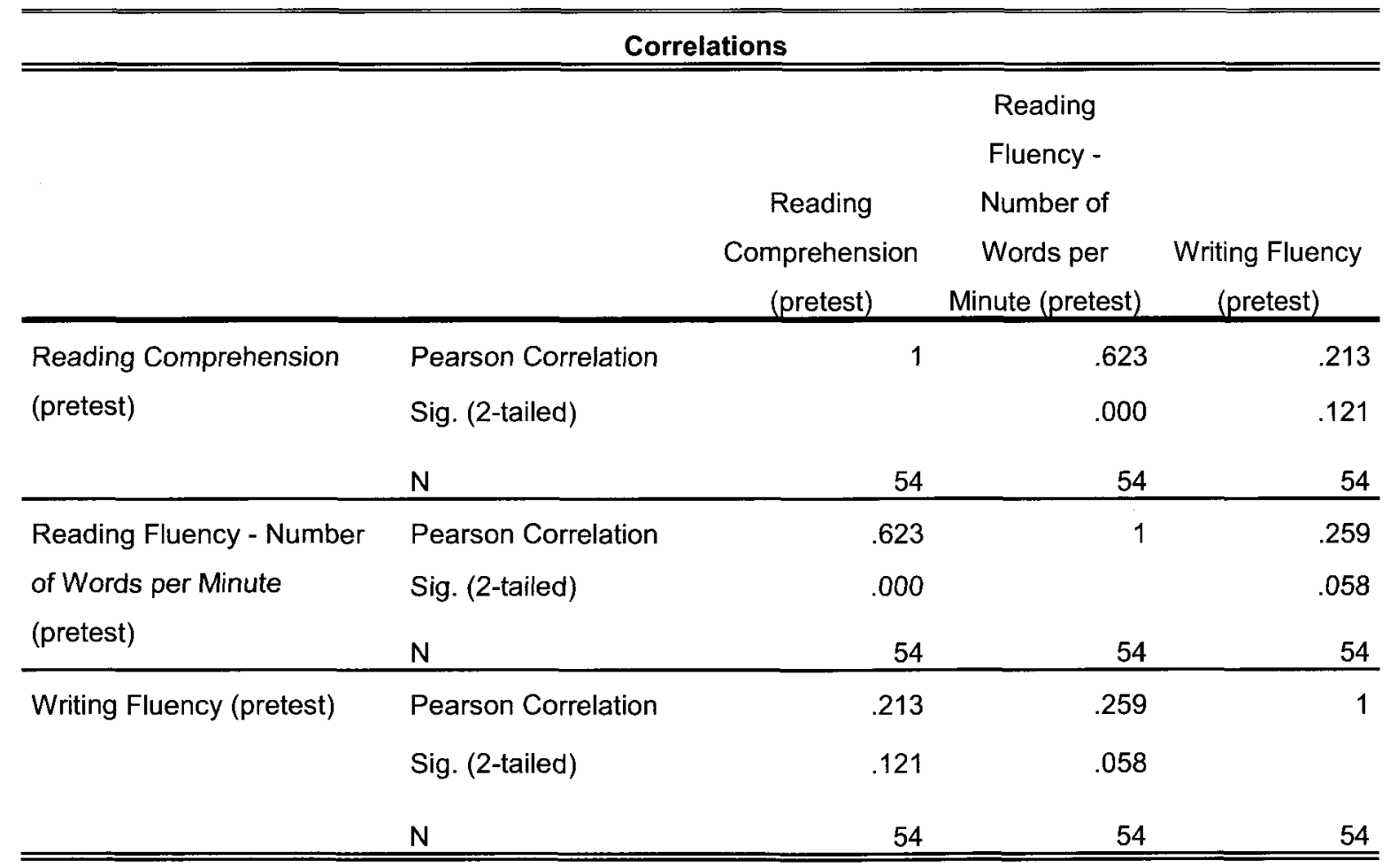




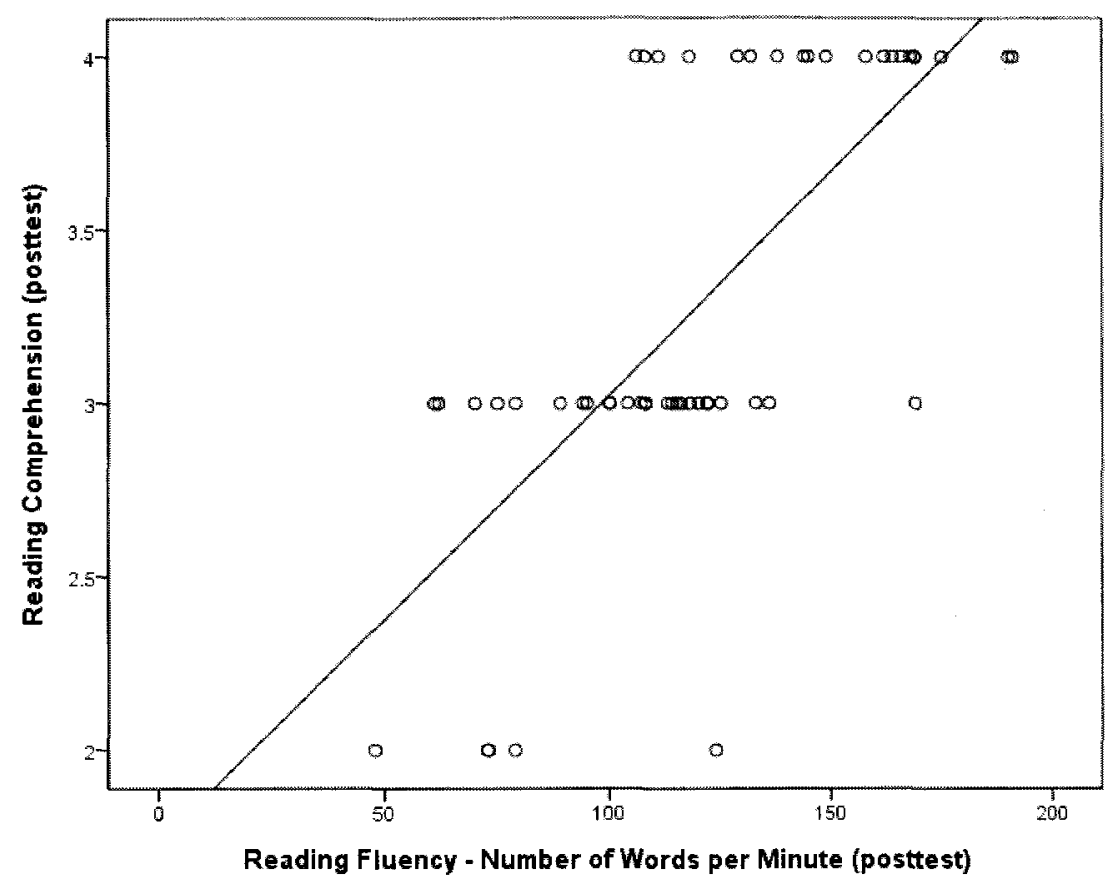

Figure 4. Posttest measurement of reading comprehension and reading fluency.

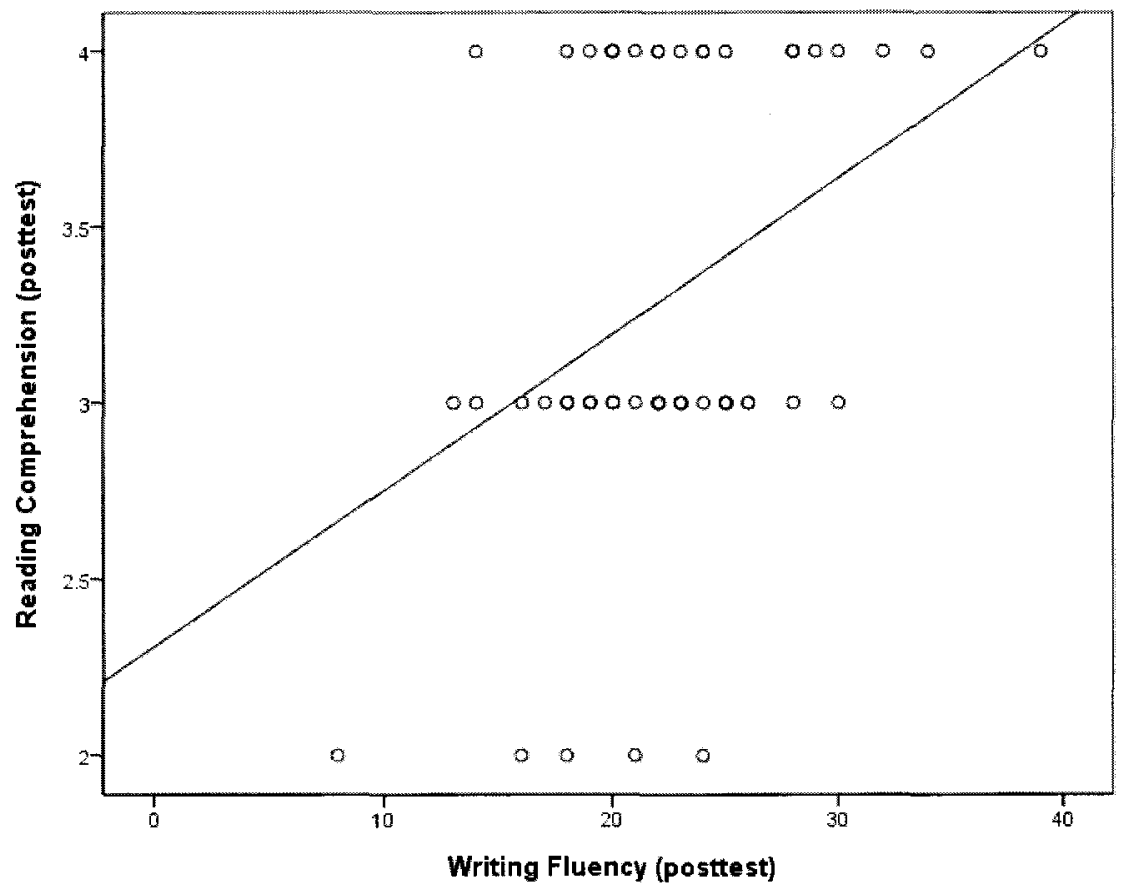

Figure 5. Posttest measurement of reading comprehension and writing fluency. 


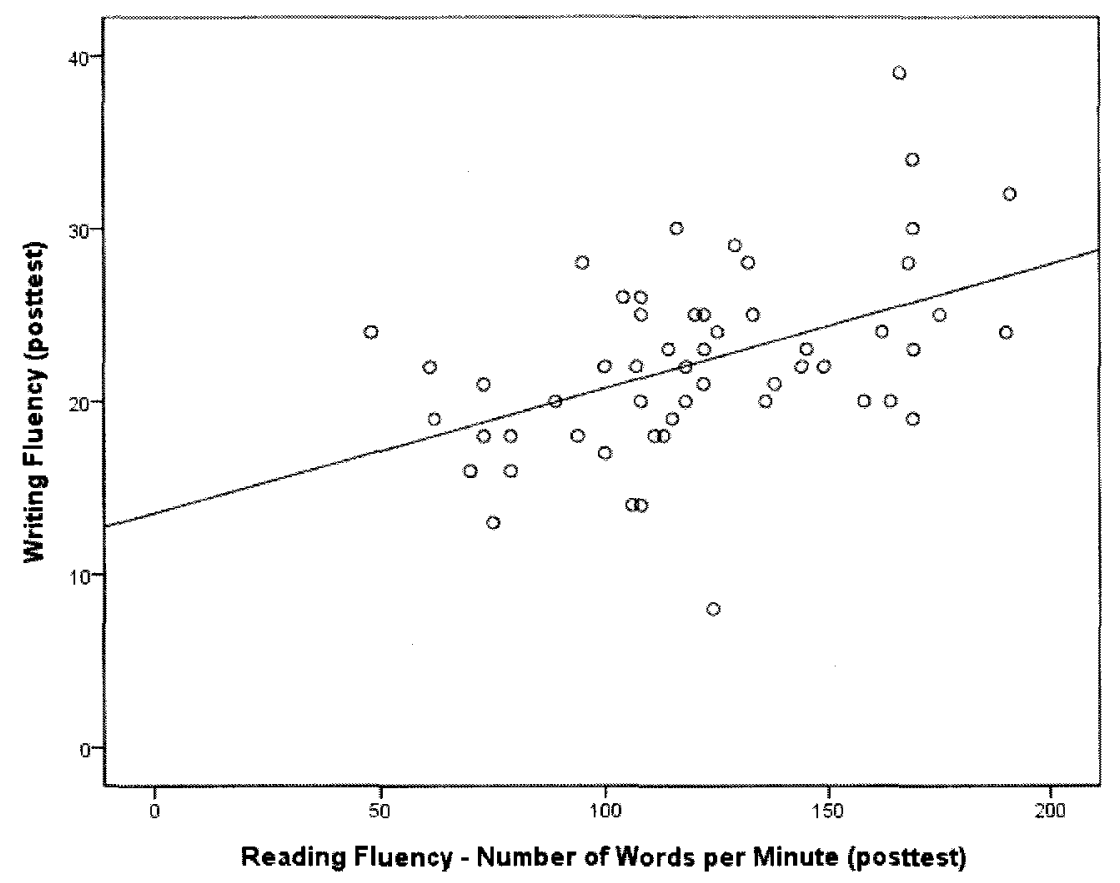

Figure 6. Posttest measurement of writing fluency and reading fluency.

Table 10. Correlations Between Reading Comprehension, Reading Fluency, and Writing Fluency (Posttest)

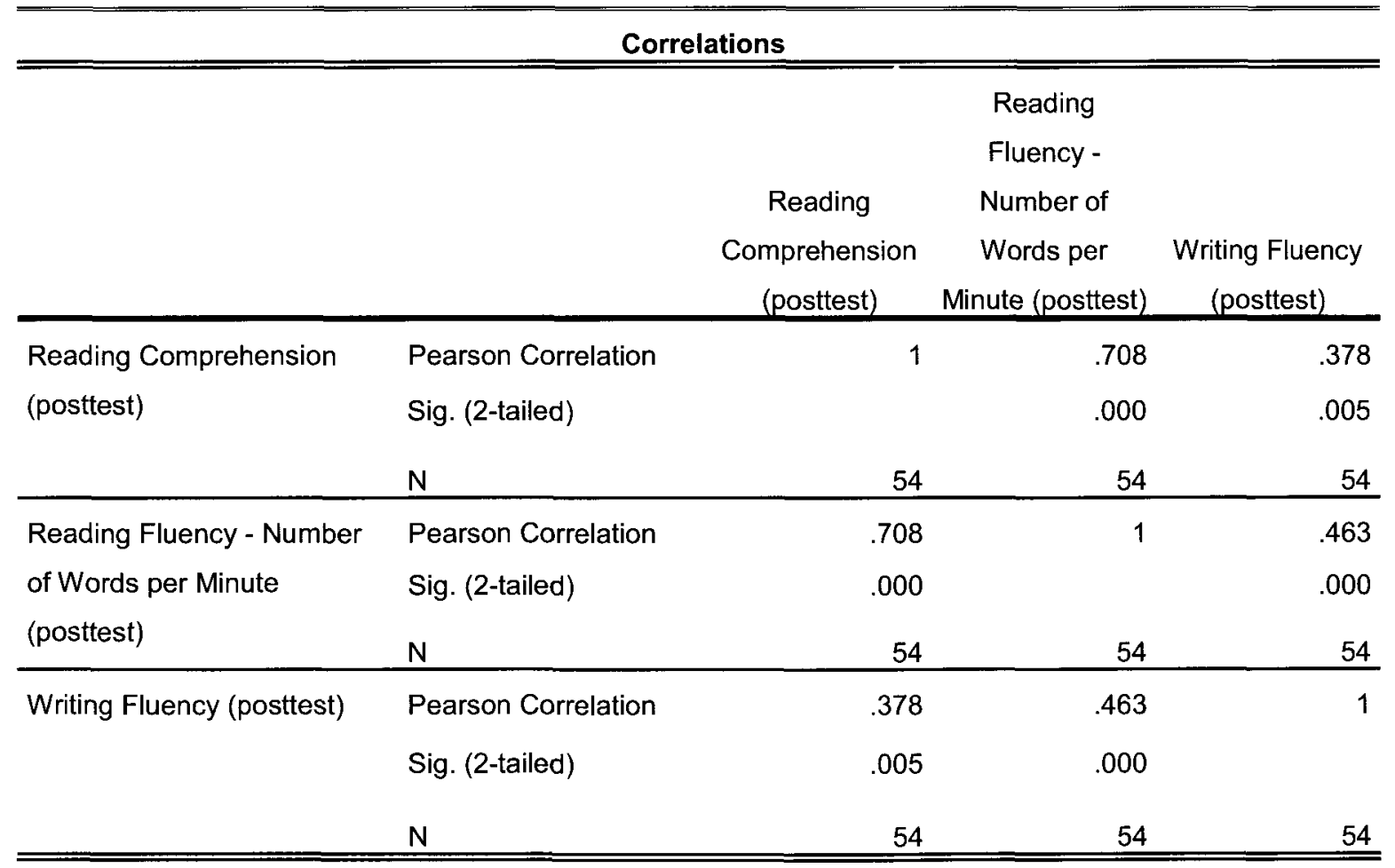




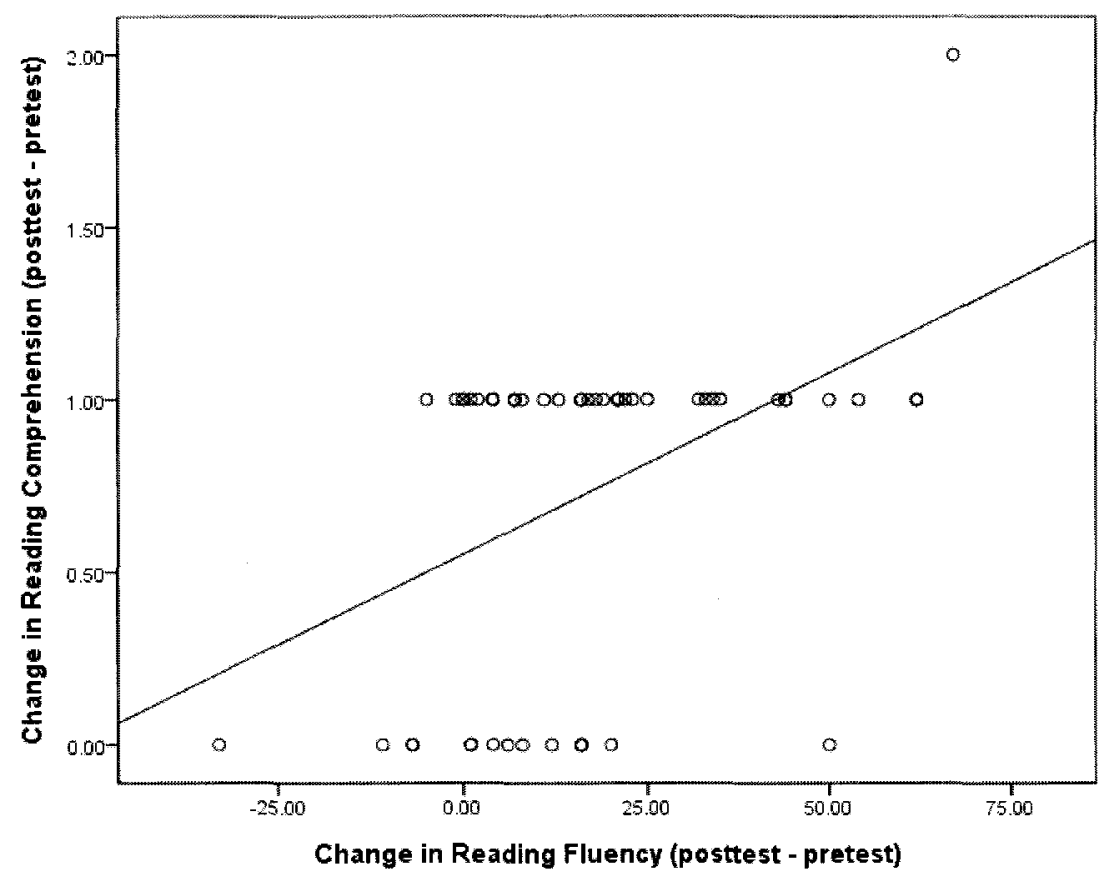

Figure 7. Posttest-pretest change in reading comprehension and change in reading fluency.

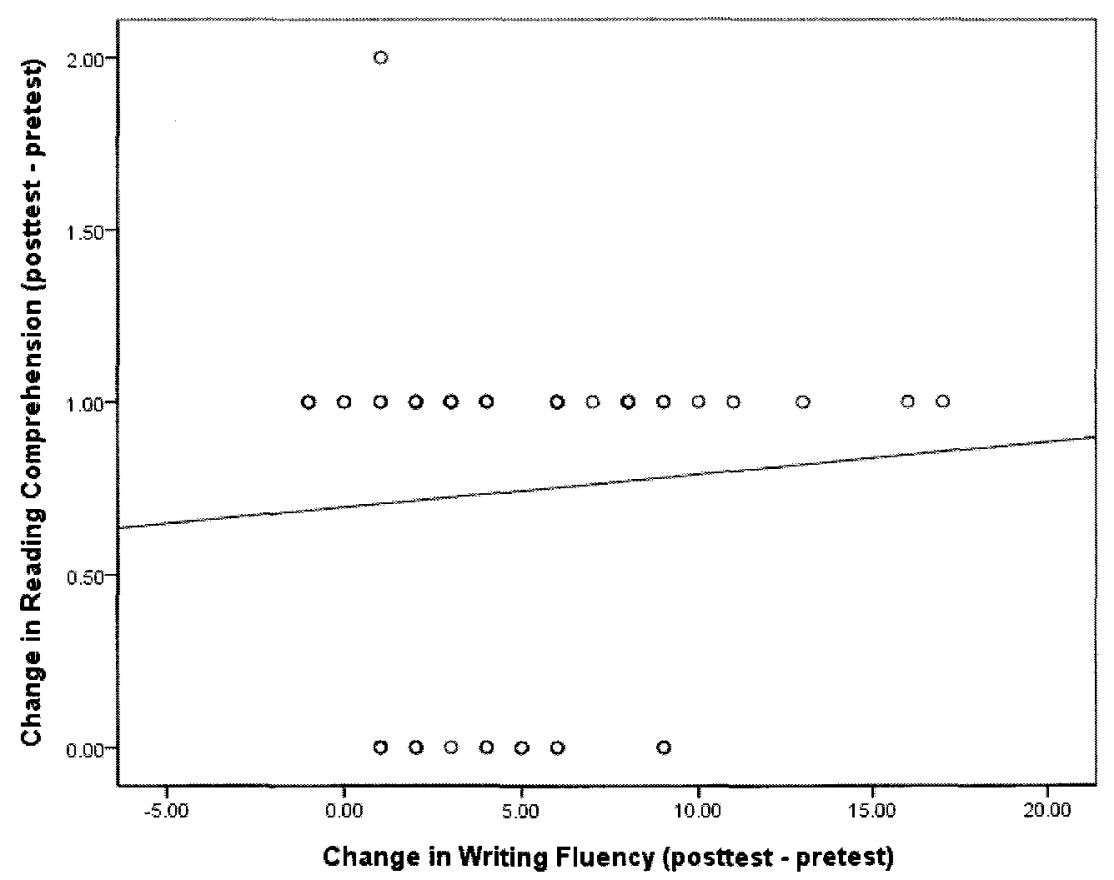

Figure 8. Posttest-pretest change in reading comprehension and change in writing fluency. 


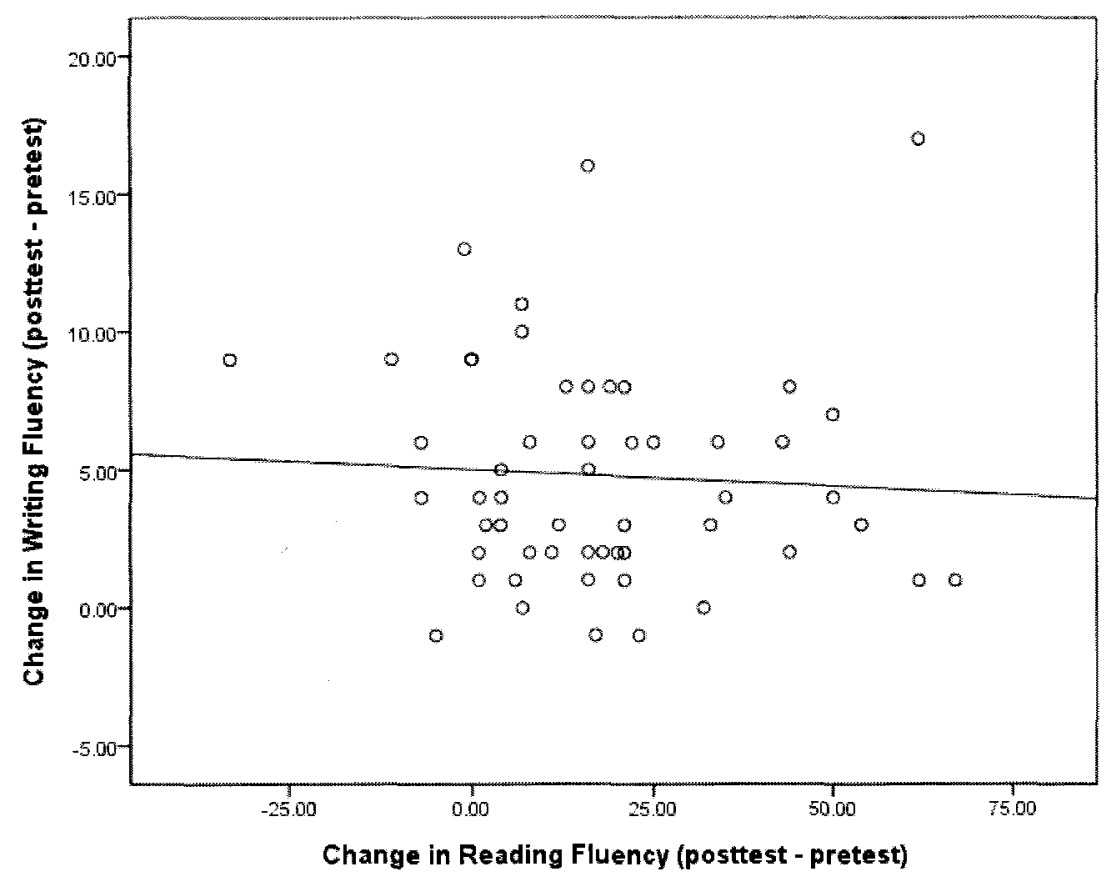

Figure 9. Posttest-pretest change in writing fluency and change in reading fluency.

Table 11. Correlations Between Change in Reading Comprehension, Change in Reading Fluency, and Change in Writing Fluency (Posttest-Pretest)

\begin{tabular}{|c|c|c|c|c|}
\hline \multicolumn{5}{|c|}{ Correlations } \\
\hline & & $\begin{array}{c}\text { Change in } \\
\text { Reading } \\
\text { Comprehension } \\
\text { (posttest - } \\
\text { pretest) }\end{array}$ & $\begin{array}{l}\text { Change in } \\
\text { Reading } \\
\text { Fluency } \\
\text { (posttest - } \\
\text { pretest) }\end{array}$ & $\begin{array}{c}\text { Change in } \\
\text { Writing Fluency } \\
\text { (posttest - } \\
\text { pretest) }\end{array}$ \\
\hline Change in Reading & Pearson Correlation & 1 & .437 & .079 \\
\hline $\begin{array}{l}\text { Comprehension (posttest - } \\
\text { pretest) }\end{array}$ & $\begin{array}{l}\text { Sig. (2-tailed) } \\
\mathrm{N}\end{array}$ & 54 & $\begin{array}{r}.001 \\
54 \\
\end{array}$ & $\begin{array}{r}.571 \\
54 \\
\end{array}$ \\
\hline $\begin{array}{l}\text { Change in Reading Fluency } \\
\text { (posttest - pretest) }\end{array}$ & $\begin{array}{l}\text { Pearson Correlation } \\
\text { Sig. (2-tailed) }\end{array}$ & $\begin{array}{l}.437 \\
.001\end{array}$ & 1 & $\begin{array}{r}-.060 \\
.665\end{array}$ \\
\hline & $\mathrm{N}$ & 54 & 54 & 54 \\
\hline $\begin{array}{l}\text { Change in Writing Fluency } \\
\text { (posttest - pretest) }\end{array}$ & $\begin{array}{l}\text { Pearson Correlation } \\
\text { Sig. (2-tailed) }\end{array}$ & $\begin{array}{l}.079 \\
.571\end{array}$ & $\begin{array}{r}-.060 \\
.665\end{array}$ & 1 \\
\hline & $N$ & 54 & 54 & 54 \\
\hline
\end{tabular}


predictable. Since there was no correlation in the pretest, it is understandable that there is no correlation with reading fluency and writing fluency in the posttest-pretest.

\section{Research Question \#2}

Students will be pretested before they receive instruction. Will pretesting should show that the treatment and control groups do not differ before instruction?

Independent samples t-tests were used to compare the average pretest reading fluency, writing fluency and reading comprehension scores between the control and experimental groups. Figure 10 is an error bar chart which shows the average (and 95\% confidence interval for the average) pretest reading comprehension score, separately for the control and experimental group. Tables 12 and 13 show there was not a statistically significant difference between the two groups. The average (SD) pretest reading comprehension score was $2.56(0.74)$ versus $2.56(0.78)$ for the control group and experimental group respectively, $t(52)=0.000 ; p=1.00 ; d=0.00$. Therefore, this positively answers the research question that the control and treatment group do not differ in reading comprehension before instruction. Figure 11 and Tables 14 and 15 show there was not a statistically significant difference in the average pretest reading fluency score between the control and experimental groups. The average (SD) pretest reading fluency score was 103.5 (34.8) versus 102.8 (29.8) for the control group and experimental group respectively, $t(52)=$ $0.069 ; \mathrm{p}=0.95 ; \mathrm{d}=0.02$. Again the pretest shows the control and treatment group do not differ before instruction. Figure 12 and Tables 16 and 17 show there was not a statistically significant difference in the average pretest writing fluency score between the control and experimental groups. The average (SD) pretest writing fluency score was 17.8 (6.1) versus 16.8 (5.7) for the control group and experimental group respectively, $t(52)=0.57 ; \mathrm{p}=0.57$; $\mathrm{d}=0.17$. In summary, the control and treatment groups do not differ before instruction in reading comprehension, reading fluency, and writing fluency. This is beneficial to the study since all the students were at the same starting point. When the groups were initially chosen, the groups were similar and well balanced. 


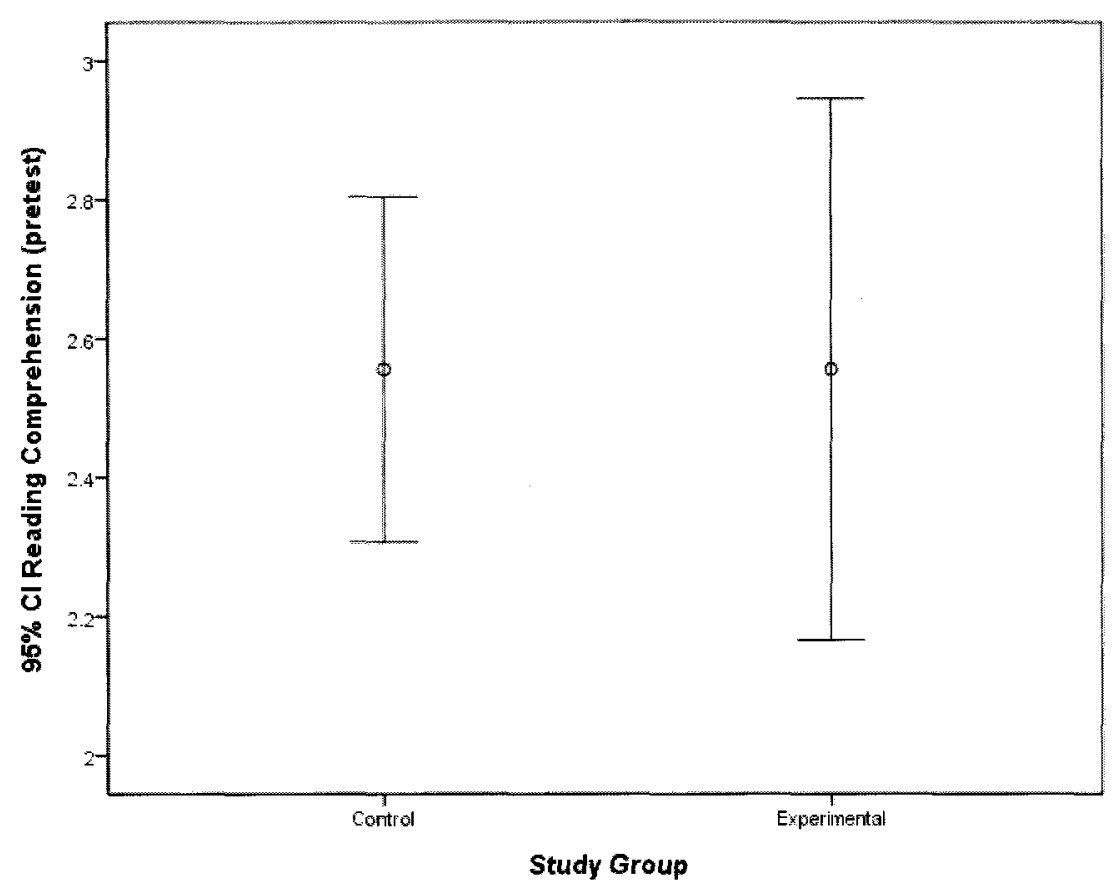

Figure 10. Control/experimental groups: Pretest reading comprehension score.

Table 12. Reading Comprehension Control Group and Experimental Group

\begin{tabular}{llllcc}
\hline \hline \multicolumn{5}{c}{ Group Statistics } \\
\hline \hline & Study Group & $\mathrm{N}$ & Mean & Std. Deviation & Std. Error Mean \\
\hline Reading Comprehension & Control & 36 & 2.56 & .735 & .122 \\
(pretest) & Experimental & 18 & 2.56 & .784 & .185 \\
\hline \hline
\end{tabular}

Table 13. Reading Comprehension Independent Samples Test

\begin{tabular}{lccc}
\hline \hline \multicolumn{4}{c}{ Independent Samples Test } \\
\hline & \multicolumn{3}{c}{ t-test for Equality of Means } \\
\hline $\begin{array}{l}\text { Reading Comprehension } \\
\text { (pretest) }\end{array}$ & $\mathrm{t}$ & $\mathrm{df}$ & Sig. (2-tailed) \\
\hline \hline
\end{tabular}




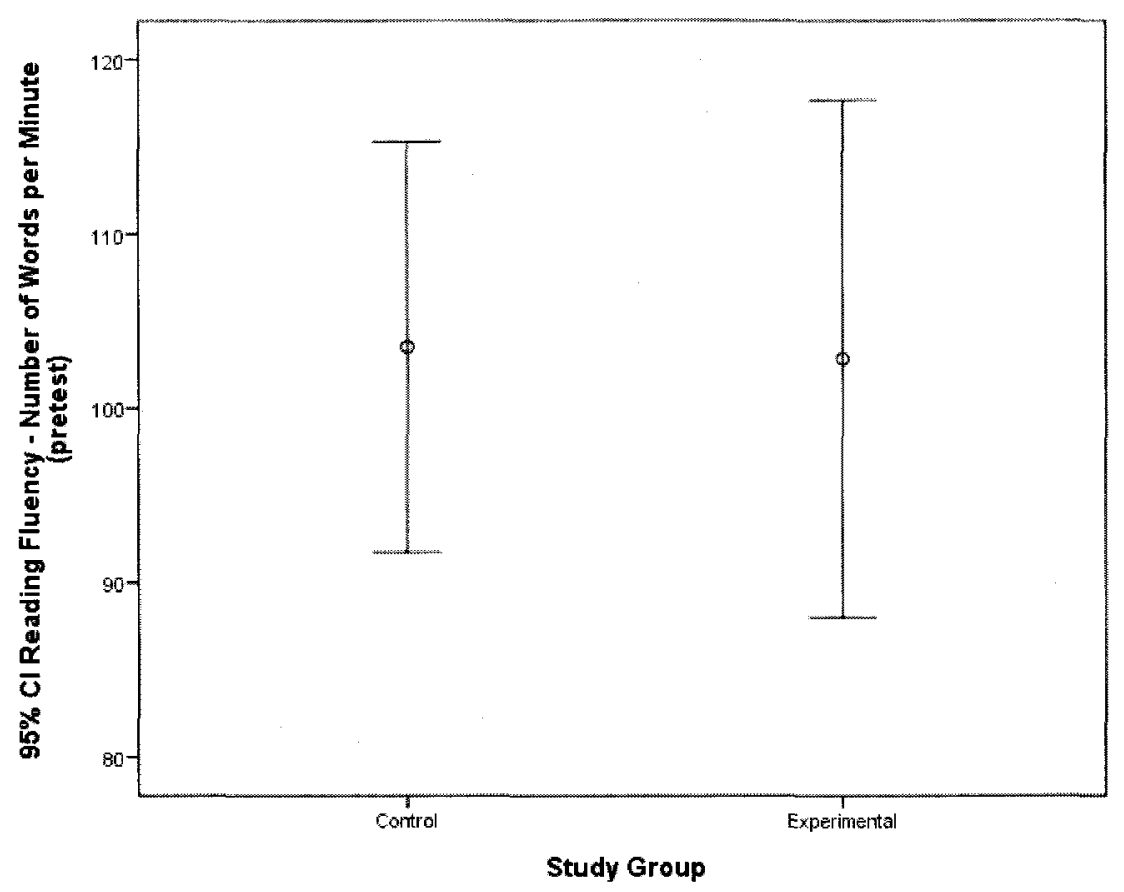

Figure 11. Control/experimental groups: Pretest reading fluency score.

Table 14. Reading Fluency Control Group and Experimental Group

\begin{tabular}{lllllc}
\hline \multicolumn{5}{c}{ Group Statistics } \\
\hline \hline & Study Group & $\mathrm{N}$ & Mean & Std. Deviation & Std. Error Mean \\
\hline Reading Fluency - Number & Control & 36 & 103.50 & 34.776 & 5.796 \\
$\begin{array}{l}\text { of Words per Minute } \\
\text { (pretest) }\end{array}$ & Experimental & 18 & 102.83 & 29.831 & 7.031 \\
\hline \hline
\end{tabular}

Table 15. Reading Fluency Independent Samples Test

\begin{tabular}{lcccc}
\hline \multicolumn{4}{c}{ Independent Samples Test } \\
\hline \hline & \multicolumn{3}{c}{ t-test for Equality of Means } \\
\cline { 2 - 5 } & t & df & Sig. (2-tailed) \\
\hline $\begin{array}{l}\text { Reading Fluency - Number } \\
\text { of Words per Minute } \\
\text { (pretest) }\end{array}$ & .069 & 52 & .945 \\
\hline \hline
\end{tabular}




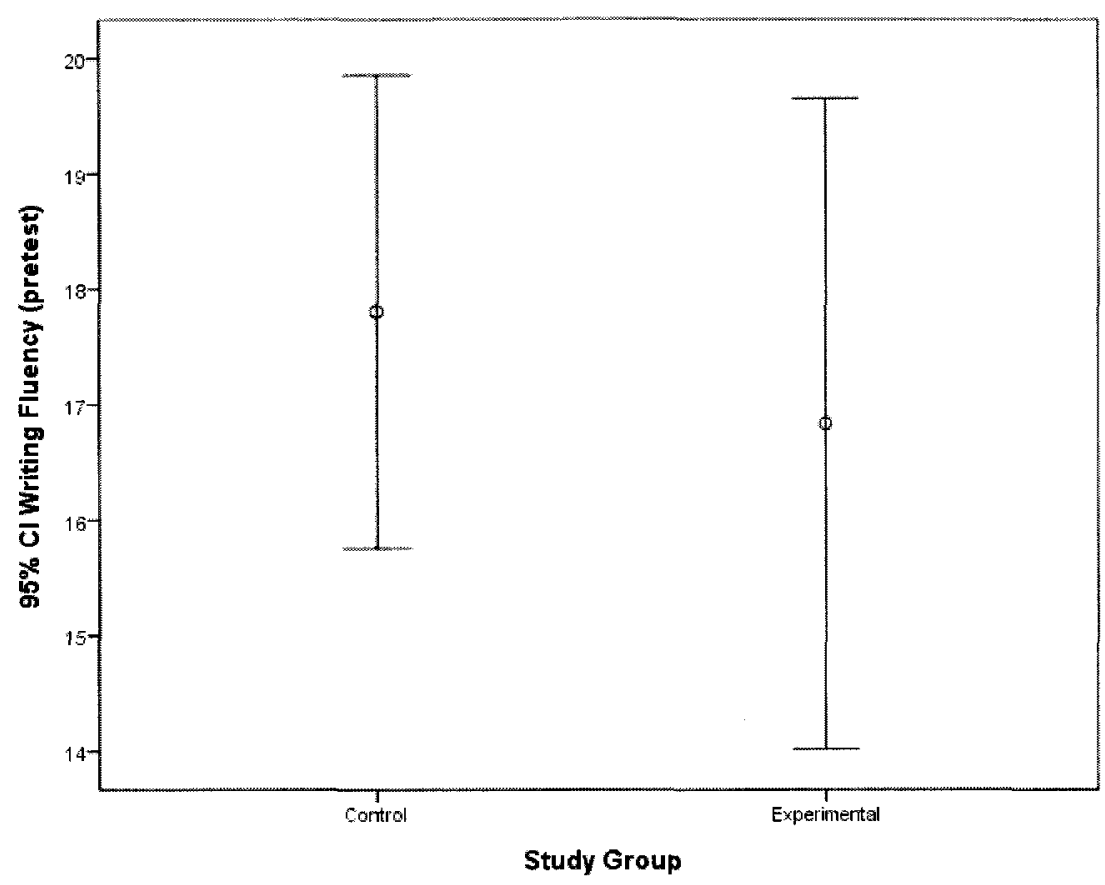

Figure 12. Control/experimental groups: Pretest writing fluency score.

Table 16. Writing Fluency Control Group and Experimental Group

\begin{tabular}{llllcc}
\hline \hline \multicolumn{5}{c}{ Group Statistics } \\
\hline & Study Group & $\mathrm{N}$ & Mean & Std. Deviation & Std. Error Mean \\
\hline \multirow{2}{*}{ Writing Fluency (pretest) } & Control & 36 & 17.81 & 6.056 & 1.009 \\
& Experimental & 18 & 16.83 & 5.659 & 1.334 \\
\hline \hline
\end{tabular}

Table 17. Writing Fluency Independent Samples Test

\begin{tabular}{lccc}
\hline \hline \multicolumn{4}{c}{ Independent Samples Test } \\
\hline \hline & \multicolumn{3}{c}{ t-test for Equality of Means } \\
\cline { 2 - 5 } & $\mathrm{t}$ & $\mathrm{df}$ & Sig. (2-tailed) \\
\hline Writing Fluency (pretest) & .568 & 52 & .572 \\
\hline \hline
\end{tabular}




\section{Research Question \#3}

Comparing pretest to posttest performance should show whether gains have resulted from the instruction. Will the control group show gains from instruction from pretest to posttest?

Paired t-tests were used to compare the average reading fluency, writing fluency and reading comprehension scores between pretest and posttest, separately for the control group and experimental group. Figure 13 is an error bar chart which shows the average (and 95\% confidence interval for the average) reading comprehension score for the control group, separately for the pretest and posttest. Tables 18 and 19 show there was a statistically significant increase in the average reading comprehension score from pre to post test. The average (standard deviation) reading comprehension score was $2.56(0.74)$ versus $3.28(0.62)$ for pretest and posttest respectively, $\mathrm{t}(35)=-8.44 ; \mathrm{p}<0.001 \mathrm{~d}=1.41$. Although the control group did not receive specific fluency instruction, there was a significant increase in reading comprehension using the school's regular language arts curriculum. Figure 14 is an error bar chart which shows the average (and 95\% confidence interval for the average) reading fluency score for the control group, separately for the pretest and posttest. Tables 20 and 21 show there was a statistically significant increase in the average reading fluency score from pre to post test. The average (standard deviation) reading fluency score was 103.5 (34.8) versus 124.6 (36.6) for pretest and posttest respectively, $\mathrm{t}(35)=-5.64 ; \mathrm{p}<0.001 ; \mathrm{d}=0.94$. Again, there was significant increase in the control's group reading fluency even though the group did not receive specific reading fluency instruction. Figure 15 is an error bar chart which shows the average (and 95\% confidence interval for the average) writing fluency score for the control group, separately for the pretest and posttest. Tables 22 and 23 show there was a statistically significant increase in the average writing fluency score from pre to post test. The average (standard deviation) writing fluency score was 17.8 (6.1) versus 22.8 (5.5) for pretest and posttest respectively, $\mathrm{t}(35)=-7.50 ; \mathrm{p}<0.001 ; \mathrm{d}=1.25$. There was significant increase in the control group's writing fluency even though they did not receive specific reading fluency or writing fluency instruction. 


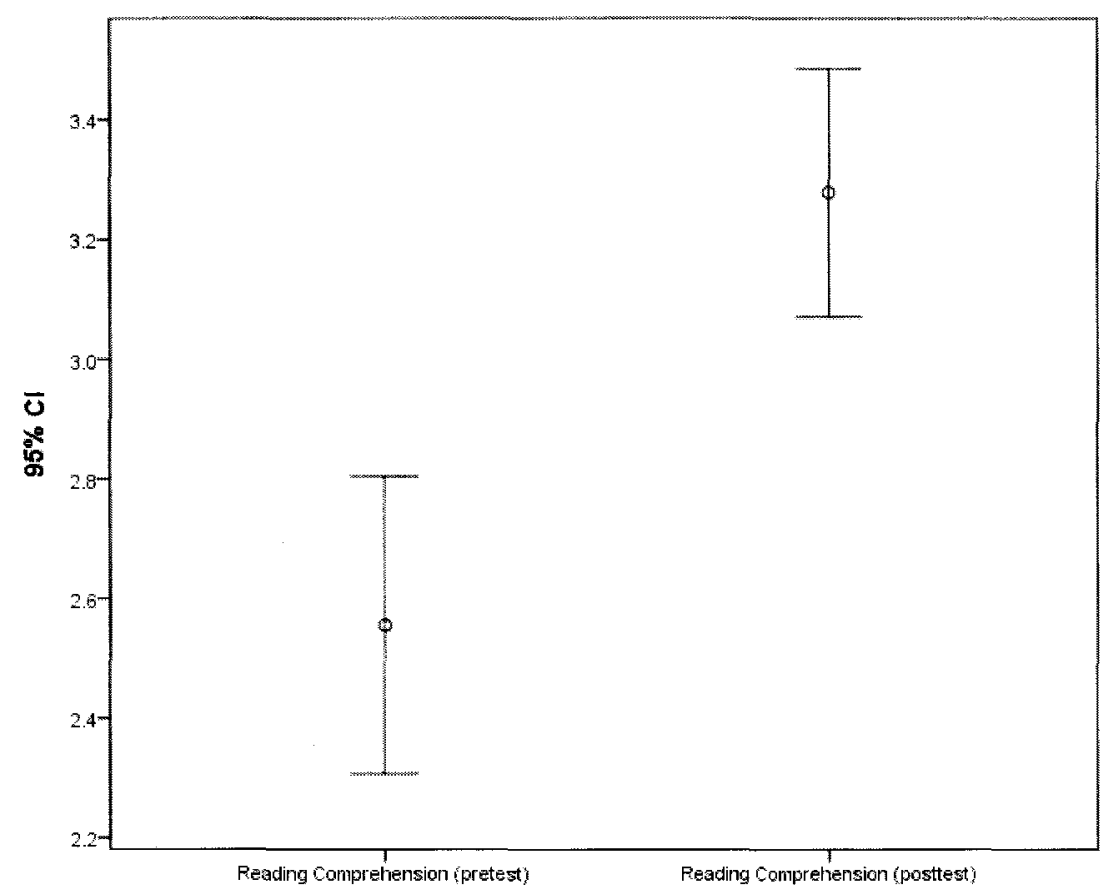

Figure 13. Control group: Pretest reading comprehension score.

Table 18. Reading Comprehension Control Group

\begin{tabular}{llcccc}
\hline \hline \multicolumn{5}{c}{ Paired Samples Statistics } \\
\hline Pair 1 & Mean & $\mathrm{N}$ & Std. Deviation & Std. Error Mean \\
\hline & $\begin{array}{l}\text { Reading Comprehension } \\
\text { (pretest) }\end{array}$ & 2.56 & 36 & .735 & .122 \\
& $\begin{array}{l}\text { Reading Comprehension } \\
\text { (posttest) }\end{array}$ & 3.28 & 36 & .615 & .102 \\
\hline \hline
\end{tabular}

Table 19. Reading Comprehension Control Group Independent Samples Test

\begin{tabular}{llccc}
\hline \hline \multicolumn{5}{c}{ Paired Samples Test } \\
\hline \hline Pair 1 & $\begin{array}{l}\text { Reading Comprehension } \\
\text { (pretest) - Reading } \\
\text { Comprehension (posttest) }\end{array}$ & -8.442 & 35 & .000 \\
& & & \\
\hline \hline
\end{tabular}




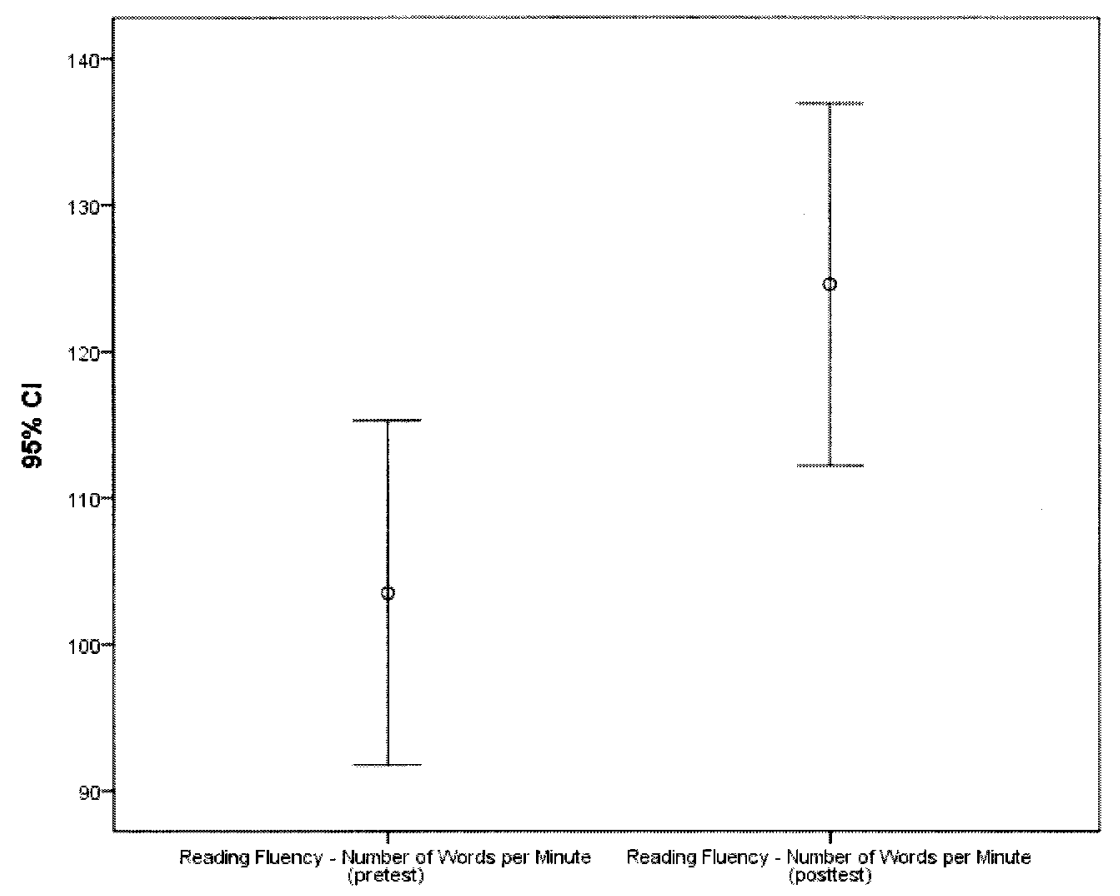

Figure 14. Control group: Pretest reading fluency score.

Table 20. Reading Fluency Control Group

\begin{tabular}{llcccc}
\hline \hline \multicolumn{5}{c}{ Paired Samples Statistics } \\
\hline \hline Pair 1 & $\begin{array}{l}\text { Mean } \\
\text { Reading Fluency - Number } \\
\text { of Words per Minute } \\
\text { (pretest) }\end{array}$ & 103.50 & 36 & 34.776 & 5.796 \\
& $\begin{array}{l}\text { Reading Fluency - Number } \\
\text { of Words per Minute } \\
\text { (posttest) }\end{array}$ & 124.56 & 36 & 36.559 & 6.093 \\
\hline \hline
\end{tabular}

Table 21. Reading Fluency Control Group Independent Samples Test

\begin{tabular}{llccc}
\hline \hline \multicolumn{4}{c}{ Paired Samples Test } \\
\hline \hline Pair 1 & $\begin{array}{l}\text { Reading Fluency - Number } \\
\text { of Words per Minute } \\
\text { (pretest) - Reading Fluency - }\end{array}$ & -5.635 & 35 & df \\
& $\begin{array}{l}\text { Number of Words per Minute } \\
\text { (posttest) }\end{array}$ & & \\
\hline \hline
\end{tabular}




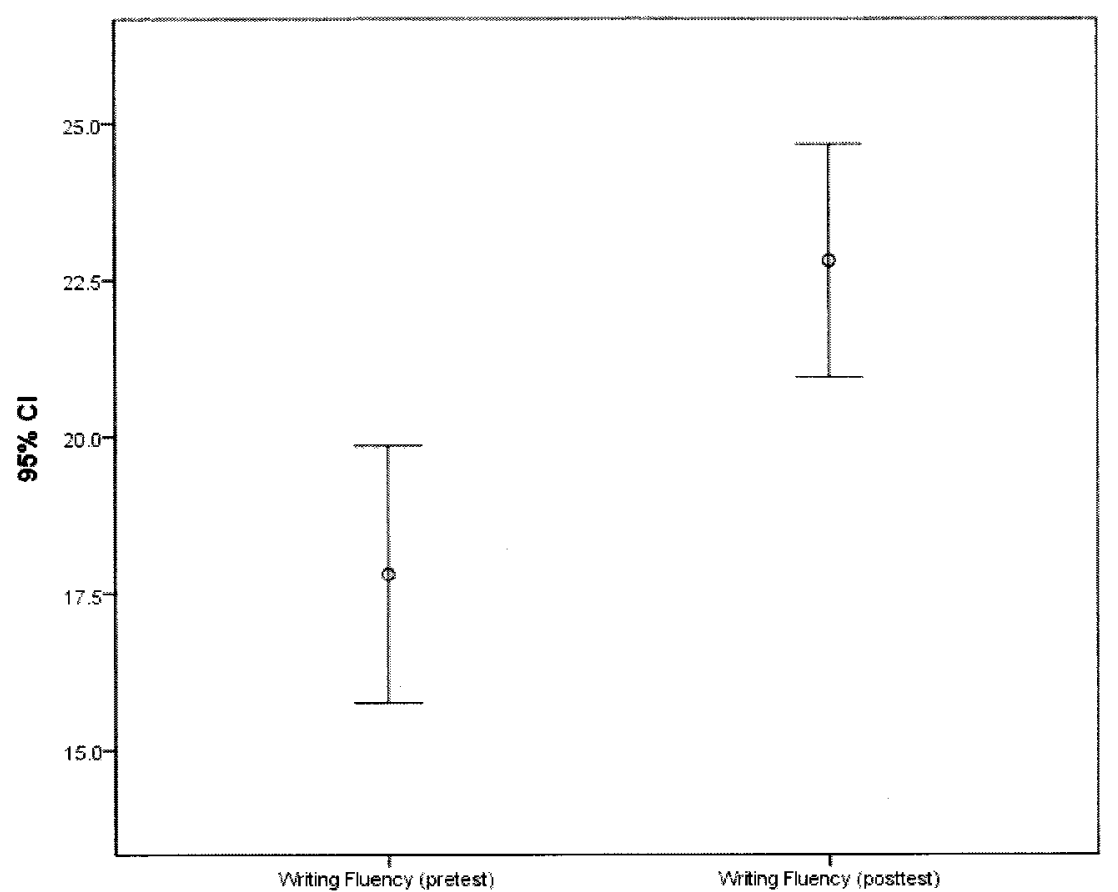

Figure 15. Control group: Pretest writing fluency score.

Table 22. Writing Fluency Control Group

\begin{tabular}{llllcc}
\hline \multicolumn{5}{c}{ Paired Samples Statistics } \\
\hline \hline \multirow{6}{*}{ Pair 1 } & Mean & $\mathrm{N}$ & Std. Deviation & Std. Error Mean \\
& Writing Fluency (pretest) & 17.81 & 36 & 6.056 & 1.009 \\
& Writing Fluency (posttest) & 22.81 & 36 & 5.502 & .917 \\
\hline \hline
\end{tabular}

Table 23. Writing Fluency Control Group Independent Samples Test

Paired Samples Test

\begin{tabular}{llccc}
\hline \hline & & & & \\
\hline Pair 1 & Writing Fluency (pretest) - & -7.500 & 35 & Sig. (2-tailed) \\
& Writing Fluency (posttest) & & & .000 \\
\hline \hline
\end{tabular}




\section{Research Question \#4}

Comparing pretest to posttest performance should show whether gains have resulted from the instruction. Will the experimental group show an increase from specific instruction in reading fluency and writing fluency as well as the school's regular language art's curriculum?

Paired t-tests were used to compare the average reading fluency, writing fluency and reading comprehension scores between pretest and posttest, separately for the control group and experimental group. Figure 16 is an error bar chart which shows the average (and 95\% confidence interval for the average) reading comprehension score for the experimental group, separately for the pretest and posttest. Tables 24 and 25 show there was a statistically significant increase in the average reading comprehension score from pre to post test. The average (standard deviation) reading comprehension score was $2.56(0.78)$ versus $3.33(0.69)$ for pretest and posttest respectively, $\mathrm{t}(17)=-7.71 ; \mathrm{p}<0.001 ; \mathrm{d}=1.82$. In agreement with the thesis, the experimental group increased in reading comprehension. Figure 17 is an error bar chart which shows the average (and 95\% confidence interval for the average) reading fluency score for the experimental group, separately for the pretest and posttest. Tables 26 and 27 show there was a statistically significant increase in the average reading fluency score from pre to post test. The average (standard deviation) reading fluency score was $102.8(29.8)$ versus 114.4 (30.6) for pretest and posttest respectively, $\mathrm{t}(17)=-3.82 ; \mathrm{p}=0.001 ; \mathrm{d}=0.90$. Again in agreement with the thesis, the experimental group increased in reading fluency. Figure 18 is an error bar chart which shows the average (and 95\% confidence interval for the average) writing fluency score for the experimental group, separately for the pretest and posttest. Tables 28 and 29 show there was a statistically significant increase in the average writing fluency score from pre to post test. The average (standard deviation) writing fluency score was $16.8(5.7)$ versus $21.2(5.2)$ for pretest and posttest respectively, $t(17)=-4.45 ; \mathrm{p}<$ $0.001 ; \mathrm{d}=1.05$. In summary, the experimental group increased in reading comprehension, reading fluency, and writing fluency after specific instruction in reading and writing fluency.

\section{Research Question \#5}

This next part involves post-testing students after instruction. The posttest would show whether fluency trained-groups made greater gains than control groups, indicating 


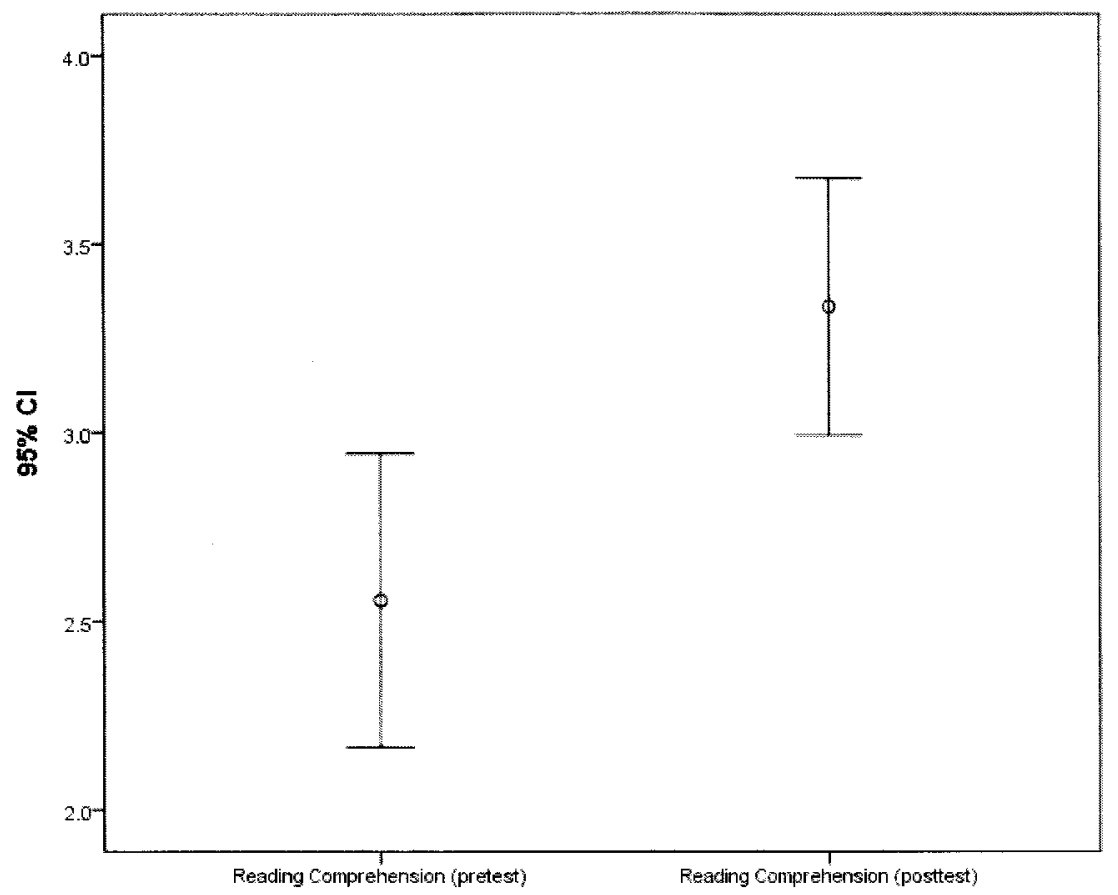

Figure 16. Experimental group: Pretest/Posttest reading comprehension score.

Table 24. Reading Comprehension Experimental Group

\begin{tabular}{llcccc}
\hline \hline \multicolumn{5}{c}{ Paired Samples Statistics } \\
\hline Pair 1 & Mean & $\mathrm{N}$ & Std. Deviation & Std. Error Mean \\
\hline & $\begin{array}{l}\text { Reading Comprehension } \\
\text { (pretest) }\end{array}$ & 2.56 & 18 & .784 & .185 \\
& $\begin{array}{l}\text { Reading Comprehension } \\
\text { (posttest) }\end{array}$ & 3.33 & 18 & .686 & .162 \\
\hline \hline
\end{tabular}

Table 25. Reading Comprehension Experimental Group Paired Samples Test

\begin{tabular}{llccc}
\hline \hline \multicolumn{5}{c}{ Paired Samples Test } \\
\hline \hline Pair 1 & $\begin{array}{l}\mathrm{t} \\
\text { Reading Comprehension } \\
\text { (pretest) - Reading } \\
\text { Comprehension (posttest) }\end{array}$ & -7.714 & 17 & Sig. (2-tailed) \\
\hline \hline
\end{tabular}




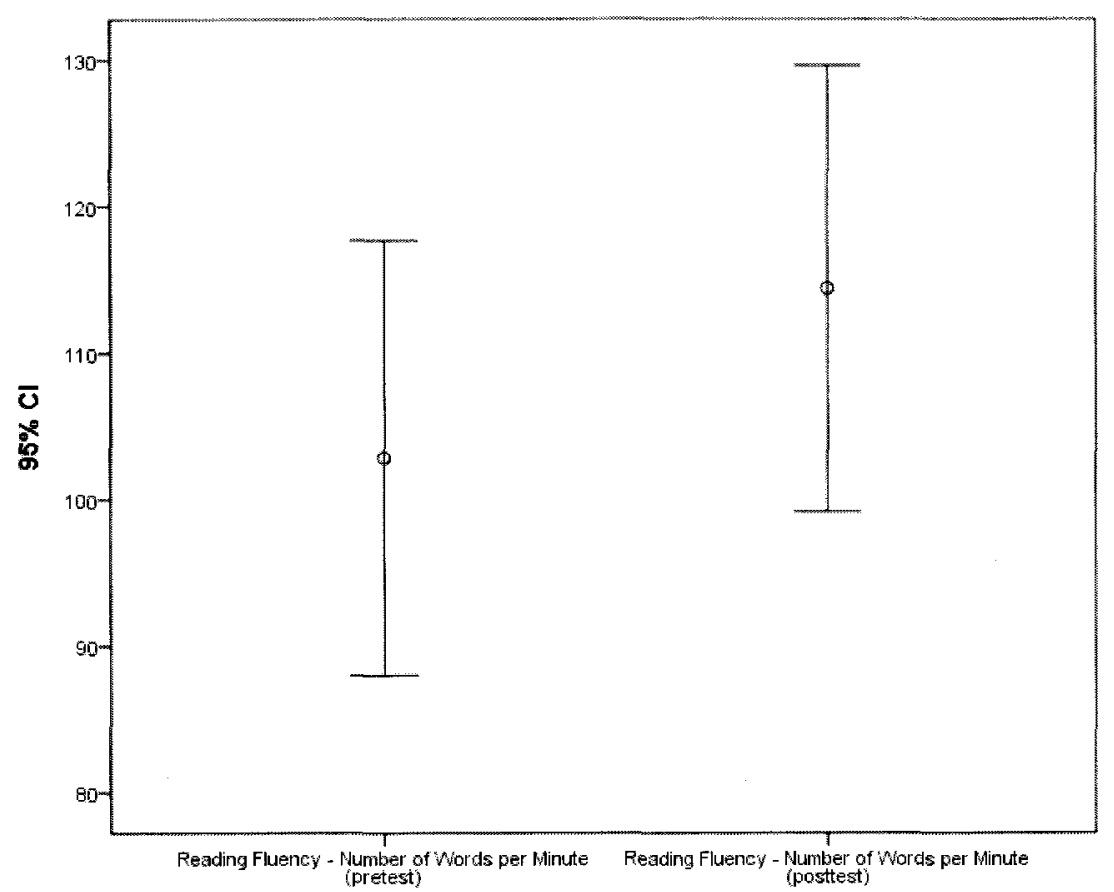

Figure 17. Experimental group: Pretest/Posttest reading fluency score.

Table 26. Reading Fluency Experimental Group

\begin{tabular}{llllcc}
\hline \hline \multicolumn{5}{c}{ Paired Samples Statistics } \\
\hline \hline Pair 1 & $\begin{array}{l}\text { Mean } \\
\text { Reading Fluency - Number } \\
\text { of Words per Minute } \\
\text { (pretest) }\end{array}$ & 102.83 & 18 & 29.831 & 7.031 \\
$\begin{array}{l}\text { Reading Fluency - Number } \\
\text { of Words per Minute } \\
\text { (posttest) }\end{array}$ & 114.39 & 18 & 30.598 & 7.212 \\
\hline \hline
\end{tabular}

Table 27. Reading Fluency Experimental Group Paired Samples Test

\begin{tabular}{|c|c|c|c|c|}
\hline \multicolumn{5}{|c|}{ Paired Samples Test } \\
\hline & & $\mathrm{t}$ & df & Sig. (2-tailed) \\
\hline \multirow[t]{5}{*}{ Pair 1} & Reading Fluency - Number & -3.823 & 17 & .001 \\
\hline & of Words per Minute & & & \\
\hline & (pretest) - Reading Fluency - & & & \\
\hline & Number of Words per Minute & & & \\
\hline & (posttest) & & & \\
\hline
\end{tabular}




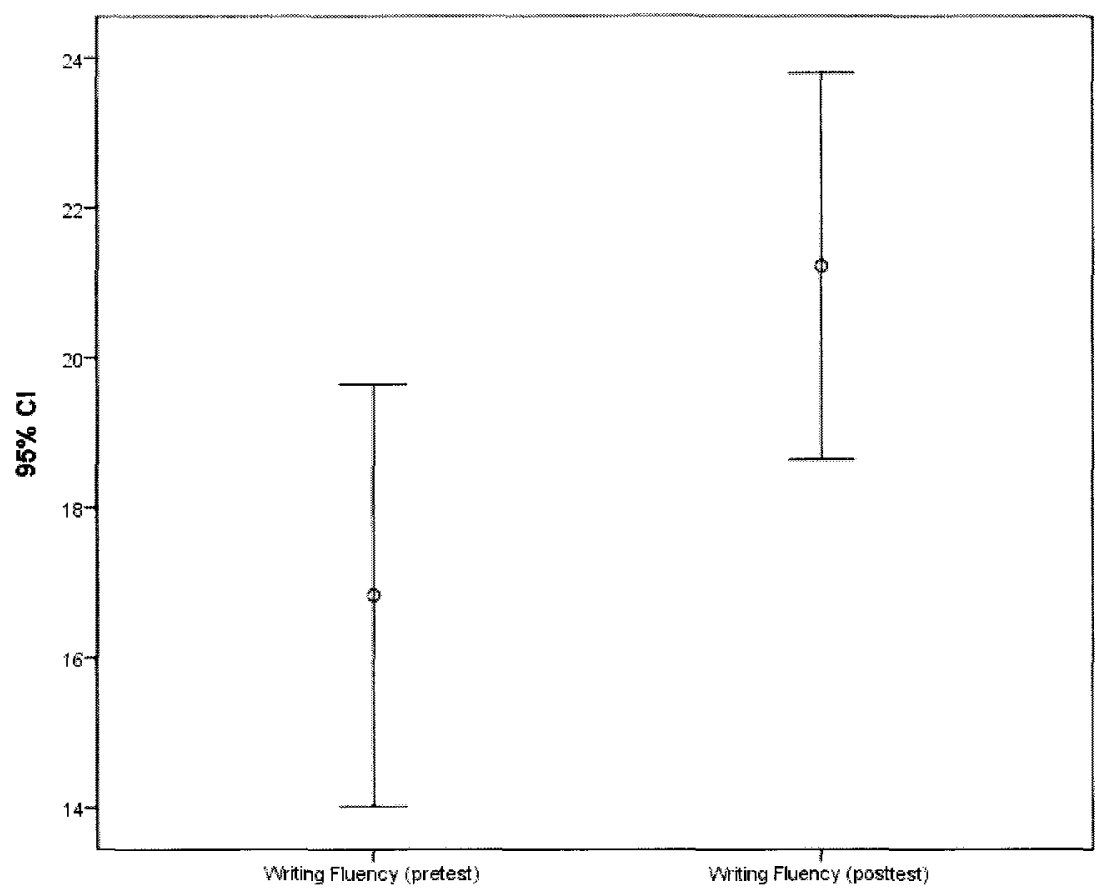

Figure 18. Experimental group: Pretest/Posttest writing fluency score.

Table 28. Writing Fluency Experimental Group

\begin{tabular}{llllcc}
\hline \multicolumn{5}{c}{ Paired Samples Statistics } \\
\hline \hline & Mean & $\mathrm{N}$ & Std. Deviation & Std. Error Mean \\
\hline Pair 1 & Writing Fluency (pretest) & 16.83 & 18 & 5.659 & 1.334 \\
& Writing Fluency (posttest) & 21.22 & 18 & 5.185 & 1.222 \\
\hline \hline
\end{tabular}

Table 29. Writing Fluency Experimental Group Paired Samples Test

\begin{tabular}{llccc}
\hline \multicolumn{5}{c}{ Paired Samples Test } \\
\hline \hline & & $\mathrm{t}$ & $\mathrm{df}$ & Sig. (2-tailed) \\
\hline Pair 1 & $\begin{array}{l}\text { Writing Fluency (pretest) } \\
\text { Writing Fluency (posttest) }\end{array}$ & -4.445 & 17 & .000 \\
\hline \hline
\end{tabular}


whether that instruction was effective. Reading posttest shows whether fluency instruction improved students' reading ability.

Independent samples t-tests were used to compare the average posttest reading fluency, writing fluency and reading comprehension scores between the control and experimental groups. Figure 19 is an error bar chart which shows the average (and 95\% confidence interval for the average) posttest reading comprehension score, separately for the control and experimental group. Tables 30 and 31 show there was not a statistically significant difference between the two groups. The average (SD) posttest reading comprehension score was $3.28(0.62)$ versus $3.33(0.69)$ for the control group and experimental group respectively, $t(52)=-0.30 ; p=0.76 ; d=0.08$. In disagreement with my thesis, the control group did just as well as the experimental group in reading comprehension. Figure 20 and Tables 32 and 33 show there was not a statistically significant difference in the average posttest reading fluency score between the control and experimental groups. The average (SD) posttest reading fluency score was 124.6 (36.6) versus 114.4 (30.6) for the control group and experimental group respectively, $\mathrm{t}(52)=1.01 ; \mathrm{p}=0.32 ; \mathrm{d}=0.29$. Again the control group and the experimental group did equally well in reading fluency. Figure 21 and Tables 34 and 35 show there was not a statistically significant difference in the average posttest writing fluency score between the control and experimental groups. The average (SD) posttest writing fluency score was 22.8 (5.5) versus $21.2(5.2)$ for the control group and experimental group respectively, $\mathrm{t}(52)=1.02 ; \mathrm{p}=0.32 ; \mathrm{d}=0.30$. In summary, the control group and the experimental group did equally well in reading comprehension, reading fluency, and writing fluency.

\section{Research Question \#6}

This next part involves post-testing students after instruction. The posttest would show whether fluency-trained groups made greater gains than control groups, indicating whether that instruction was effective. Reading posttest shows whether fluency instruction improved students' reading ability.

This analysis addresses the same as Research Question \#5 but this analysis looks at change scores. Independent samples t-tests were used to compare the average change from pretest to post test in reading fluency, writing fluency and reading comprehension between 


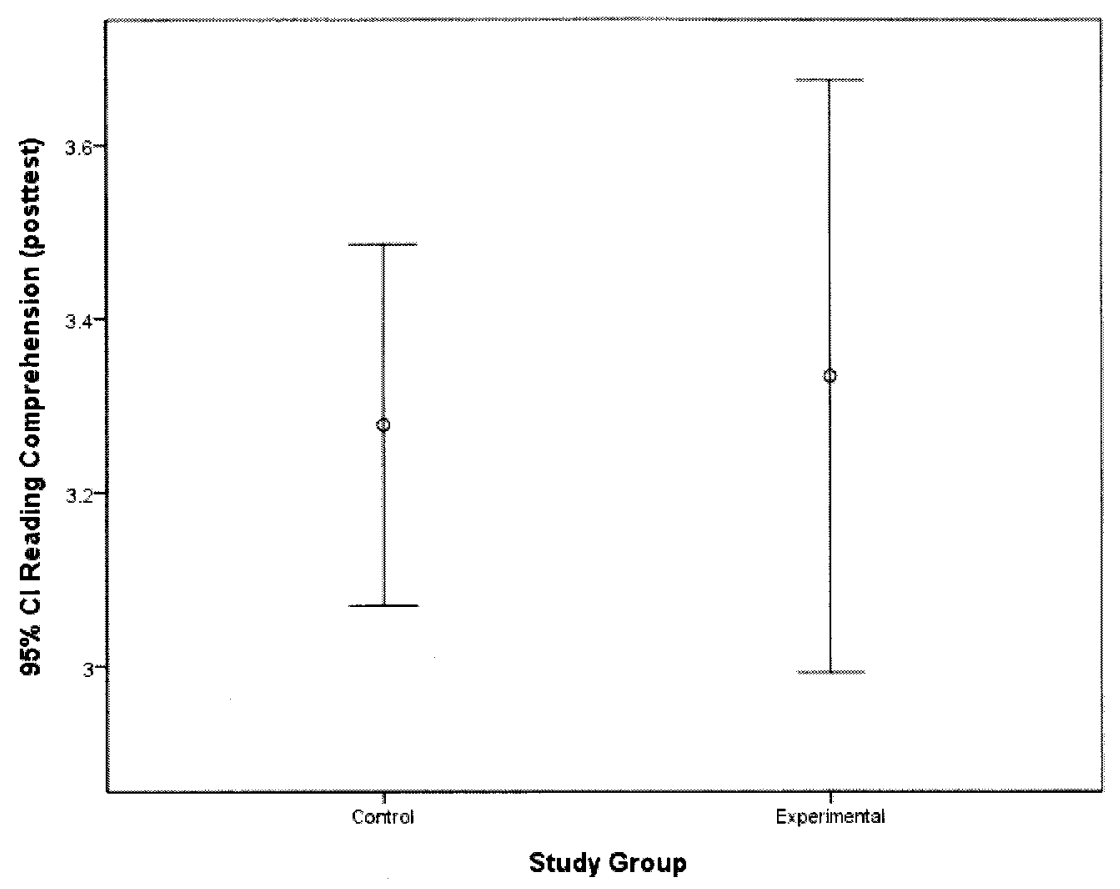

Figure 19. Posttest control/experimental reading comprehension scores.

Table 30. Reading Comprehension Control/Experimental Group

\begin{tabular}{llllll}
\hline \hline \multicolumn{5}{c}{ Group Statistics } \\
\hline \hline & Study Group & $\mathrm{N}$ & Mean & Std. Deviation & Std. Error Mean \\
\hline Reading Comprehension & Control & 36 & 3.28 & .615 & .102 \\
(posttest) & Experimental & 18 & 3.33 & .686 & .162 \\
\hline \hline
\end{tabular}

Table 31. Reading Comprehension Control/Experimental Independent Samples Test

\begin{tabular}{lcccc}
\hline \hline \multicolumn{4}{c}{ Independent Samples Test } \\
\hline \hline & \multicolumn{4}{c}{ t-test for Equality of Means } \\
\cline { 2 - 4 } & $\mathrm{t}$ & $\mathrm{df}$ & Sig. (2-tailed) \\
\hline $\begin{array}{l}\text { Reading Comprehension } \\
\text { (posttest) }\end{array}$ & -.301 & 52 & .764 \\
\hline \hline
\end{tabular}




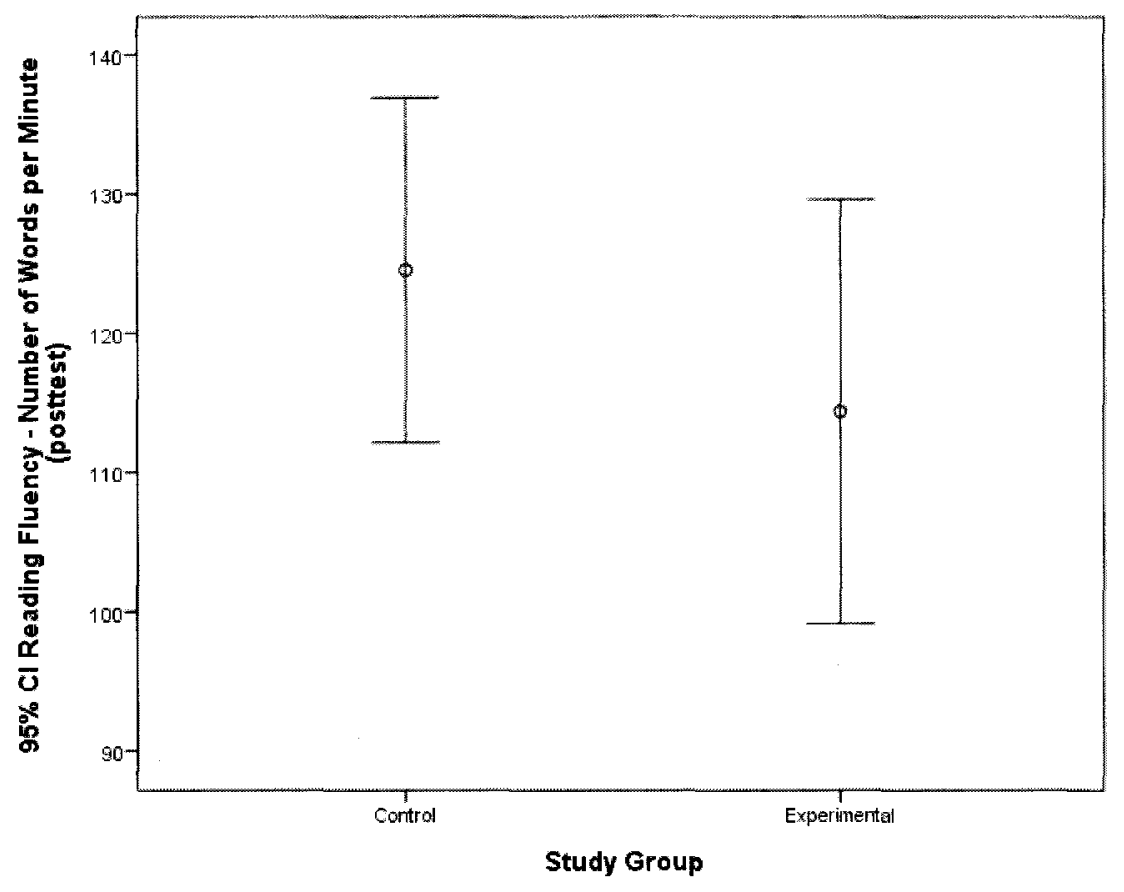

Figure 20. Posttest control/experimental reading fluency scores.

Table 32. Reading Fluency Control/Experimental Groups Reading Fluency

\begin{tabular}{lllllc}
\hline \hline \multicolumn{5}{c}{ Group Statistics } \\
\hline & Study Group & $\mathrm{N}$ & Mean & Std. Deviation & Std. Error Mean \\
\hline Reading Fluency - Number & Control & 36 & 124.56 & 36.559 & 6.093 \\
of Words per Minute & Experimental & 18 & 114.39 & 30.598 & 7.212 \\
(posttest) & & & & & \\
\hline \hline
\end{tabular}

Table 33. Reading Fluency Control/Experimental Groups Reading Fluency Independent Samples Test

\begin{tabular}{lcccc}
\hline \hline \multicolumn{3}{c}{ Independent Samples Test } \\
\hline \hline & \multicolumn{3}{c}{ t-test for Equality of Means } \\
\cline { 2 - 4 } & $\mathrm{t}$ & $\mathrm{df}$ & Sig. (2-tailed) \\
\hline $\begin{array}{l}\text { Reading Fluency - Number } \\
\text { of Words per Minute } \\
\text { (posttest) }\end{array}$ & 1.014 & 52 & .315 \\
\hline \hline
\end{tabular}




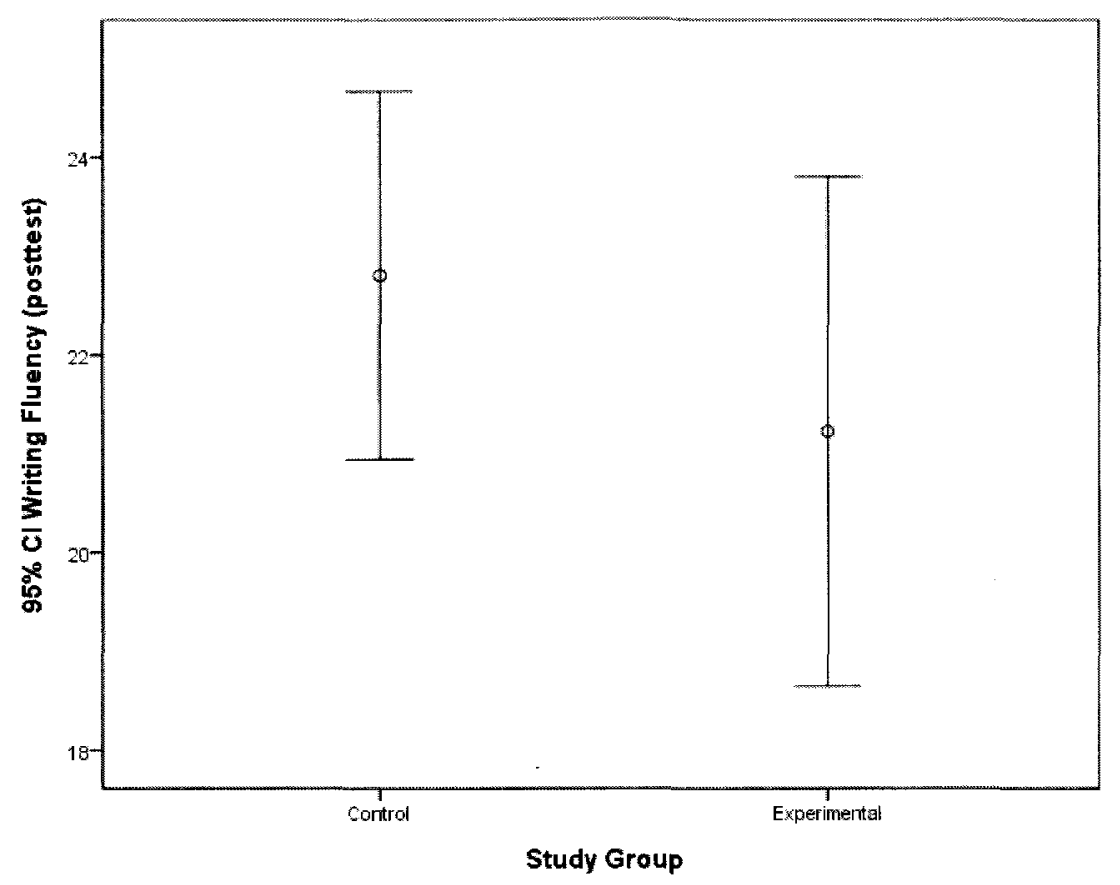

Figure 21. Posttest control/experimental writing fluency.

Table 34. Writing Fluency Control/Experimental Groups

\begin{tabular}{llllcc}
\hline \hline \multicolumn{5}{c}{ Group Statistics } \\
\hline \hline Study Group & $\mathrm{N}$ & Mean & Std. Deviation & Std. Error Mean \\
\hline \multirow{2}{*}{ Writing Fiuency (posttest) } & Control & 36 & 22.81 & 5.502 & .917 \\
& Experimental & 18 & 21.22 & 5.185 & 1.222 \\
\hline \hline
\end{tabular}

Table 35. Writing Fluency Control/Experimental Groups

\begin{tabular}{lcccc}
\hline \hline \multicolumn{4}{c}{ Independent Samples Test } \\
\hline \hline & \multicolumn{3}{c}{ t-test for Equality of Means } \\
\cline { 2 - 5 } & $\mathrm{t}$ & $\mathrm{df}$ & Sig. (2-tailed) \\
\hline Writing Fluency (posttest) & 1.016 & 52 & .315 \\
\hline \hline
\end{tabular}


the control and experimental groups. Figure 22 is an error bar chart which shows the average (and 95\% confidence interval for the average) change (posttest-pretest) in reading comprehension score, separately for the control and experimental group. Tables 36 and 37 show there was not a statistically significant difference between the two groups. The average (SD) change in the reading comprehension score was $0.72(0.51)$ versus $0.78(0.43)$ for the control group and experimental group respectively, $\mathrm{t}(52)=-0.40 ; \mathrm{p}=0.69 ; \mathrm{d}=0.12$.

Figure 23 is an error bar chart which shows the average (and 95\% confidence interval for the average) change (posttest-pretest) in reading fluency score, separately for the control and experimental group. Tables 38 and 39 show there was not a statistically significant difference between the two groups. The average (SD) change in the reading fluency score was 21.1 (22.4) versus $11.6(12.8)$ for the control group and experimental group respectively, $\mathrm{t}(52)=$ $1.66 ; p=0.10 ; d=0.48$. Figure 24 is an error bar chart which shows the average (and $95 \%$ confidence interval for the average) change (posttest-pretest) in writing fluency score, separately for the control and experimental group. Tables 40 and 41 show there was not a statistically significant difference between the two groups. The average (SD) change in the writing fluency score was $5.0(4.0)$ versus $4.4(4.2)$ for the control group and experimental group respectively, $\mathrm{t}(52)=0.52 ; \mathrm{p}=0.61 ; \mathrm{d}=0.15$.

\section{Research Question \#7}

The quantitative method of multiple regression will be used to analyze the data. Multiple regression analysis examines the degree of relationship among the variables. I will be examining the effects of the variables of reading fluency and writing fluency to reading comprehension.

Multiple linear regression analysis was used to evaluate the relationship between posttest reading comprehension and, posttest reading and writing fluency collectively. Table 42 shows that collectively, reading and writing fluency explained a statistically significant percentage of the variance in reading comprehension scores, $F(2,51)=25.9 ; \mathrm{p}<$ $0.001 ; \mathrm{R}$-square $=0.50$. The interpretation of $\mathrm{R}$-square is that collectively, reading and writing fluency explain $50 \%$ of the total variance in reading comprehension scores. In agreement with my thesis, reading and writing fluency has a great impact on reading comprehension-explaining over half of the variance in reading comprehension scores. 


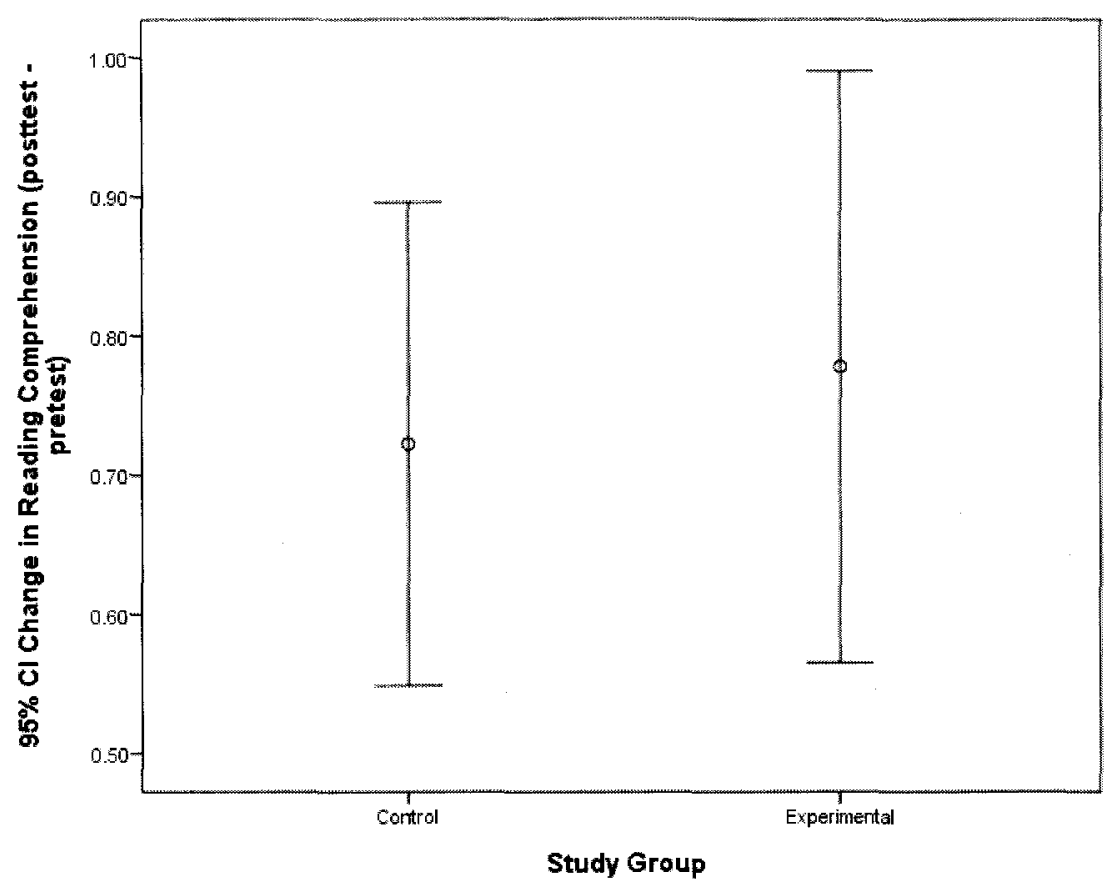

Figure 22. Control/Experimental posttest-pretest reading comprehension.

Table 36. Reading Comprehension Control/Experimental (Posttest/Pretest)

\begin{tabular}{llllcc}
\hline \hline & \multicolumn{5}{c}{ Group Statistics } \\
\hline \hline & Study Group & $\mathrm{N}$ & Mean & Std. Deviation & Std. Error Mean \\
\hline Change in Reading & Control & 36 & .7222 & .51331 & .08555 \\
$\begin{array}{l}\text { Comprehension (posttest - } \\
\text { pretest) }\end{array}$ & Experimental & 18 & .7778 & .42779 & .10083 \\
\hline \hline
\end{tabular}

Table 37. Reading Comprehension Control/Experimental (Posttest/Pretest)

\begin{tabular}{lcccc}
\hline \hline \multicolumn{4}{c}{ Independent Samples Test } \\
\hline \hline & \multicolumn{3}{c}{ t-test for Equality of Means } \\
\cline { 2 - 5 } & $\mathrm{t}$ & $\mathrm{df}$ & Sig. (2-tailed) \\
\hline $\begin{array}{l}\text { Change in Reading } \\
\begin{array}{l}\text { Comprehension (posttest - } \\
\text { pretest) }\end{array}\end{array}$ & -.395 & 52 & .694 \\
\hline \hline
\end{tabular}




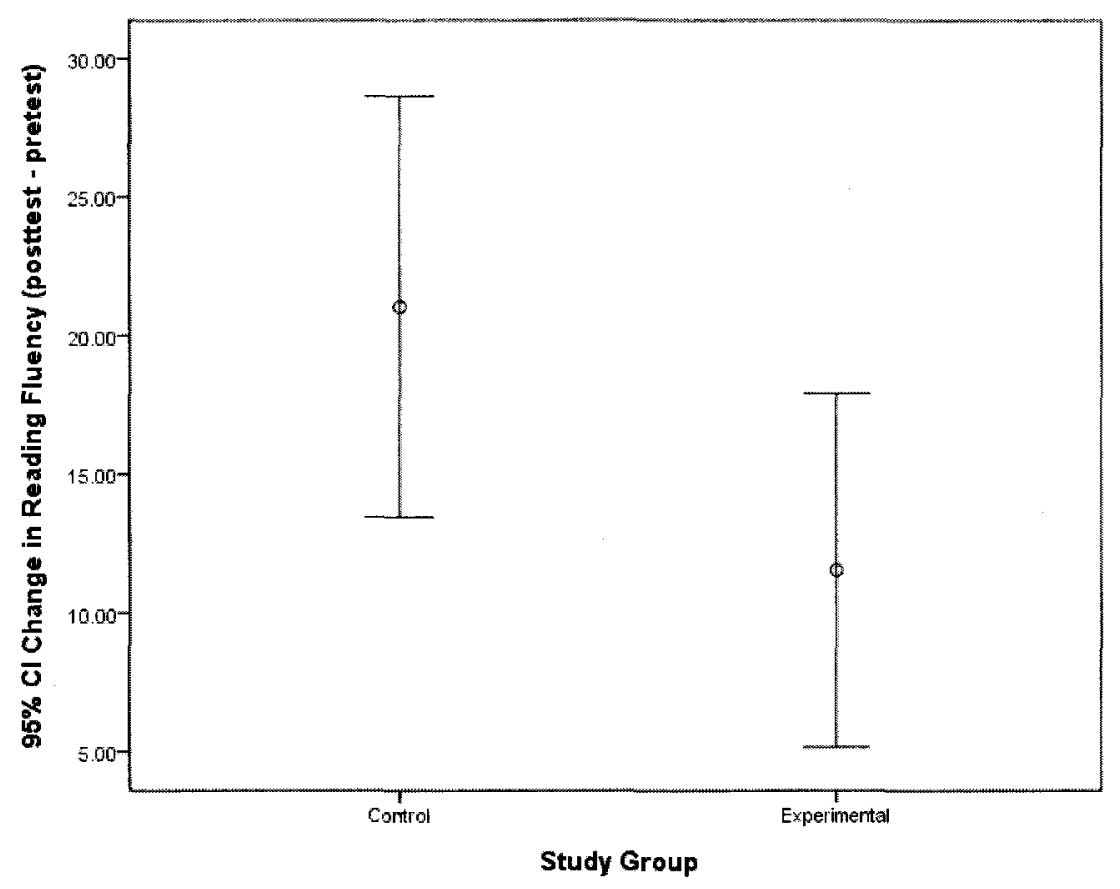

Figure 23. Control/experimental posttest/pretest reading fluency.

Table 38. Reading Fluency Control/Experimental Posttest/Pretest

\begin{tabular}{llllll}
\hline \multicolumn{5}{c}{ Group Statistics } \\
\hline \hline & Study Group & $\mathrm{N}$ & Mean & Std. Deviation & Std. Error Mean \\
\hline Change in Reading Fluency & Control & 36 & 21.0556 & 22.42058 & 3.73676 \\
(posttest - pretest) & Experimental & 18 & 11.5556 & 12.82563 & 3.02303 \\
\hline \hline
\end{tabular}

Table 39. Reading Fluency Control/Experimental Posttest/Pretest

\begin{tabular}{lcccc}
\hline \hline \multicolumn{4}{c}{ Independent Samples Test } \\
\hline \hline & \multicolumn{4}{c}{ t-test for Equality of Means } \\
\cline { 2 - 4 } & $\mathrm{t}$ & $\mathrm{df}$ & Sig. (2-tailed) \\
\hline $\begin{array}{l}\text { Change in Reading Fluency } \\
\text { (posttest - pretest) }\end{array}$ & 1.662 & 52 & .103 \\
\hline \hline
\end{tabular}




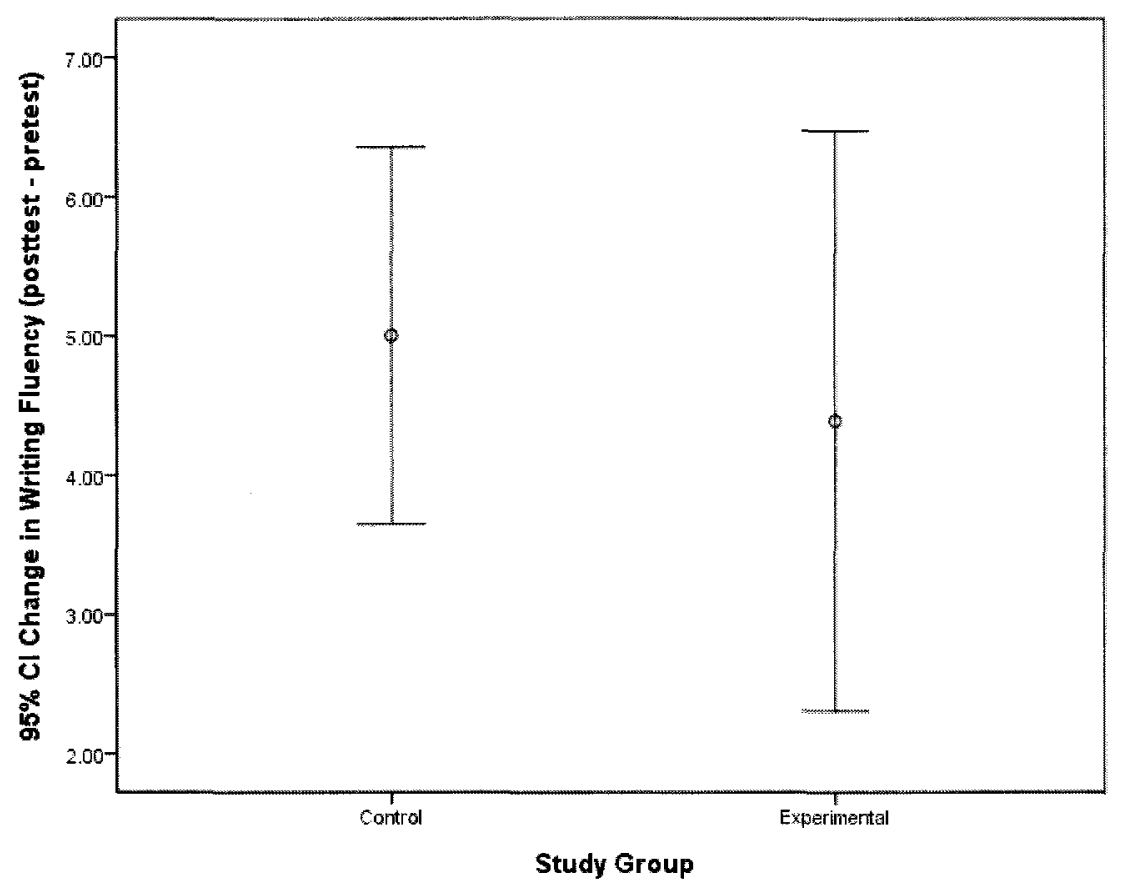

Figure 24. Control/experimental posttest/pretest writing fluency.

Table 40. Writing Fluency Control/Experimental Posttest/Pretest

\begin{tabular}{llllll}
\hline \multicolumn{5}{c}{ Group Statistics } \\
\hline \hline & Study Group & $\mathrm{N}$ & Mean & Std. Deviation & Std. Error Mean \\
\hline Change in Writing Fluency & Control & 36 & 5.0000 & 4.00000 & .66667 \\
(posttest - pretest) & Experimental & 18 & 4.3889 & 4.18876 & .98730 \\
\hline \hline
\end{tabular}

Table 41. Writing Fluency Control/Experimental Posttest/Pretest Independent Samples Test

\begin{tabular}{lcccc}
\hline \hline \multicolumn{4}{c}{ Independent Samples Test } \\
\hline & \multicolumn{3}{c}{ t-test for Equality of Means } \\
\cline { 2 - 5 } & $\mathrm{t}$ & $\mathrm{df}$ & Sig. (2-tailed) \\
\hline $\begin{array}{l}\text { Change in Writing Fluency } \\
\text { (posttest - pretest) }\end{array}$ & .521 & 52 & .605 \\
\hline \hline
\end{tabular}


Table 42. Dependent Variable Reading Comprehension Scores (Posttest) in Relation to Reading and Writing Fluency

\begin{tabular}{llccccc}
\hline \multicolumn{5}{c}{ ANOVA $^{\mathrm{b}}$} \\
\hline \hline Model $^{\mathrm{c}}$ & & Sum of Squares & $\mathrm{df}$ & Mean Square & $\mathrm{F}$ & Sig. $^{\circ}$ \\
\hline 1 & Regression & 10.722 & 2 & 5.361 & 25.949 & $.000^{\mathrm{a}}$ \\
& Residual & 10.537 & 51 & .207 & & \\
& & & & & & \\
& Total & 21.259 & 53 & & & \\
\hline \hline
\end{tabular}

a. Predictors: (Constant), Writing Fluency (posttest), Reading Fluency - Number of Words per Minute (posttest)

b. Dependent Variable: Reading Comprehension (posttest)

c. R Square $=0.50$

However, Table 43 shows that only reading fluency $(\mathrm{p}<0.001)$ was statistically significantly associated with reading comprehension. This shows, in keeping with research, reading fluency is positively correlated with reading comprehension. However, reading and writing fluency together were not correlated with reading comprehension.

The equation of the model was:

$\mathrm{RC}=1.63+0.012 * \mathrm{RF}+0.008 * \mathrm{WF}$

Where:

$\mathrm{RC}=$ The average posttest reading comprehension score

$\mathrm{RF}=$ The posttest reading fluency score

$\mathrm{WF}=$ The posttest writing fluency score

The interpretation of the model is, after controlling for the level of writing fluency, the average posttest reading comprehension score is expected to increase by 0.012 points for every one-point increase in the posttest reading fluency score.

\section{Research Question \#8}

I will also use the demographic variables of gender, ethnicity, and socioeconomic status as determined by eligibility of free and reduced lunch.

In addition, multiple linear regression analysis was used to determine if gender, ethnicity, or socioeconomic status collectively were associated with posttest reading comprehension. Table 44 shows that collectively, study group, gender, ethnicity, 
Table 43. Coefficients of Dependent Variable Reading Comprehension Scores (Posttest) in Relation to Reading and Writing Fluency

\begin{tabular}{|c|c|c|c|c|c|c|}
\hline \multicolumn{7}{|c|}{ Coefficients $^{\mathrm{a}}$} \\
\hline \multirow[t]{3}{*}{ Model } & & \multicolumn{5}{|c|}{ Standardized } \\
\hline & & \multicolumn{2}{|c|}{ Unstandardized Coefficients } & \multirow{2}{*}{$\begin{array}{c}\text { Coefficients } \\
\text { Beta } \\
\end{array}$} & \multirow[b]{2}{*}{$\mathrm{t}$} & \multirow[b]{2}{*}{ Sig. } \\
\hline & & B & Std. Error & & & \\
\hline \multirow[t]{3}{*}{1} & (Constant) & 1.630 & .287 & & 5.676 & .000 \\
\hline & $\begin{array}{l}\text { Reading Fluency - Number } \\
\text { of Words per Minute } \\
\text { (posttest) }\end{array}$ & .012 & .002 & .678 & 6.098 & .000 \\
\hline & Writing Fluency (posttest) & .008 & .013 & .064 & .576 & .567 \\
\hline
\end{tabular}

a. Dependent Variable: Reading Comprehension (posttest)

Table 44. Dependent Variable Reading Comprehension in Relation to Demographic Variables

\begin{tabular}{llccccc}
\hline \multicolumn{7}{c}{ ANOVA $^{\mathrm{b}}$} \\
\hline \hline Model $^{\mathrm{C}}$ & & Sum of Squares & df & Mean Square & F & Sig. \\
\hline 1 & Regression & 2.233 & 5 & .447 & 1.127 & $.359^{\mathrm{a}}$ \\
& Residual & 19.027 & 48 & .396 & & \\
& Total & 21.259 & 53 & & & \\
\hline \hline
\end{tabular}

a. Predictors: (Constant), English as a Second Language Learner, Gender, Study Group,

Ethnicity, Free/Reduced Lunch Program

b. Dependent Variable: Reading Comprehension (posttest)

c. $R$ Square $=0.11$

free/reduced lunch, and English as a second language status did not explain a statistically significant percentage of the variance in reading comprehension scores, $F(5,48)=1.13 ; p=$ 0.36 ; R-square $=0.11$. Since the F-test was not statistically significant, the R-square cannot be statistically distinguished from zero.

Although the model was not statistically significant, Table 45 presents the regression coefficients for completeness. The equation of the model was:

$\mathrm{RC}=3.52+0.22 * \mathrm{SG}-0.12 * \mathrm{GEN}-0.065 * \mathrm{ETH}-0.44 * \mathrm{FRL}-0.50 * \mathrm{ESL}$ 
Table 45. Coefficients of Dependent Variable Reading Comprehension in Relation to Demographic Variables

\begin{tabular}{|c|c|c|c|c|c|c|}
\hline \multicolumn{7}{|c|}{ Coefficients $^{a}$} \\
\hline \multirow{3}{*}{\multicolumn{2}{|c|}{ Model }} & & & \multirow{3}{*}{$\begin{array}{c}\begin{array}{c}\text { Standardized } \\
\text { Coefficients }\end{array} \\
\text { Beta }\end{array}$} & \multirow[b]{3}{*}{$t$} & \multirow[b]{3}{*}{ Sig. } \\
\hline & & \multicolumn{2}{|c|}{ Unstandardized Coefficients } & & & \\
\hline & & B & Std. Error & & & \\
\hline \multirow[t]{8}{*}{1} & (Constant) & 3.522 & .398 & & 8.847 & .000 \\
\hline & Study Group & .221 & .202 & .166 & 1.098 & .278 \\
\hline & Gender & -.118 & .178 & -.092 & -.664 & .510 \\
\hline & Ethnicity & -.065 & .236 & -.044 & -.276 & .784 \\
\hline & Free/Reduced Lunch & -.441 & .636 & -.133 & -.694 & .491 \\
\hline & Program & & & & & \\
\hline & English as a Second & -.496 & .507 & -.207 & -.977 & .333 \\
\hline & Language Learner & & & & & \\
\hline
\end{tabular}

a. Dependent Variable: Reading Comprehension (posttest)

Where:

$\mathrm{RC}=$ The average posttest reading comprehension score

$\mathrm{SG}=0$ if control group, 1 if experimental group

$\mathrm{GEN}=1$ if female, 2 if male

$\mathrm{ETH}=1$ if white, 2 if other

$\mathrm{FRL}=0$ if not on free/reduced lunch, 1 if on free/reduced lunch

$\mathrm{ESL}=0$ if not English as a second language, 1 if English as a second language

Since none of the regression coefficients were statistically significant, the model has no interpretation, other than none of the independent variables are statistically significant predictors of posttest reading comprehension.

\section{Research Question \#9}

Are writing strategies and sentence structure related to reading comprehension? Pearson's correlation statistic was used to evaluate the relationships between writing strategies, sentence structure and reading comprehension, separately for the pretest and posttest measurements. In addition, Pearson's correlation statistic was used to evaluate the relationships between the change from pretest to post test in writing strategies, sentence 
structure and reading comprehension. Figures 25 through 27 are scatter plots which graphically depict the relationships between writing strategies, sentence structure and reading comprehension based on the pretest measurements. Table 46 shows there was a statistically significant, strong positive correlation between reading comprehension and writing strategies, $\mathrm{r}(36)=0.78 ; \mathrm{p}<0.001$. There was a statistically significant, strong positive correlation between reading comprehension and sentence structure, $r(36)=0.70 ; p<0.001$. There was a statistically significant, strong positive correlation between sentence structure and writing strategies, $\mathrm{r}(36)=0.65 ; \mathrm{p}<0.001$. In summary, there is a strong correlation between reading comprehension and writing strategies as well as between reading comprehension and sentence structure. This shows a positive relationship between reading comprehension and writing. There is also a strong relationship between writing strategies and sentence structure. This is in agreement with my thesis, that writing has an impact on reading comprehension. Figures 28 through 30 are scatter plots which graphically depict the relationships between writing strategies, sentence structure and reading comprehension based on the posttest measurements. Table 47 shows there was a statistically significant, strong positive correlation between reading comprehension and writing strategies, $r(36)=0.62 ; \mathrm{p}<$ 0.001 . There was a statistically significant, strong positive correlation between reading comprehension and sentence structure, $r(36)=0.46 ; p=0.005$. There was a statistically significant, strong positive correlation between writing strategies and sentence structure, $r(36)=0.59 ; \mathrm{p}<0.001$. Again, the posttest results are in agreement with my thesis, that there is a strong relationship between reading comprehension and writing. Figures 31 through 33 are scatter plots which graphically depict the relationships between the change (posttestpretest) in writing strategies, sentence structure and reading comprehension. Table 48 shows there was a statistically significant, moderately strong positive correlation between the change in reading comprehension and the change writing strategies, $r(36)=0.34 ; p=0.042$. There was not a statistically significant correlation between the change in reading comprehension and the change in sentence structure, $r(36)=0.26 ; p=0.13$. There was not a statistically significant correlation between the change in writing strategies and the change in sentence structure, $r(36)=0.20 ; p=0.24$. See Appendix B for note for formulas for effect size on statistical tests. 


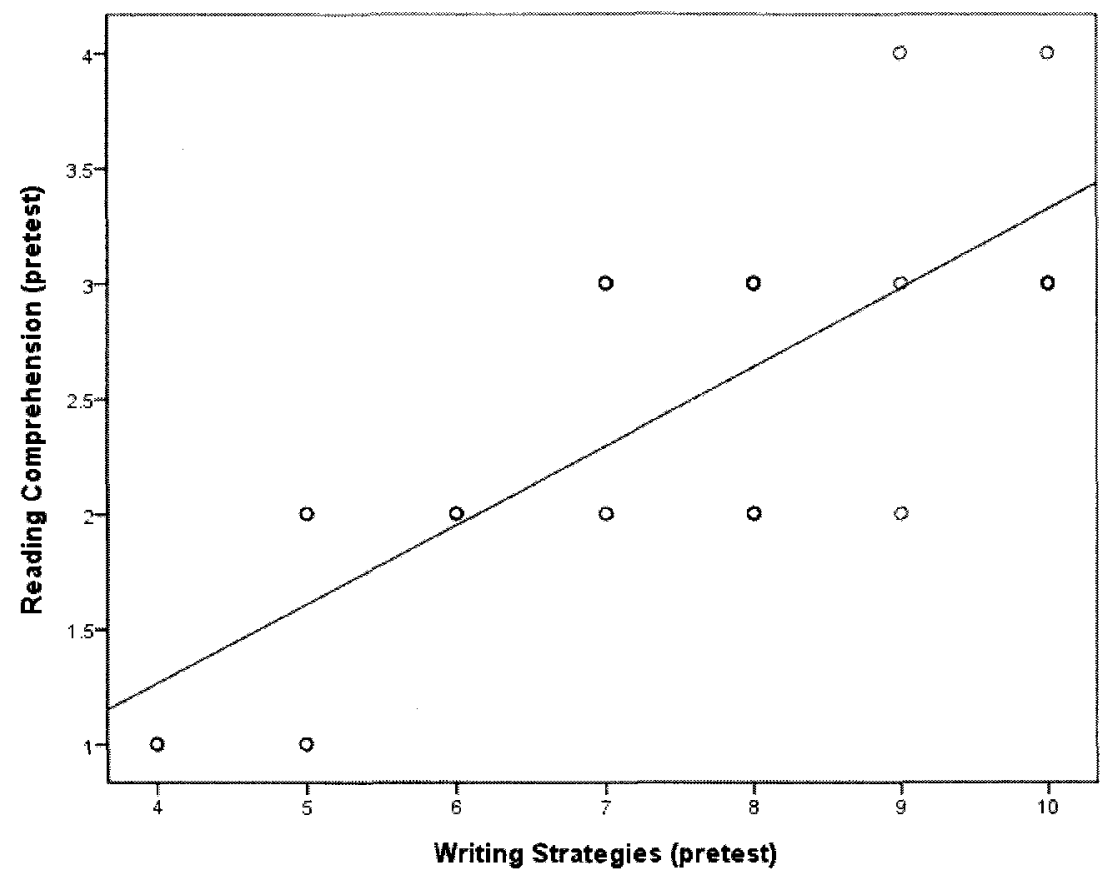

Figure 25. Pretest measurement of reading comprehension and writing strategies.

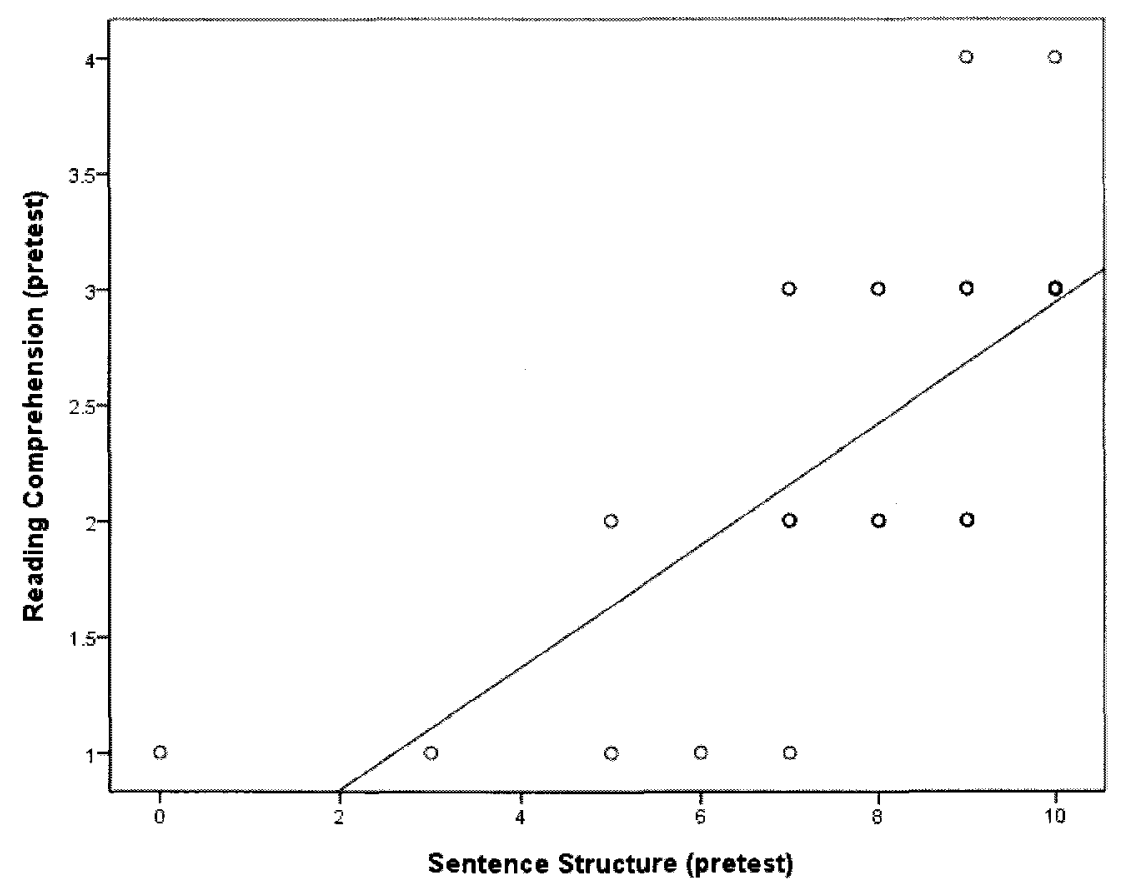

Figure 26. Pretest measurement of reading comprehension and sentence structure. 


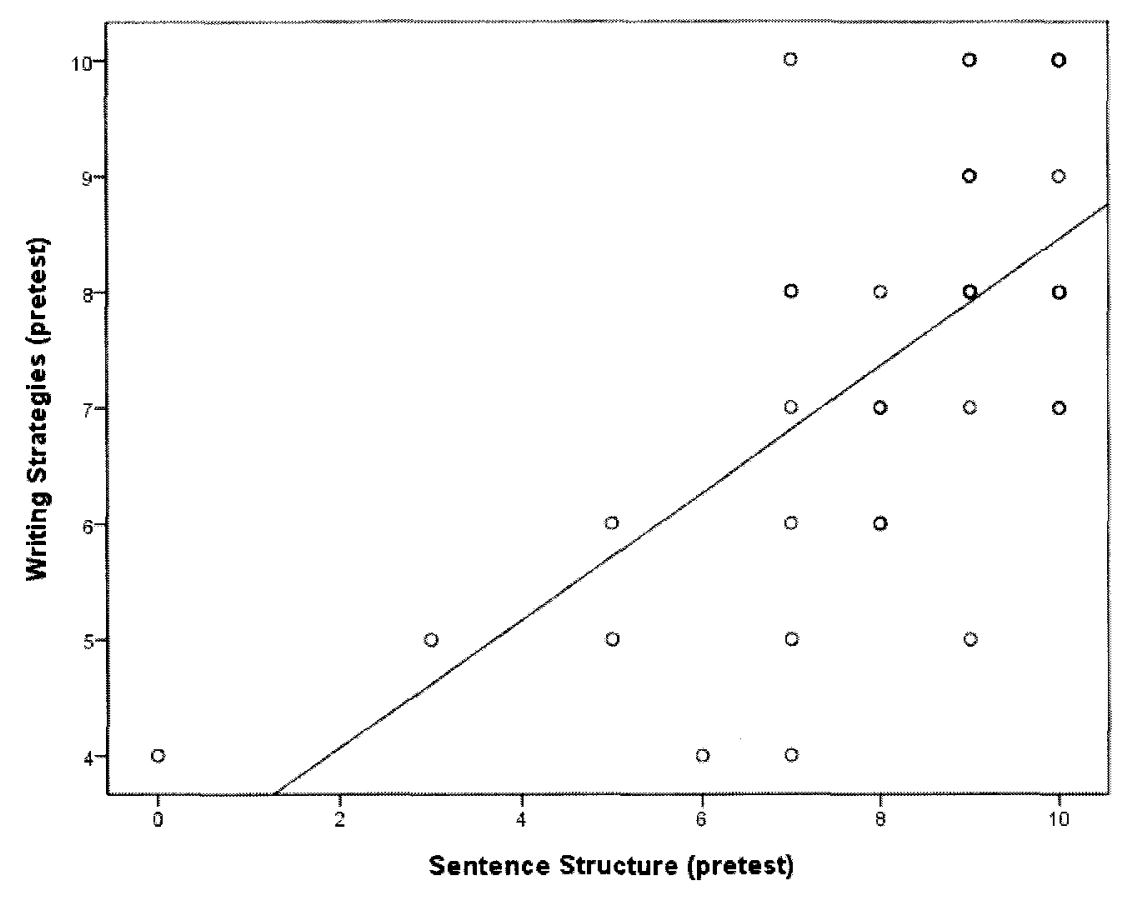

Figure 27. Pretest measurement of writing strategies and sentence structure.

Table 46. Correlations Between Reading Comprehension and Writing Strategies and Sentence Structure (Pretest)

\begin{tabular}{|c|c|c|c|c|}
\hline \multicolumn{5}{|c|}{ Correlations } \\
\hline & & $\begin{array}{c}\text { Reading } \\
\text { Comprehension } \\
\text { (pretest) }\end{array}$ & $\begin{array}{c}\text { Writing } \\
\text { Strategies } \\
\text { (pretest) }\end{array}$ & $\begin{array}{l}\text { Sentence } \\
\text { Structure } \\
\text { (pretest) }\end{array}$ \\
\hline \multirow{3}{*}{$\begin{array}{l}\text { Reading Comprehension } \\
\text { (pretest) }\end{array}$} & Pearson Correlation & 1 & .782 & .704 \\
\hline & Sig. (2-tailed) & & .000 & .000 \\
\hline & $\mathrm{N}$ & 54 & 36 & 36 \\
\hline \multirow[t]{3}{*}{ Writing Strategies (pretest) } & Pearson Correlation & .782 & 1 & .646 \\
\hline & Sig. (2-tailed) & .000 & & .000 \\
\hline & $\mathrm{N}$ & 36 & 36 & 36 \\
\hline \multirow[t]{3}{*}{ Sentence Structure (pretest) } & Pearson Correlation & .704 & .646 & 1 \\
\hline & Sig. (2-tailed) & .000 & .000 & \\
\hline & $\mathrm{N}$ & 36 & 36 & 36 \\
\hline
\end{tabular}




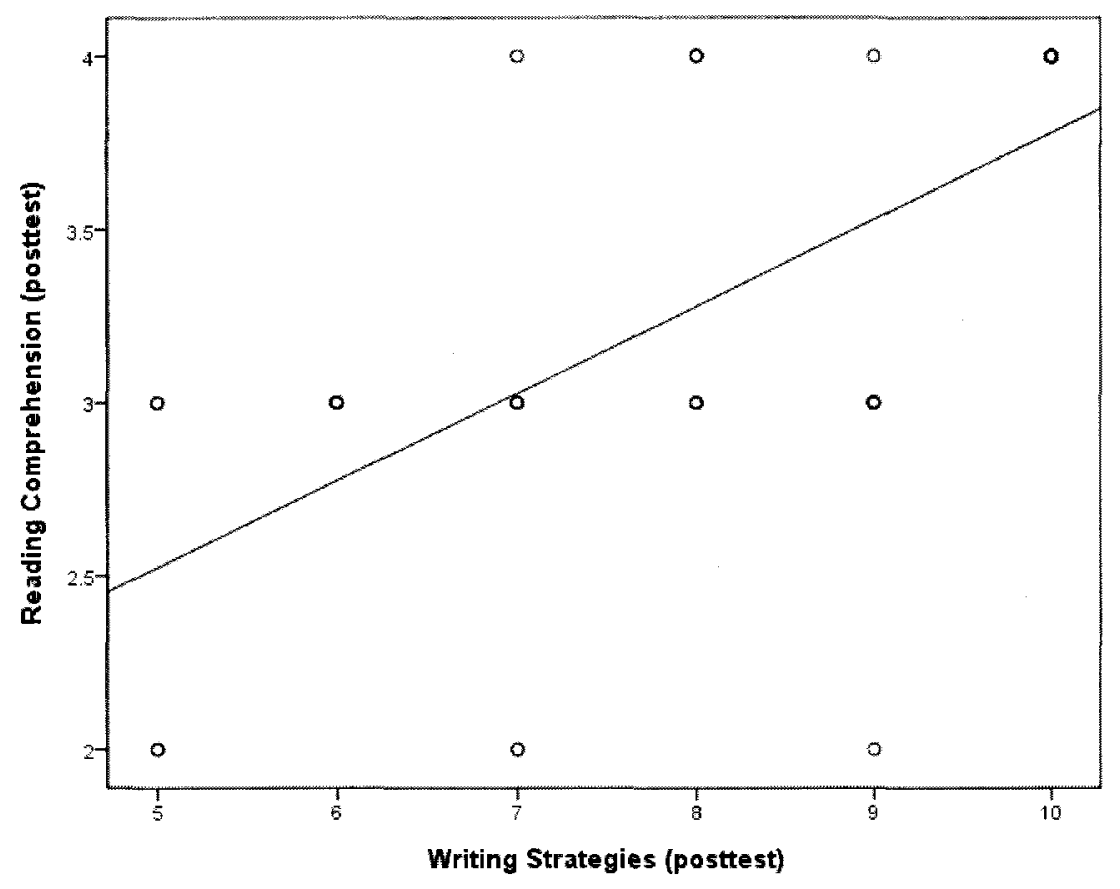

Figure 28. Posttest measurement of reading comprehension and writing strategy.

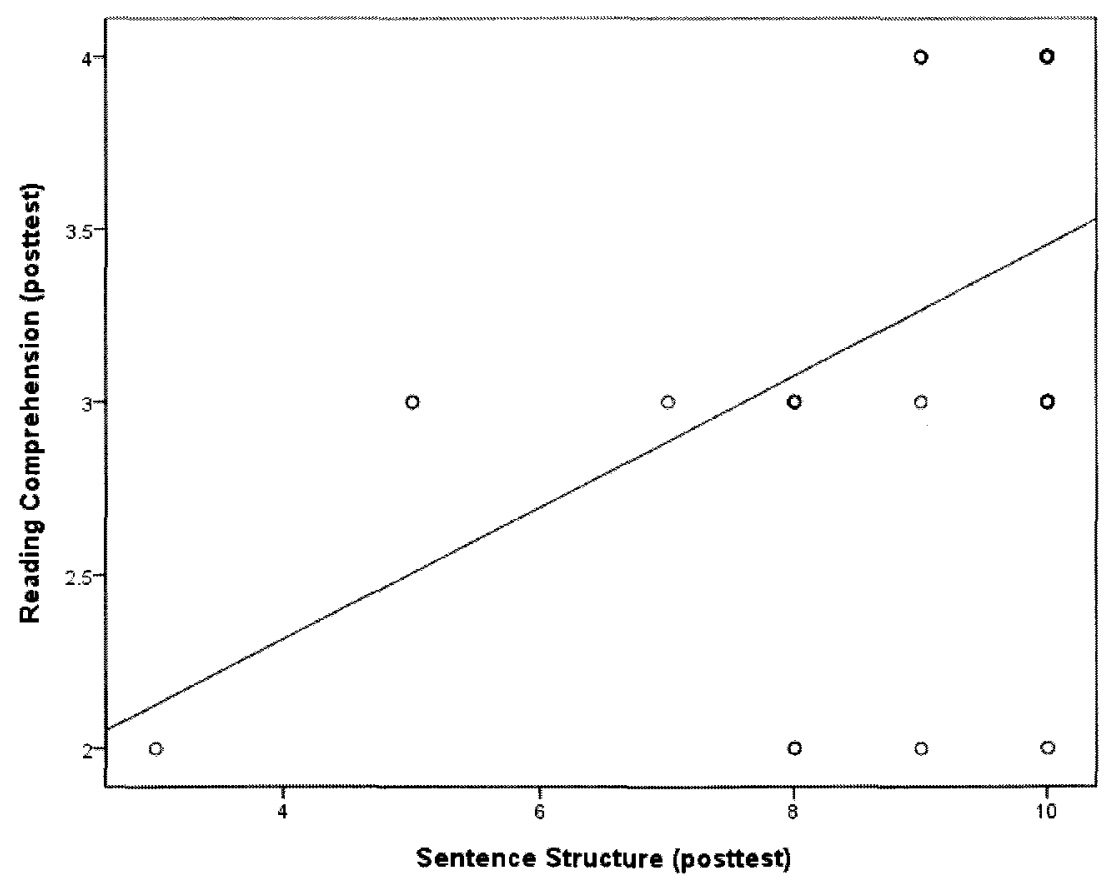

Figure 29. Posttest measurement of reading comprehension and sentence structure. 


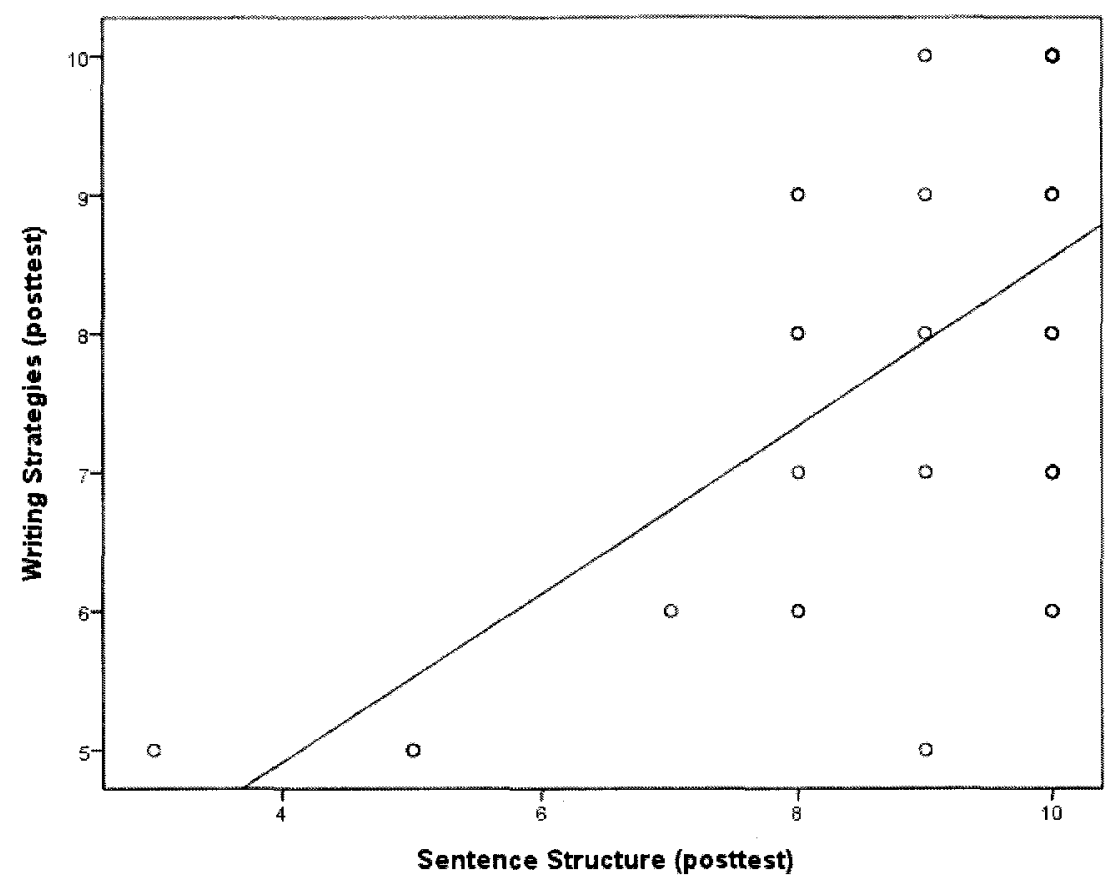

Figure 30. Posttest measurement of and writing strategies and sentence structure.

Table 47. Correlations Between Reading Comprehension and Writing Strategies and Sentence Structure (Posttest)

\begin{tabular}{llrrr}
\hline \multicolumn{5}{c}{ Correlations } \\
\end{tabular}




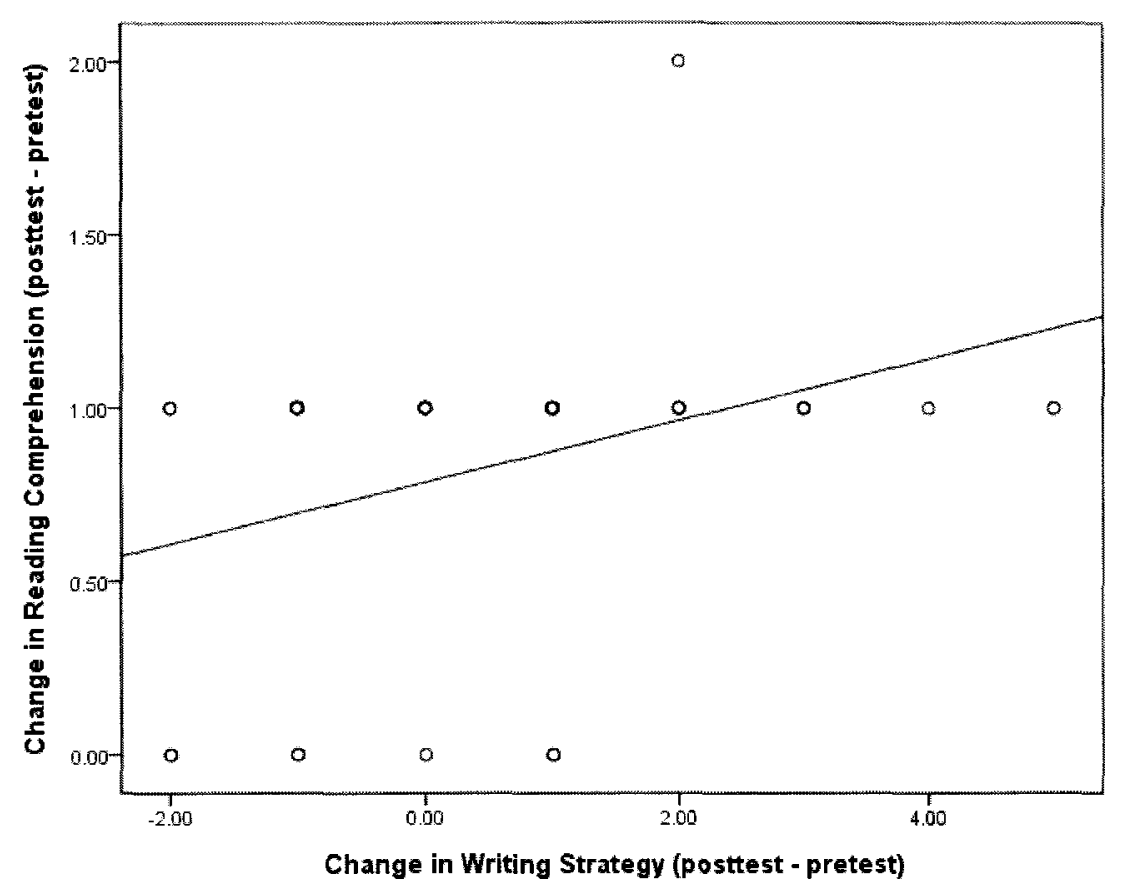

Figure 31. Change in reading comprehension and change in writing strategy.

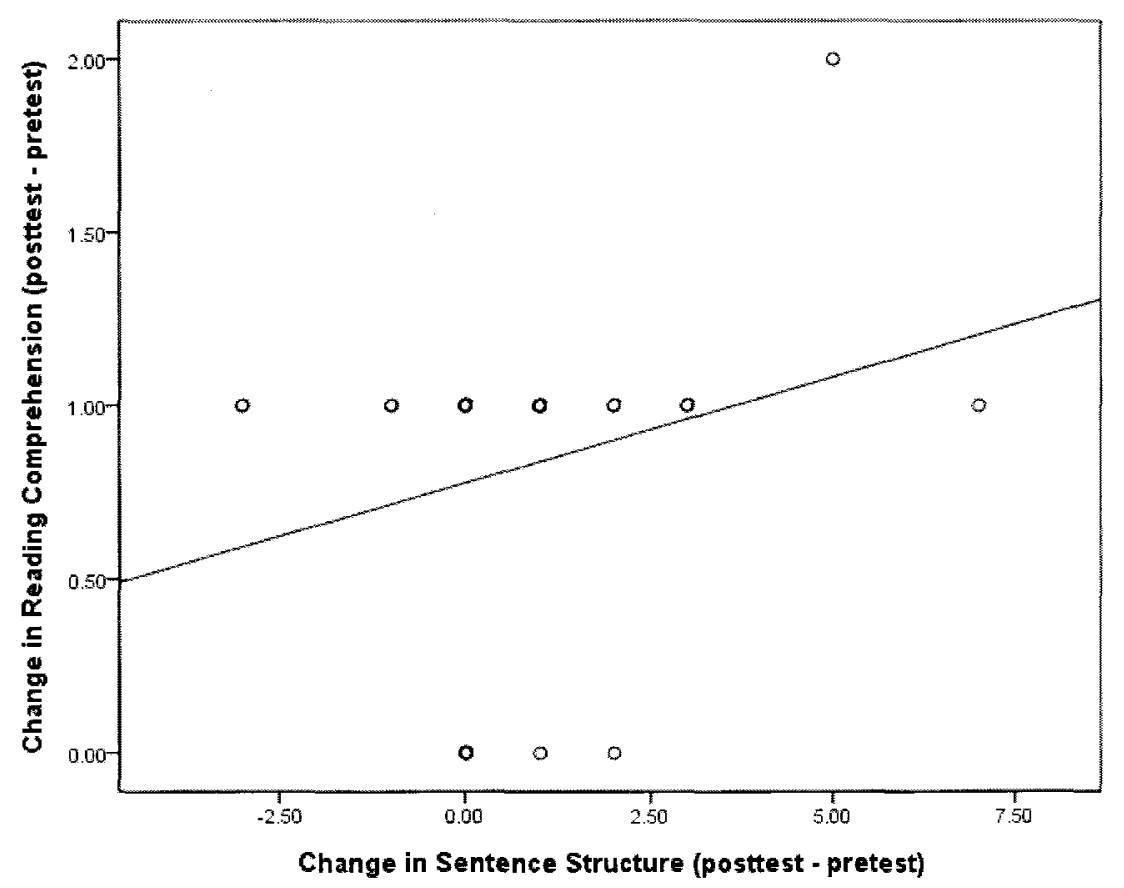

Figure 32. Change in reading comprehension and change in sentence structure. 


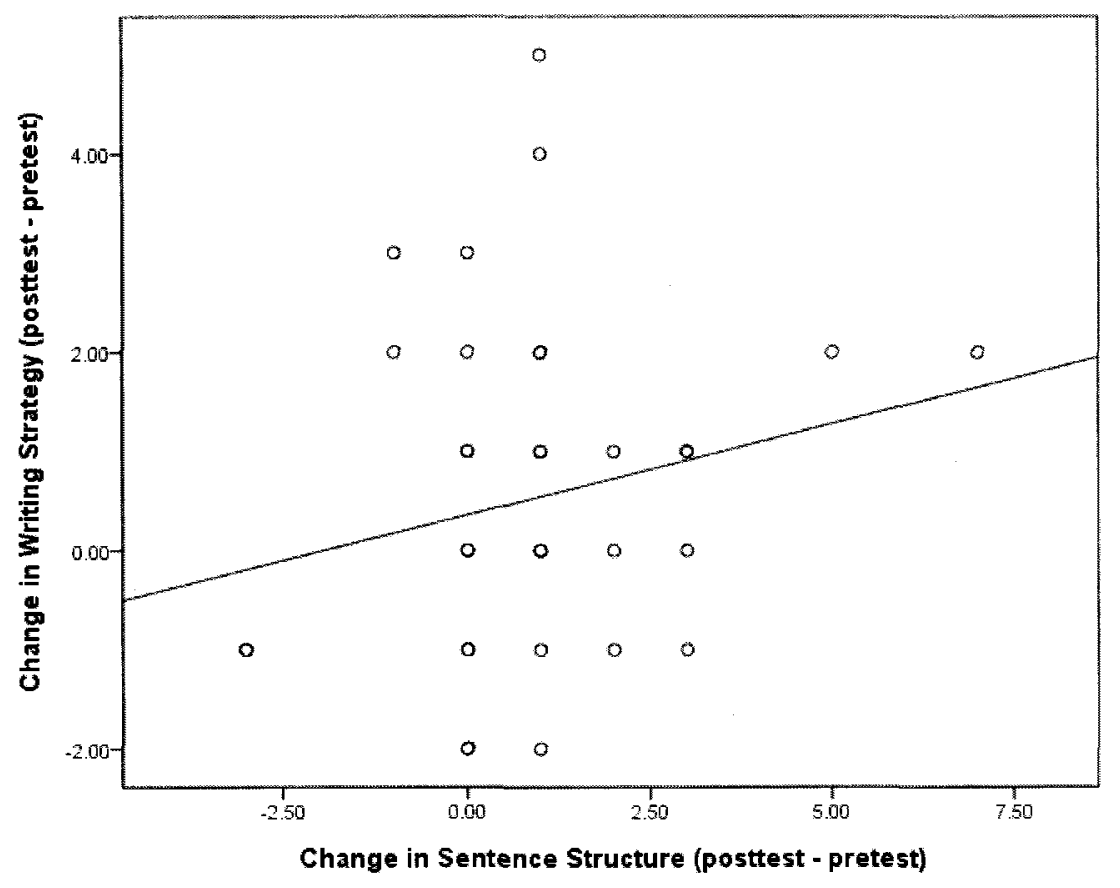

Figure 33. Change in reading comprehension and change in sentence structure.

Table 48. Correlations Between Change in Reading Comprehension and Change in Writing Strategy and Change in Sentence Structure (Posttest-Pretest)

\begin{tabular}{|c|c|c|c|c|}
\hline \multicolumn{5}{|c|}{ Correlations } \\
\hline & & $\begin{array}{c}\text { Change in } \\
\text { Reading } \\
\text { Comprehension } \\
\text { (posttest - } \\
\text { pretest) }\end{array}$ & $\begin{array}{c}\text { Change in } \\
\text { Writing Strategy } \\
\text { (posttest - } \\
\text { pretest) }\end{array}$ & $\begin{array}{l}\text { Change in } \\
\text { Sentence } \\
\text { Structure } \\
\text { (posttest - } \\
\text { pretest) }\end{array}$ \\
\hline \multirow{2}{*}{$\begin{array}{l}\text { Change in Reading } \\
\text { Comprehension (posttest - } \\
\text { pretest) }\end{array}$} & Pearson Correlation & 1 & .341 & .256 \\
\hline & $\begin{array}{l}\text { Sig. (2-tailed) } \\
\mathrm{N}\end{array}$ & 54 & $\begin{array}{r}.042 \\
36 \\
\end{array}$ & $\begin{array}{r}.132 \\
36 \\
\end{array}$ \\
\hline \multirow[t]{2}{*}{$\begin{array}{l}\text { Change in Writing Strategy } \\
\text { (posttest - pretest) }\end{array}$} & $\begin{array}{l}\text { Pearson Correlation } \\
\text { Sig. (2-tailed) }\end{array}$ & $\begin{array}{l}.341 \\
.042\end{array}$ & 1 & $\begin{array}{l}.201 \\
.240\end{array}$ \\
\hline & $\mathrm{N}$ & 36 & 36 & 36 \\
\hline Change in Sentence & Pearson Correlation & .256 & .201 & 1 \\
\hline \multirow[t]{2}{*}{ Structure (posttest - pretest) } & Sig. (2-tailed) & .132 & .240 & \\
\hline & $\mathrm{N}$ & 36 & 36 & 36 \\
\hline
\end{tabular}




\section{CHAPTER 5}

\section{DISCUSSION}

The research in this study produced results that were predictable, encouraging, potentially groundbreaking, surprising, as well as disappointing. The research showing the correlation between reading comprehension and reading fluency was predictable. The research showing the link between reading comprehension and writing was encouraging as well as potentially ground breaking. However, since this link was inconsistent, it was somewhat disappointing. The quasi-experimental scientific study of the three third grade classrooms was very surprising in that the class with specific reading and writing fluency instruction did not outperform the control group. The research on the demographic variables was also surprising since none of the independent variables were predictors of reading comprehension. The research questions for this study can be summarized into six main topics.

\section{SiX Main Topics OF THE STUdy}

First, the relationships between reading comprehension, reading fluency, and writing will be explained. Then the results of the quasi-experimental scientific study will be analyzed. Finally, the correlations of demographic variables will be addressed.

\section{Reading Comprehension and Reading Fluency}

Many studies show high reading fluency correlates to high comprehension scores. The national study of Fourth-Grade Students Reading Aloud: NAEP 2002 Special Study of Oral Reading (Daane et al., 2005) found students who read with the fewest errors demonstrated greater comprehension. It also showed the speed of oral reading was positively related to comprehension. Another ground breaking study showed "oral reading fluency from text serves to predict reading comprehension, and comprehension in turns serves to predict oral reading text fluency" (Fuchs et al., 2001, p. 247). The significant positive relationship between reading fluency and reading comprehension is almost indisputable. One of the major findings of this study is consistent with that conclusion. In every test in this paper there was a 
statistically significant, strongly positive correlation between reading comprehension and reading fluency. I was very pleased that the results from this study matched the results of the vast majority of research on reading comprehension. As a teacher, this was also positive news. One of the major goals of education is to increase a student's reading comprehension (National Institute of Child Health and Human Development [NICHD], 2000). When a teacher helps students increase their reading fluency, it may help increase their reading comprehension. This gives teachers another tool in helping their students achieve the important task of increasing their reading comprehension.

\section{Reading Comprehension and Writing}

The link between reading comprehension and writing is often found in reading theory. Rosenblatt's ground breaking work states "the parallels in the reading and writing processes and the nature of the transaction between author and reader make it reasonable to expect that the teaching of one can affect the student's operation in the other" (Rosenblatt, 2004, p. 138). Clay (2001) wrote about the reciprocity of learning to read and write and believed writing can help a student to learn to read. While this link of reading and writing is found often in theory, there is scant evidence of it in research. The major goal of this study was to discover if there was a link between reading comprehension and writing. This study did find a link between reading comprehension and writing as well a link between reading comprehension and writing fluency. This was exciting as well as potentially ground breaking news. Writing was measured by components of writing, such as writing strategies and sentences structure. Writing strategies include understanding topic sentences and how to construct a paragraph while sentence structure includes how to recognize and construct a sentence. Using the Pearson's correlation statistic, there was a statistically significant, strong positive correlation between reading comprehension and writing strategies. There was also a statistically significant, strong positive correlation between reading comprehension and sentence structure. Again this is great news for teachers because this presents another tool for a teacher to try to increase a child's reading comprehension. Therefore, when a teacher is teaching writing skills she may be helping the students' reading comprehension.

In this study, the link between reading comprehension and writing was established. However, while the connection between reading comprehension and writing fluency was 
encouraging, it was also inconsistent. Writing fluency was measured by the number of words the student could read correctly in a one minute assessment. Using Pearson's correlation statistic, in the posttest, there was a statistically significant, moderately strong positive correlation between reading comprehension and writing fluency. However, this same link was not found in the pretest measurement, or the posttest-pretest measurement. This was disappointing because a stronger, more consistent link would better support my thesis.

\section{Correlations Between Reading Fluency and Writing Fluency to Reading Comprehension}

In a different analysis, multiple linear regression analysis, reading comprehension (posttest) was the dependent variable and predictors were writing fluency (posttest) and reading fluency (posttest). The ANOVA results showed that reading and writing fluency explained a statistically significant $50 \%$ of the total variance in reading comprehension scores. Although the link between reading fluency and reading comprehension was well known, this was excellent news for my study to find that writing fluency was linked to reading comprehension. Again, this could be ground breaking results linking writing and reading comprehension. However, the same results showed that only reading fluency was statistically significantly associated with reading comprehension. It was disappointing that writing fluency was not significantly associated with reading comprehension. We had a glimmer of the connection between writing fluency and reading comprehension but it was not fully developed or statistically supported.

\section{The Link Between Reading Fluency and Writing Fluency}

With the link between reading comprehension and reading fluency well established and the link between reading comprehension and writing introduced, what is the link between reading fluency and writing fluency? There is no research I know of linking reading fluency with writing fluency. However, this study shows a statistically significant, strong positive correlation between reading fluency and writing fluency in the posttest measurement. This is a positive and encouraging result. If writing fluency helps reading fluency, then improving writing fluency may increase a student's reading comprehension. Again, this could be good news for a teacher as this would be another tool to use to help students. However, this 
positive correlation between reading fluency and writing fluency did not exist in the pretest measurement or the posttest-pretest measurement, so it is discouraging that this result was inconclusive.

The San Diego Area Writing Project (SDAWP) uses writing fluency to help writing skills. Using Power Writing (Fearn \& Farnan, 2001), the Writing Project suggests students attain writing fluency by writing as many words as they can in two minutes and then count the number of words. They recommend doing this two times a week and tracking the increased number of words written. Although this exercise is not used to help reading comprehension, it is still positive because it puts an emphasis on writing fluency and makes the practice better known to teachers.

\section{Quasi-Experimental Scientific Study}

With the latest reading research linking reading comprehension and reading fluency, there have been many studies showing that an increase in reading fluency will increase reading comprehension scores. Stecker et al. (1998) found "fluency has been shown to have a 'reciprocal relationship' with comprehension, with each fostering the other" (p. 300). Klauda and Guthrie (2008) found "the results involving the directionality of the relationship between fluency and comprehension support the ideas that theses two reading skills have a reciprocally predictive relationship “

A quasi-experimental scientific study of second graders in New York found the experimental group with direct, specific instruction in reading fluency significantly increased oral reading fluency, while students in the control group had no such increase. Also, students' improvement in fluency corresponded with improvements in reading comprehension (Sivin-Kachala \& Bialo, 2004). As a result of this link of an increase in reading fluency to an increase in reading comprehension, there has been a plethora of books, programs, and teaching aids on the market for teachers to use to help their students increase their fluency, thus leading to the goal of greater reading comprehension. Two such popular books are The Fluent Reader: Oral Reading Strategies for Building Word Recognition, Fluency, and Comprehension (Rasinki, 2003) and Building Fluency: Lessons and Strategies for Reading Success (Blevins, 2001). 
This study also contained a quasi-experimental study. In two third grade classes, teachers taught the regular language arts curriculum. However, in the experimental group the teacher taught the regular curriculum but supplemented it with systematic direct instruction in reading and writing fluency. It was important that all three classes be demographically and academically equal. All three teachers had similar experience and teaching styles. The research in this study showed that the classes were very balanced. There was not a statistically significant difference between the control and experimental group in pretest reading comprehension, reading fluency, or in writing fluency.

In keeping with major research, it was expected that the experimental group with explicit reading and writing fluency instruction would outperform the control group that only used the regular language arts curriculum. Surprising, in this study, the control and experimental classes all did equally well. The experimental class did not outperform the control groups: all groups made significant progress. While the extra instruction in fluency may have helped some students, it did not produce a statically significant positive correlation. The reason for the experimental group not outscoring the control groups may be as simple as this being a top school in the state with highly involved parents, motivated students, and an excellent regular language curriculum. It is possible that these students would do well in school regardless of specific instruction. Also, the district-approved language arts curriculum that the control teachers used did have some reading fluency and writing strategies embedded in it.

\section{Correlations of Demographic Variables}

This study included a multiple linear regression analysis to determine if gender, ethnicity, or socioeconomic status collectively were associated with posttest reading comprehension. The dependent variable was reading comprehension (posttest) and the predictors were English as a Second Language Learner, gender, ethnicity, or participation in a free or reduced lunch program. The study found none of the independent variables were statistically significant predictors of posttest reading comprehension. I was not surprised to see that neither gender nor ethnicity affected reading comprehension. The study sample sized comprised to $59 \%$ female and $41 \%$ male. Traditionally at this school males and females do equally well in school. With $76 \%$ of the student sample white, the non-white populations 
may have been too small to have an impact on the statistics. I was surprised that English as a Second Language Learner did not have an impact on reading comprehension. With English not the main language spoken at home, it could be considered a disadvantage in reading comprehension, but it was not. With only less than $3 \%$ of the sample size participating in the free or reduced lunch program, the size was probably too small to have an impact.

\section{IMPLICATIONS}

The results from this study could have wide ranging implications. The exciting correlation between reading comprehension and writing could potentially have the greatest impact on reading education. Although theory has always linked reading and writing, I believe this is one of the first studies that showed this connection. This could potentially change the way teachers teach reading and writing. A teacher may use writing skills to help boost reading comprehension, and while students are working on writing sentences and paragraphs, they may be increasing their reading comprehension. This may lead to resurgence in writing instruction in the classroom. With the emphasis on standardized testing, many teachers may focus on reading comprehension (which is on the test) at the expense of writing instruction (which is not on the test). Now a teacher may rest assured that while they are teaching writing strategies, they may be helping their students' reading comprehension at the same time.

With the link between reading fluency and writing fluency, teachers may pay greater attention to writing fluency. If writing fluency is a way to increase reading fluency, and reading fluency is linked to greater reading comprehension, then writing fluency may help increase reading comprehension. In the future, perhaps groups such as SDAWP could employ their use of writing fluency not just to increase writing skills but reading comprehension skills.

Another implication of this study may be for teachers to put away all those reading fluency books and just use the school's regular language arts curriculum. This study showed that the experimental group with specific reading and writing fluency instruction did not outperform the control group in reading comprehension, reading fluency, or in writing fluency. With all the demands placed on teachers and so many new practices given to them each year, 
teachers may be relieved not to do extra fluency instruction, but to concentrate on the regular school curriculum and requirements.

Another implication would be for teachers or administrators not to be prejudiced by demographic variables. This study showed that variables such gender, ethnicity, English as a Second Language Learner, or participation in a free or reduced lunch program were not associated with posttest reading comprehension. As a teacher I have over heard other teachers concerned that boys, or minorities, or non English speaking families, or poorer families may have difficulties in reading and may score lower on STAR reading comprehension tests: that may not be the case.

\section{RECOMMENDATIONS}

Recommendations from this study can be applied the classroom, school, and district levels. With the link between reading comprehension and writing, classroom teachers may want to increase their time in teaching writing skills, especially skills such writing strategies (writing topic sentences and paragraphs) and sentence structure (recognizing and writing sentences). Also, teachers may want to use specific writing fluency instruction to increase reading comprehension scores. The Power Writing from the SDWP would be an excellent technique for teachers to employ.

At the school level, the principal or administrator may require more writing instruction in intervention or professional growth development. For example, although we have after school intervention and special reading classes at my school, none of these programs teach writing strategies or use writing in any way. For professional development classes, classes dealing with reading comprehension are readily available but classes on writing are rarely offered.

At the district level, as long as the district-approved language arts curriculum is complete and comprehensive, a separate fluency program may not be needed. For example, our district-approved language arts curriculum has reading fluency and writing strategies embedded in it, which makes it an excellent program. The district could also allocate more time and money toward more writing inservices, that just reading comprehension inservices 


\section{FUTURE RESEARCH RECOMMENDATIONS}

With the link between reading comprehension and reading fluency so solid, I would not recommend further research on that topic. However, I would definitely recommend further research between reading comprehension and writing. While this study's link between reading comprehension and writing and writing fluency was somewhat inconsistent, its existence does merit more research on the subject. Also, the link between reading fluency and writing could be explored further.

Further quasi-experimental studies in which the control group uses the regular language arts curriculum while the experimental group uses the regular language arts curriculum with specific fluency instruction may not be needed. Fluency instruction has seemed to have lost its importance in educational research today. Educational papers, magazines, and journals seem not to spotlight fluency as much. The International Reading Association publication, Reading Today, annual survey ranks fluency as "Not Hot" and "Should Not Be Hot" in the field of education today (Cassidy \& Cassidy, 2009/2010). Fluency instruction has been important in education for the past ten years, however, its influence has waned over time, as often happens in education.

It would be beneficial if additional research could use a more diverse population than this study used. With $76 \%$ of the study sample listed as white and only $7 \%$ listed as English as a Second Language Learner, this was a rather homogenous group. The study's research questions asked with a more diverse group could show interesting results and additional insights, especially in English as a Second Language instruction. 


\section{REFERENCES}

Allington, R. L. (1983). Fluency: The neglected reading goal in reading instruction. The Reading Teacher, 37, 556-561.

Allington, R. L. (2006). Fluency: Still waiting after all of these years. In A. Farstrup \& J. Samuels (Ed.), What research has to say about fluency instruction (pp. 94-105). Newark, DE: International Reading Association.

Altwerger, B., Jordan, N., \& Shelton, N. (2007). Rereading fluency. Portsmouth, NH: Heinemann.

Au, K. (2002). Multicultural factors and the effective instruction of students of diverse backgrounds. In A. Farstrup \& J. Samuels (Eds.), What research has to say about reading instruction. Newark, DE: International Reading Association.

Binder, C. (1996). Behavorial fluency: Evolution of a new paradigm. The Behavior Analyst, 19, 163-197.

Binder, C., Haughton, E., \& Van Eyk, D. (1990). Increasing endurance by building fluency: Precision teaching attention span. Teaching Exceptional Children, 22(3), 24-27.

Blevins, W. (2001). Building fluency: Lessons and strategies for reading success. New York: Scholastic.

Brand, M., \& Brand, G. (2006). Practical fluency: Classroom perspectives, grades k-6. Portland, ME: Stenhouse.

Carbo, M. (1978). Teaching reading with talking books. The Reading Teacher, 32, 267-273.

Cassidy, J., \& Cassidy, D. (December 2005/January 2006). What's hot, what's not for 2006. Reading TODAY, 23(3), 1.

Chall, J. S. (1996). Stages of reading development (2nd ed.). Fort Worth, TX: HarcourtBrace.

Chard, D., Vaughn, S., \& Tyler, B. (2002). A synthesis of research on effective interventions for building reading fluency with elementary students with learning disabilities. Journal of Learning Disabilities, 35, 386-407.

Chomsky, C. (1978). When you still can't read in the third grade: After decoding, what? In S. J. Samuels (Ed.), What research as to say about reading instruction (pp. 13-30). Newark, DE: International Reading Association.

Clay, M. (2001). Change over time in children's literacy development. Portsmouth, NH: Heineman.

Cooper, J. D., Chard, D. J., \& Kiger, N. D. (2006). The struggling reader: Interventions that work. New York: Scholastic. 
Daane, M. C., Campbell, J. R., Grigg, W. S., Goodman, M. J., \& Oranje, A. (2005). Fourthgrade students reading aloud: NAEP 2002 special study of oral reading (NCES 2006-469). Washington, DC: Government Printing Office.

Deno, S. L. (1985). Curriculum-based measurement: The emerging alternative. Exceptional Children, 52, 219-232.

Dewey, J. (1938). Experience \& education. New York: Simon \& Schuster.

Dowhower, S. L. (1987). Effects of repeated reading on second-grade transitional readers' fluency and comprehension. Reading Research Quarterly, 22(4), 389-406.

Dowhower, S. L. (1991). Speaking of prosody: Fluency's unattended bedfellow. Theory in Practice, 30, 158-164.

Ehri, L. (1991). Development of the ability to read words. In M. L. Kamil, M. L. Kamil, P. B. Mosenthal, P. D. Pearson, \& R. Barr (Eds.), Handbook of reading research (Vol. III, pp. 383-417). New York: Longman.

Farnan, N., \& Dahl, K. (2003). Children's writing: research and practice. In J. Flood, D. Lapp, J. R. Squire, \& J. M. Jensen (Eds.), Handbook of research on teaching the English language arts (pp. 993-1007). Mahwah, NJ: Lawrence Erlbaum Associates.

Fearn, L., \& Farnan, N. (2001). Interactions: Teaching writing and the language arts. New York: Houghton Mifflin.

Flood, J., Lapp, D., \& Fisher, D. (2003). Reading comprehension instruction. In J. Flood, D. Lapp, J. R. Squire, \& J. M. Jensen (Eds.), Handbook of research on teaching the English language arts (pp. 931-941), Mahwah, NJ: Lawrence Erlbaum Associates.

Fountas, I., \& Pinnell, G. S. (2006). Teaching for comprehending and fluency. Portsmouth, NH: Heinemann.

Fuchs, L. S., Fuchs, D., Hosp, M. K., \& Jenkins, J. R. (2001). Oral reading fluency as an indicator of reading competence: A theoretical, empirical, and historical analysis. Scientific Studies of Reading, 5(3), 239-256.

Good, R. H., III, \& Kaminski, R. A. (Eds.). (2002). Dynamic indicators of basic early literacy skills (6th ed.). Eugene, OR: Institute for the Development of Educational Achievement.

Heckelman, R. G. (1969). A neurological-impress method of remedial-reading instruction. Academic Therapy, 4, 277-282.

Johns, J. (2007, June). Monitoring progress in fluency: Possible unintended consequences. Reading Today, 24(6), 18.

Klauda, S. L., \& Guthrie, J. T. (2008). Relationships of three components of reading fluency to reading comprehension. Journal of Educational Psychology, 100(2), 310-321.

Koskinen, P. S., \& Blum, I. H. (1984). Repeated oral reading and the acquisition of fluency. In J. Niles \& L. Harris (Eds.), Changing perspectives on research in reading/language processing and instruction. Thirty-third yearbook of the National Reading Conference (pp. 183-187). Rochester, NY: National Reading Conference. 
Kuhn, M. (2004). Helping students become accurate, expressive readers: Fluency instruction for small groups. The Reading Teacher, 58(4), 338-344.

Kuhn, M., \& Stahl, S. (2003). Fluency: A review of developmental and remedial practices. Journal of Educational Psychology, 95(1), 3-19.

LaBerge, D., \& Samuels, S. J. (1974). Toward a theory of automatic information processing in reading. Cognitive Psychology, 6, 293-323.

Leal, D. J. (2005). The word writing CAFÉ: Assessing student writing for complexity, accuracy, and fluency. The Reading Teacher, 59(4), 340-350.

Lee, C. D., \& Smagorinsky, P. (2000). Vygotskian perspectives on literacy research. New York: Cambridge University Press.

Manning, M. (2004/November). The fluency fallacy. Teaching $K-8$. Retrieved October 6, 2008, from http://www.TeachingK-8.com/,88-89

Marcell, B. (2007, June). Fluent to a fault: Put fluency in the passenger seat and let comprehension take the wheel! Reading Today, 24(6), 18.

Miller, J., \& Schwanenflugel, P. (2008). A longitudinal study of the development of reading prosody as a dimension of oral reading fluency in early elementary school children. Reading Research Quarterly, 43(4), 336-354.

National Institute of Child Health and Human Development. (2000). Report of the National Reading Panel. Teaching children to read: An evidence-based assessment of the scientific research literature on reading and its implications for reading instruction. Retrieved August 12, 2008, from http://www.nichd.nih.gov/publications/nrp/ smallbook.htm

Pikulski, J. (2006), Fluency: A developmental and language perspective, In A. Farstrup \& J. Samuels (Eds.), What research has to say about fluency instruction (pp. 70-93). Newark, DE: International Reading Association.

Pinnell, G. S., Pikulski, J. J., Wixson, K. K., Campbell, J. R., Gough, P. B., \& Beatty, A. S. (1995). Listening to children read aloud: Data from NAEP's Integrated Reading Performance Record (IRPR) at grade 4. The nation's report card. Washington, DC: U.S. Department of Education, National Center for Educational Statistics.

Pressley, M. (2002). Metacognition and self-regulated comprehension. In A. Farstrup \& J. Samuels (Eds.), What research has to say about reading instruction (pp. 291-309). Newark, DE: International Reading Association.

Rasinski, T. (2000). Speed does matter in reading. The Reading Teacher, 52, 146-151.

Rasinski, T. (2003). The fluent reader: Oral reading strategies for building word recognition, fluency, and comprehension. New York: Scholastic.

Rasinski, T. (2006). A brief history of reading fluency. In A. Farstrup \& J. Samuels (Eds.), What research has to say about fluency instruction (pp. 4-23). Newark, DE: International Reading Association. 
Rosenblatt, L. (2004). The transactional theory of reading and writing. In R. B. Ruddell \& N. J. Unrau (Eds.), Theoretical models and processes of reading (5th ed., pp. 13631398). Newark, DE: International Reading Association.

Samuels, S. J. (1979). The method of repeated reading. The Reading Teacher, 32, 403-408.

Samuels, S. J. (2002). Reading fluency: Its development and assessment. In A. Farstrup \& J. Samuels (Eds.), What research has to say about reading instruction. Newark, DE: International Reading Association.

Samuels, S. J. (2007). The DIBELS tests: Is speed of barking at print what we mean by reading fluency? Reading Research Quarterly, 42(4), 563.

Samuels, S. J., \& Farstrup, A. E. (2006). Reading fluency instruction: Will it be a passing fad or permanent fixture? In A. Farstrup \& J. Samuels (Eds.), What research has to say about fluency instruction (pp. 1-3). Newark, DE: International Reading Association.

Schreiber, P. A. (1991). Understanding prosody's role in reading acquisition. Theory into Practice, 30(3), 158-164.

Sivin-Kachala, J., \& Bialo, E. (2003). Second-grade study on Long Island, New York. New York: Scholastic.

Smith, F. (1988). Joining the literacy club. Portsmouth, NH: Heinemann.

Stahl, S. A., \& Heubach, K. M. (2005). Fluency-oriented reading instruction. Journal of Literacy Research, 37(1), 25-60.

Stanovich, K. E. (1986). Matthew effects in reading: Some consequences of individual differences in the acquisition of literacy. Reading Research Quarterly, 21, 360-406.

Stecker, S. K., Roser, N. L., \& Martinex, M. G. (1998). Understanding oral reading fluency. In T. Shanahan \& F. V. Rodrigues-Brown (Eds.), 47th yearbook of the National Reading Conference (pp. 295-310). Chicago: National Reading Conference.

Stieglitz, E. L. (1997). The Stieglitz Informal Reading Inventory (2nd ed.). Boston: Allyn and Bacon.

Topping, K. (1987). Paired reading: A powerful technique for parent use. The Reading Teacher, 40, 608-614.

Vaughn, S., Chard, D. J., Bryant, D. P., Coleman, M., Tyler, B. J., Thompson, S. L., et al. (2000, November/December). Fluency and comprehension interventions for thirdgrade students. Remedial and Special Education, 21(6), 325-335.

Wadsworth, B. J. (1978). Piaget for the classroom teacher. New York: Longman.

Walczyk, J. J., \& Griffith-Ross, D. A. (2007). How important is reading skill fluency for comprehension? The Reading Teacher, 60(6), 560-569.

Wolf, M. (2001). The double-deficit hypothesis, fluency, and a new intervention for children with dyslexia. Dyslexia Contact. British Dyslexia Association.

Wolf, M. (n.d.). Common questions about fluency. Retrieved December 12, 2005, from http://teacher.scholastic.com/reading/bestpractices/fluency/understand.htm 
Wolf, M., \& Katzir-Cohen, T. (2001). Reading fluency and its intervention. Scientific Studies of Reading, 5, 211-238. 
APPENDIX A

SAMPLE DATA 
Table 49. Sample Data From My Third Grade Class of 19 Students

\begin{tabular}{|c|c|c|c|c|c|c|c|}
\hline & $\begin{array}{l}\text { Reading } \\
\text { Compre- } \\
\text { hension }\end{array}$ & $\begin{array}{l}\text { Reading } \\
\text { Fluency }\end{array}$ & $\begin{array}{l}\text { Writing } \\
\text { Fluency }\end{array}$ & Gender & Ethnicity & $\begin{array}{l}\text { SES: } \\
\text { Free or } \\
\text { Reduced } \\
\text { Lunch }\end{array}$ & ESL \\
\hline 1. Samara & 12 & 106 & 23 & $\mathrm{~F}$ & Hispanic & No & Yes \\
\hline 2. Elisa & 13 & 106 & 20 & $\mathrm{~F}$ & Caucasian & No & No \\
\hline 3. Hannah & 12 & 85 & 12 & $\mathrm{~F}$ & Caucasian & No & No \\
\hline 4. Ryan C. & 11 & 119 & 18 & $M$ & Caucasian & No & No \\
\hline 5. Claire & 11 & 106 & Moved & $\mathrm{F}$ & Hispanic & No & No \\
\hline 6. Kinson & 8 & 67 & 12 & $\mathrm{M}$ & Asian & No & Yes \\
\hline 7. Nick & 10 & 84 & 12 & $\mathrm{M}$ & Caucasian & No & No \\
\hline 8. Miles & 9 & 96 & 11 & $\mathrm{M}$ & Mid-Eastern & No & No \\
\hline 9. Luke & 12 & 137 & 14 & $\mathrm{M}$ & Japanese & No & No \\
\hline 10. Ryan A. & 11 & 153 & 24 & $\mathrm{M}$ & Caucasian & No & No \\
\hline 11. Madelyn & 12 & 80 & 14 & $\mathrm{~F}$ & Caucasian & No & No \\
\hline 12. Leah & 15 & 120 & 17 & $\mathrm{~F}$ & Caucasian & No & No \\
\hline 13. Kelly & 12 & 72 & 14 & $\bar{M}$ & Caucasian & No & No \\
\hline 14. Grant & 15 & 172 & 13 & $\mathrm{M}$ & Caucasian & No & No \\
\hline 15. Zuleyma & 15 & 153 & 9 & $\mathrm{~F}$ & Hispanic & No & Yes \\
\hline 16. Christina & 13 & 149 & 26 & $\mathrm{~F}$ & Caucasian & No & No \\
\hline 17. Alex S. & 9 & 79 & 12 & $M$ & Caucasian & No & No \\
\hline 18. Spencer & 7 & 127 & 22 & $\mathrm{M}$ & Caucasian & No & No \\
\hline 19. Alex V. & 12 & 100 & 11 & $M$ & Russian & No & No \\
\hline
\end{tabular}


APPENDIX B

NOTE FOR FORMULAS FOR EFFECT SIZE 
Note: There are different formulas for effect size for each kind of statistical test. According to Cohen, small, medium and large effect sizes for Pearson's correlation are: $r=$ $0.1, r=0.3$ and $r=0.5$ respectively (pages 79-80). For independent samples t-tests and paired t-tests, small, medium and large effect sizes are $d=0.2, d=0.5$ and $d=0.8$ respectively (pages 25-27). For multiple linear regression analysis, small, medium and large effect sizes are R-square $=0.0196, \mathrm{R}$-square $=0.13$ and R-square $=0.26$ respectively (pages 413-414). Note that for Pearson's correlation statistic, the effect size is the Pearson correlation statistic itself. For t-tests, you have to calculate the effect size by hand since SPSS doesn't provide that calculation. The formula for the effect size for a t-test is just (m1-m2)/SD where $\mathrm{m} 1=$ mean of group $1 ; \mathrm{m} 2=$ mean of group 2 , and $\mathrm{SD}$ is the common standard deviation for both groups. In the case of a paired t-test, $\mathrm{m} 1$ is the mean of the pretest and $\mathrm{m} 2$ is the mean of the posttest and SD is the standard deviation of the differences between the pretest and posttest. The effect size for multiple linear regression is R-square, which is calculated by the SPSS software.

Cohen (Statistical Power Analysis for the Behavioral Science, 1988, Jacob Cohen) Lawrence Erlbaum Associates, Inc.; 365 Broadway; Hillsdale, New Jersey 07642. 